Aus der Klinik für Hals-Nasen-Ohren-Heilkunde (kommissar. Direktor Prof. Dr. med. M. Canis) der Medizinischen Fakultät der Universität Göttingen

\title{
Zervikale Lymphknotenmetastasen bei unbekanntem Primärtumor - Eine retrospektive Analyse zu Diagnostik und Therapie
}

INAUGURAL - DISSERT ATION

zur Erlangung des Doktorgrades

der Medizinischen Fakultät der

Georg-August-Universität zu Göttingen

vorgelegt von

Barbara Dorothee Blomeyer, MPH

aus

Soest

Göttingen 2016 
Dekan:

Prof. Dr. rer. nat. H.K. Kroemer

Referent:

Prof. Dr. med. R. Rödel

Ko-Referent/in:

PD Dr. med. H. Wolff

Drittreferent/in:

Datum der mündlichen Prüfung: $\quad$ 22.05.2017 
Hiermit erkläre ich, die Dissertation mit dem Titel „Zervikale Lymphknotenmetastasen bei unbekanntem Primärtumor - Eine retrospektive Analyse zu Diagnostik und Therapie“ eigenständig angefertigt und keine anderen als die von mir angegebenen Quellen und Hilfsmittel verwendet zu haben.

Göttingen, den 


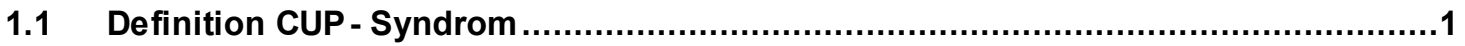

1.2 Zervikale Lymphknoten und Lymphknotenmetasta sen ....................................

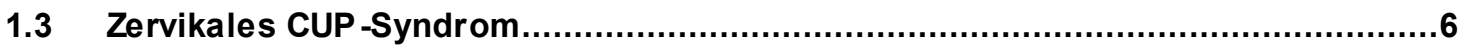

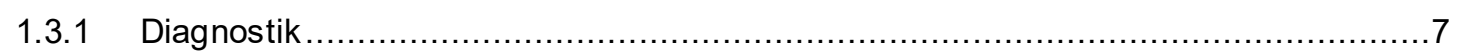

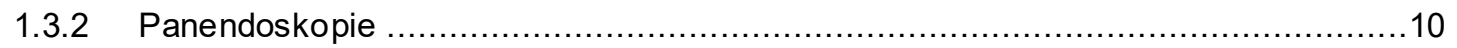

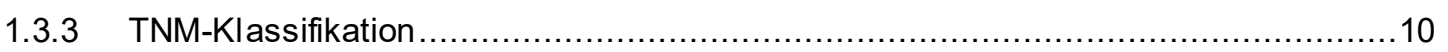

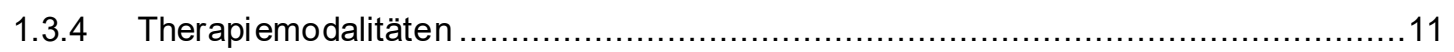

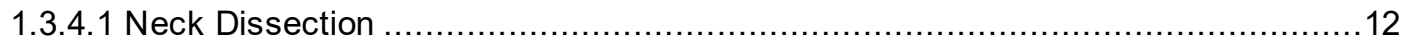

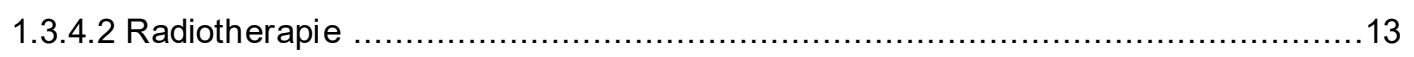

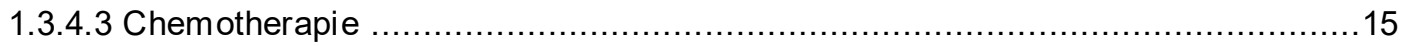

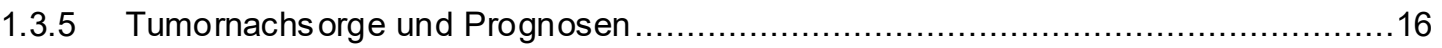

2 ZIEL DER ARBEIT .......................................................... 18

3 PATIENTEN UND METHODEN ........................................... 19

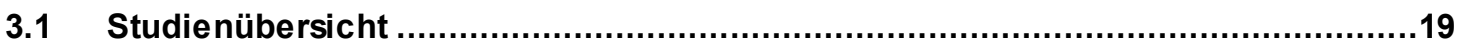

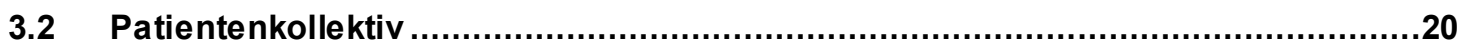

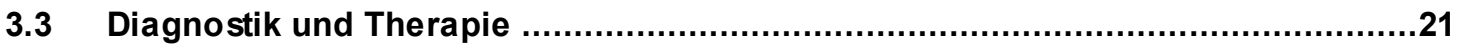

3.4 Statistische Methoden und Datenverarbeitung ................................................22

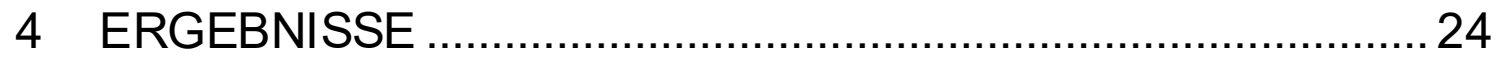

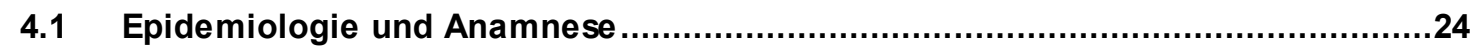

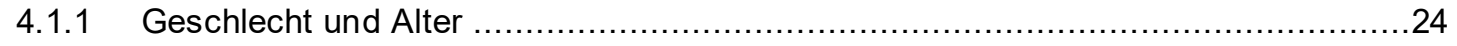

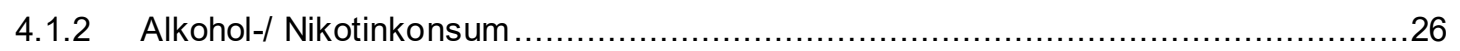

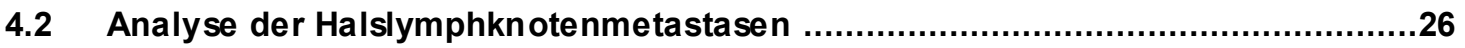

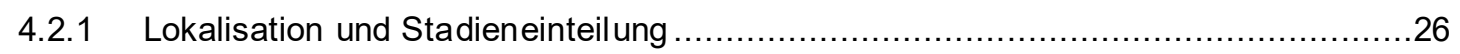

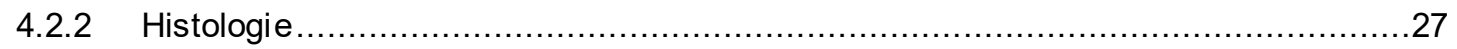




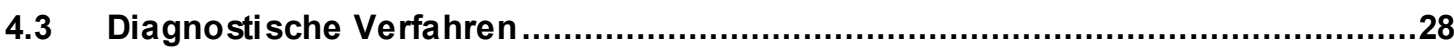

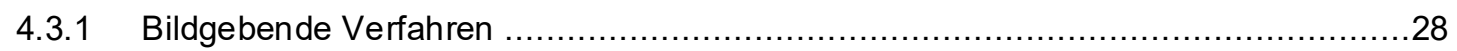

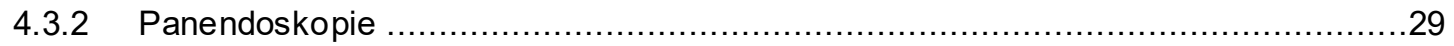

4.3.2.1 Stellenwert der Panendoskopie im Rahmen der Diagnostik bei zervikalem CUPSyndrom

4.4 Therapie der Halslymphknotenmeta sta sen .....................................................

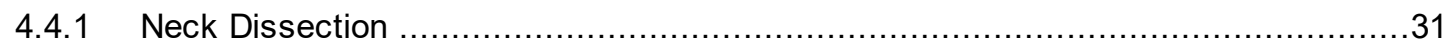

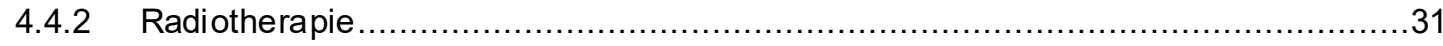

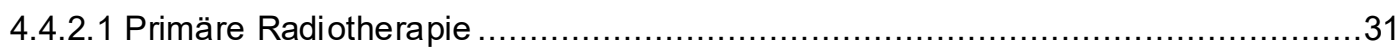

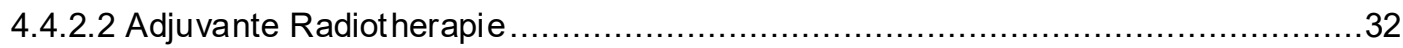

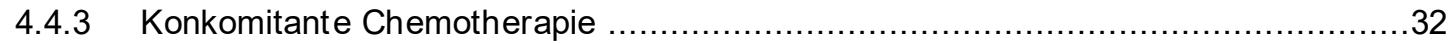

4.5 Überleben und Todesursachen ......................................................................33

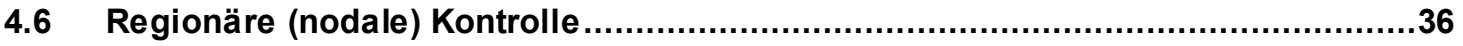

4.7 Lokale Kontrolle und späte Primärtumordemaskierung ................................39

4.7.1 Lokalisation der demaskierten Primärtumoren ........................................39

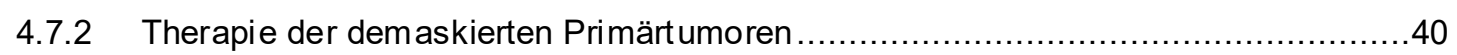

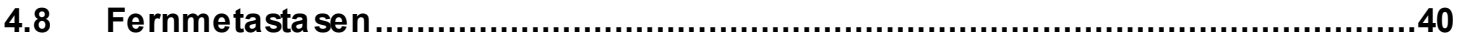

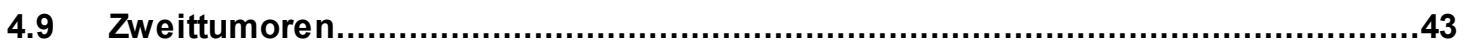

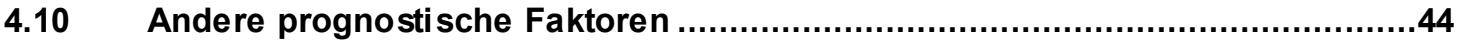

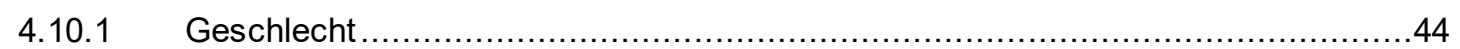

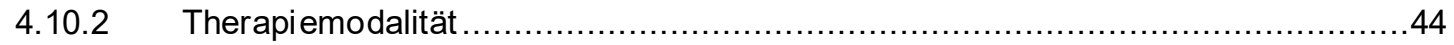

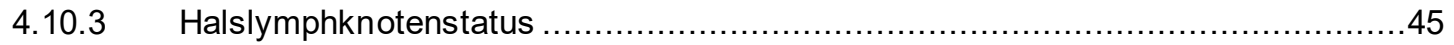

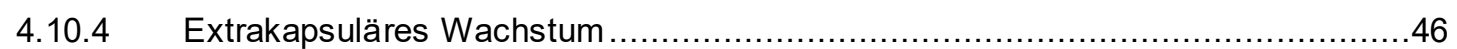

4.10.5 Lokalisation der Lymphknotenmetastasen, Histologie, Art der Neck Dissection,

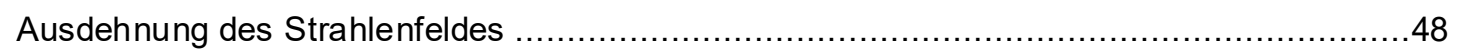

4.11 Gesamtüberleben und regionäre Kontrolle bei Patienten mit Primärtumoridentifikation im Rahmen der erweiterten Panendoskopie (Gruppe E) .......48

5 DISKUSSION........................................................................ 50

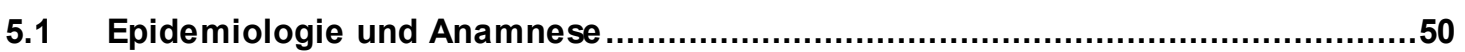

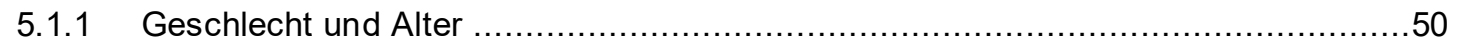

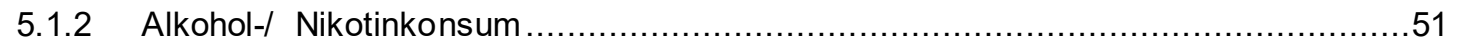




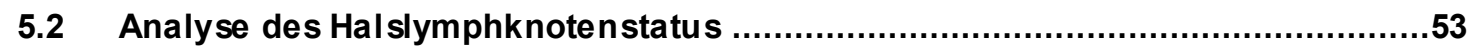

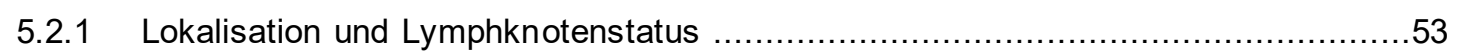

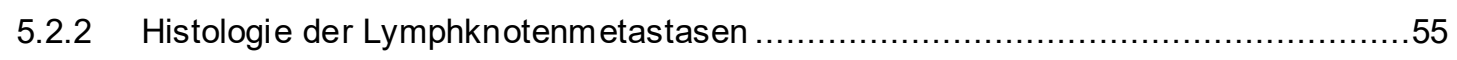

5.3 Diagnostik, bildgebende Verfahren und Panendoskopie .............................56

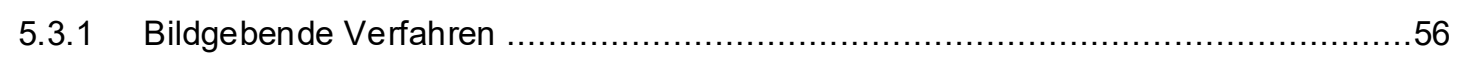

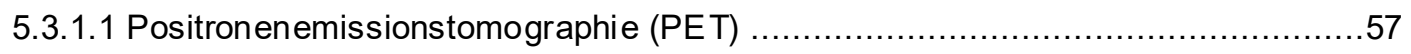

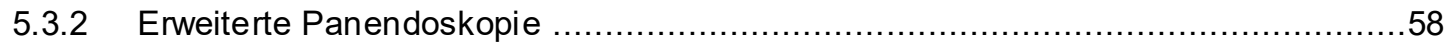

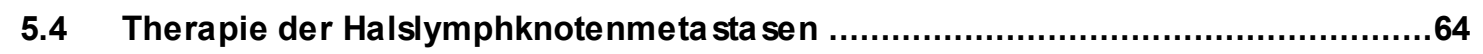

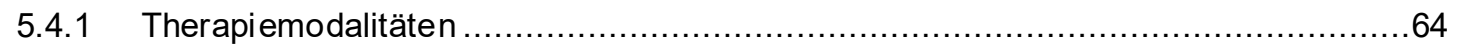

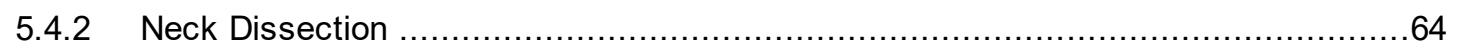

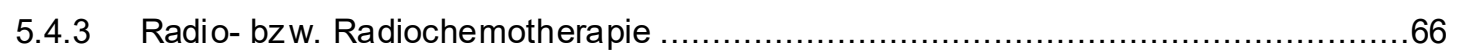

5.5 Primärtumordemaskierung nach Abschluss der Primärbehandlung (späte

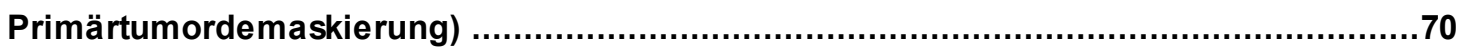

5.5.1 Aufdeckungs rate und Lokalisation des Primärtumors ................................70

5.5.2 Prognostischer Einfluss der Primärtumordemaskierung im Follow-up..................72

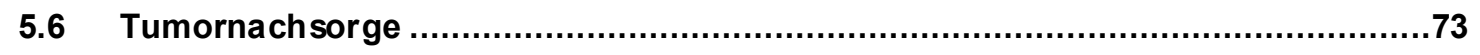

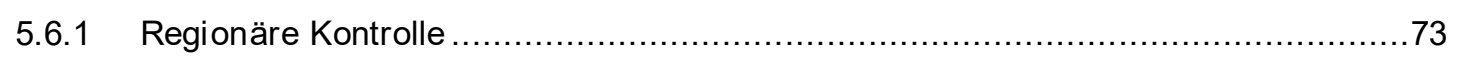

5.6.2 Auftreten von Fernmetastasen im Follow-up...................................... 75

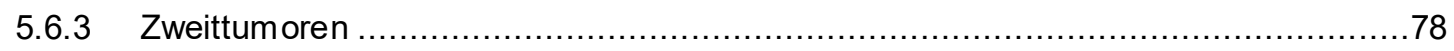

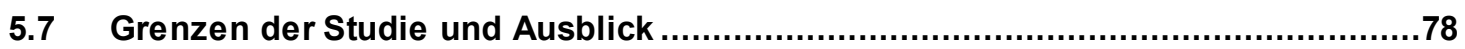

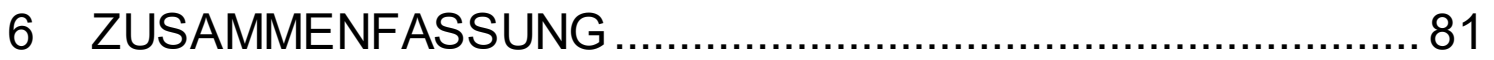

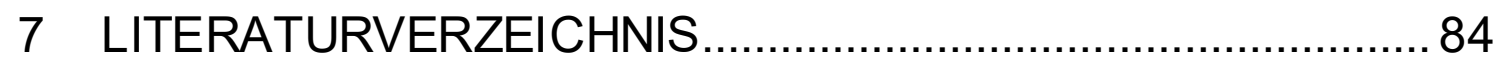




\section{Abbildungsverzeichnis}

Abb. 1: Einteilung des zervikalen Lymphknotensystems.

Abb. 2: Diagnostisches Stufenprogramm bei suspekten Lymphknoten in der KopfHals-Region ohne bisherigen Nachweis des Primärtumors

Abb. 3: Studienübersicht der 98 Patienten mit initialer Verdachtsdiagnose „zervikales CUP-Syndrom" und Aufteilung in die jeweiligen Patientengruppen A-F 19

Abb. 4: Geschlechtsverteilung im Kollektiv 24

Abb. 5: Altersverteilung getrennt nach Geschlecht 25

Abb. 6: Anzahl der Patienten mit therapiertem CUP- Syndrom pro Jahr Untersuchungszeitraum 1986-2006

Abb. 7: N-Kategorien der 58 behandelten Patienten mit zervikalem CUP-Syndrom .... 27

Abb. 8: Therapieformen (Gruppe A-D) bei Patienten mit zervikalem CUP- Syndrom aufgeteilt nach $\mathrm{N}-$ Kategorien 30

Abb. 9: Überleben bzw. Todesursachen der 58 behandelten Patienten mit zervikalem CUP-Syndrom 34

Abb. 10: Gesamtüberleben (Overall Survival) für alle therapierte Patienten 35

Abb. 11: Das krankheitsspezifische Überleben (Disease Specific Survival) für alle therapierte Patienten 36

Abb. 12: Regionäre Kontrolle für alle therapierten Patienten 37

Abb. 13: Entwicklung regionärer Rezidive in Abhängigkeit von der vorausgegangenen Therapieform bei allen therapierten Patienten 38

Abb. 14: Halsrezidive bezogen auf den N-Status vor Primärbehandlung 39

Abb. 15: Auftreten von Fernmetastasen 40

Abb. 16: Fernmetastasen in Abhängigkeit von der initialen $\mathrm{N}-$ Kategorie 42 
Abb. 17: Fernmetastasen in Abhängigkeit von der Art der Primärbehandlung

Abb. 18: Gesamtüberleben von Patienten mit Halslymphknotenfrühstadien vs. fortgeschrittenen Halslymphknotenstadien 45

Abb. 19: Gesamtüberleben für Patienten mit Halsmetastasen ohne und mit Kapseldurchbruch 46

Abb. 20: Gesamtüberleben der Gruppe E, bei der im Rahmen der Primärdiagnostik ein Primärtumor gefunden wurde 49 


\section{Tabellenverzeichnis}

Tab. 1: Metastasenlokalisation bei CUP-Syndrom und typische zugehörige Primärtumorlokalisationen

Tab. 2: Lokalisation der Halslymphknotenmetastase und jeweils typische Primärtumorlokalisationen 5

Tab. 3: Pathohistologische Tumorentitäten der zervikalen Lymphknotenmetastasen und typische Primärtumorlokalisationen.

Tab. 4: Histologische Differenzierung der Halslymphknotenmetastasen. 28

Tab. 5: Lokalisation und pT-Stadien der im Rahmen der Panendoskopie identifizierten Primärtumoren (Gruppe E) 29

Tab. 6: Patienten mit primärer/ adjuvanter Radiotherapie 32

Tab. 7: Lokalisation von Fernmetastasen

Tab. 8: Lokalisation der Zweittumoren im Beobachtungszeitraum 43

Tab. 9: Subgruppenanalyse für Gesamtüberleben, krankheitsspezifisches Überleben und regionäre Kontrolle

Tab. 10: Alters- und Geschlechtsverteilung des vorliegenden Patientenkollektivs im Vergleich mit ausgewählten Literaturangaben 50

Tab. 11: Seitenlokalisation der Halslymphknotenmetastasen bei Patienten mit zervikalem CUP-Syndrom 53

Tab. 12: Pathohistologie der zervikalen Lymphknotenmetastasen 55

Tab. 13: Literaturangaben zur Primärtumordemaskierung beim zervikalen CUPSyndrom nach Abschluss der Primärtherapie.

Tab. 14: Auftreten regionärer Rezidive beim zervikalen CUP-Syndrom in Abhängigkeit von der Primärtherapie 
Tab. 15: Häufigkeit von regionären Rezidiven bzw. Fernmetastasen bei Patienten mit zervikalem CUP-Syndrom ................................................................... 76 


\section{Abkürzungsverzeichnis}

\begin{tabular}{|c|c|}
\hline A. & Arteria \\
\hline CUP & Cancer of Unknown Primary \\
\hline CT & Computertomographie \\
\hline DNA & Desoxyribonukleinsäure \\
\hline DSS & Disease Specific Survival (= krankheitsspezifisches Überleben) \\
\hline EBV & Epstein-Barr Virus \\
\hline FDG & Fluordesoxyglucose \\
\hline FNP & Feinnadelpunktion \\
\hline Gl-Trakt & Gastrointestinal-Trakt \\
\hline Gy & Gray \\
\hline HNO & Hals-Nasen-Ohren \\
\hline HPV & Humanes Papillomavirus \\
\hline IMRT & Intensitätsmodulierte Radiotherapie \\
\hline k.A. & keine Angaben \\
\hline KM & Kontrastmittel \\
\hline M. & Musculus \\
\hline MRT & Magnetresonanztomographie \\
\hline N. & Nervus \\
\hline ND & Neck Dissection \\
\hline NR & Neck Control Rate (= regionäre Kontrolle) \\
\hline os & Overall Survival (= Gesamtüberleben) \\
\hline PECA & Plattenepithelcarcinom \\
\hline PET & Positronemissionstomographie \\
\hline PT & Primärtumor \\
\hline RNA & Ribonukleinsäure \\
\hline RCT & kombinierte Radiochemotherapie \\
\hline Rö & Röntgen \\
\hline RT & Radiotherapie \\
\hline sog. & sogenannte \\
\hline Tab. & Tabelle \\
\hline TORS & Transoral Robotic Surgery \\
\hline TU & Tumor \\
\hline UICC & Union Internationale Contre le Cancer \\
\hline
\end{tabular}


u.U. unter Umständen

V. Vena

z.B. zum Beispiel

ZNS Zentrales Nervensystem 


\section{Einleitung}

Ziel der vorliegenden Arbeit ist die Bewertung und Analyse von Diagnose- und Therapiekonzepten bei der Behandlung von Patienten mit zervikalem CUP-Syndrom im Rahmen einer retrospektiven Studie. Grundlage der Untersuchung sind entsprechende Patientenakten der Hals-Nasen-Ohrenklinik der Universität Göttingen.

\subsection{Definition CUP-Syndrom}

Unter der Bezeichnung CUP-Syndrom (Cancer of Unknown Primary) wird eine histopathologisch und klinisch heterogene Tumorerkrankung verstanden, bei der sich nach Abschluss der Primärdiagnostik trotz Vorhandensein von Metastasen kein Hinweis auf einen zugehörigen Primärtumor ergibt (Neben et al. 2008). Es handelt sich um ein insgesamt eher seltenes Krankheitsbild, welches ca. 3-5\% aller Tumorerkrankungen betrifft (Neben et al. 2008). Das CUP-Syndrom tritt als Erkrankung des höheren Lebensalters (mittleres Erkrankungsalter ca. 60 Jahre) auf, wobei überwiegend Männer betroffen sind (Abruzzesse et al. 1994; Seeber und Strumberg 2006; Neben et al. 2008).

Als häufigste Manifestationsorte gelten die Lymphknoten, gefolgt von Leber, Skelett, Lunge, Pleura, Peritoneum, ZNS, Nebenniere und Haut (Abbruzzese et al. 1994). Bei der histopathologischen Differenzierung stellt das Adenokarzinom insgesamt den häufigsten Subtyp dar (Hegewisch-Becker und Hossfeld 1997; Hemminki et al. 2011). Weitere Entitäten bilden undifferenzierte Karzinome, Plattenepithelkarzinome und maligne Melanome (Hemminki et al. 2011). Aufgrund des z.T. atypischen Metastasierungsmusters können anhand der Lage und Histologie der Metastase oft nur bedingt Rückschlüsse auf eine Lokalisation des Primärtumors gezogen werden (Seeber und Strumberg 2006; Mozet et al. 2013) (Tab. 1). 


\begin{tabular}{|l|l|}
\hline Metastasenlokalisation & typische Primärtumorlokalisation \\
\hline \hline Lymphknoten & \\
- zervikal & HNO, Lunge, Schilddrüse \\
- supraklavikulär & Mamma, Lunge, G-Trakt \\
- axillär & Mamma, Gl-Trakt \\
- inguinal & urogenital, Rektum \\
- retroperitoneal & urogenital, Keimzell-TU, GI-Trakt \\
Lunge & Mamma, Niere, Schilddrüse \\
Skelett & Mamma, Niere, Schilddrüse, Prostata, Lunge \\
Gehirn & Lunge, Mamma \\
Leber & Gl-Trakt, Pankreas, Mamma \\
Pleura & Mamma, Ovar, Lunge \\
Aszites (Peritonealkarzinose) & Gl-Trakt, Ovar \\
\hline
\end{tabular}

Tab. 1: Metastasenlokalisation bei CUP-Syndrom und typische zugehörige Primärtumorlokalisationen (nach Hegewisch-Becker und Hossfeld 1997)

Die Definition des CUP-Syndroms zeigt sich in der Literatur uneinheitlich. Allen Definitionen ist jedoch gemeinsam, dass die Metastasen histologisch oder zytologisch gesichert und nach Abschluss der primären Diagnostik die Primärtumorlokalisation unbekannt ist (Hübner und Bokemeyer 2005). Nach der Definition von Seeber und Strumberg (2006) gelten für ein CUP-Syndrom folgende Kriterien:

1. Die Malignität der Metastase ist histologisch gesichert.

2. Die physikalischen und apparativen Diagnostikverfahren ergeben keinen Hinweis auf die Primärtumorlokalisation.

3. Die histologische Untersuchung ist nicht mit einem Primärtumor an der biopsierten Lokalisation, sondern mit einer Metastase vereinbar.

Für den fehlenden Nachweis des Primarius werden verschiedene Erklärungsansätze diskutiert: 
1. Es handelt sich um einen mikroskopisch kleinen Tumor, der mit der aktuell durchgeführten Diagnostik nicht verifizierbar ist (hidden primary).

2. Nach erfolgter Metastasenbildung kommt es zur spontanen Rückbildung des Primärtumors (disappeared primary).

3. Der Primärtumor weist einen submukösen, mit den üblichen bildgebenden Verfahren nicht darstellbaren Sitz auf (Dillon und Harnsberger 1991).

Die Basisdiagnostik umfasst ausführliche Anamnese, klinische Untersuchung, Basislabordiagnostik, Ganzkörper-CT-Untersuchung sowie bei Frauen eine gynäkologische Untersuchung (Neben et al. 2008). Im Vordergrund der durchzuführenden Diagnostik steht die Differenzierung zwischen umschriebener und disseminierter bzw. kurativer und palliativer Tumorerkrankung (Abbruzzese et al. 1995). Die Therapiestrategie richtet sich individuell nach Alter, Algemeinzustand, Komorbidiät und Therapiewunsch sowie Metastasierungsverhalten und Histopathologie (Seeber und Strumberg 2006). Trotz eingehender histologischer bzw. immunhistochemischer Untersuchungen sowie intensiver Diagnostik lässt sich bei betroffenen Patienten nur in ca. $20 \%$ der Fälle ein Primärtumor lokalisieren (Abbruzesse et al. 1995). Auch durchgeführte Autopsien ergeben nach Ultmann (1991) nur in $70-90 \%$ der Fälle Aufschluss über den Sitz des Primarius.

Trotz beachtlicher Fortschritte in Diagnostik und Behandlungsstrategien stellt das CUPSyndrom für den betroffenen Patienten und den behandelnden Arzt sowohl eine Herausforderung als auch ein Dilemma zwischen onkologischer Sicherheit und Morbidität aufgrund invasiver diagnostischer Maßnahmen zur Primärtumorsuche dar. In der Mehrzahl der Fälle resultiert für die betroffenen Patienten eine eher ungünstige Prognose mit einer durchschnittlichen Überlebenszeit von lediglich wenigen Monaten.

Gegenüber anderen Metastasenlokalisationen zeichnet sich das zervikale CUPSyndrom, also das Auftreten von Halslymphknotenmetastasen ohne erkennbaren Primärtumor, durch eine vergleichsweise gute Prognose aus. In der Mehrzahl handelt es sich dabei um Metastasen von Plattenepithelkarzinomen mit potentiell kurativer Therapiemöglichkeit (Mozet et al. 2008). 


\subsection{Zervikale Lymphknoten und Lymphknotenmetastasen}

Das Lymphabflussgebiet der Kopf-Hals-Region umfasst ungefähr 300 von insgesamt 1.000 Lymphknoten des Körpers, von denen sich die meisten im Halsbereich befinden und zwischen der oberflächlichen und prävertebralen Halsfaszie lokalisiert sind (Werner et al. 2001). Als biologische Filterstationen im Lymphgefäßnetz besteht ihre Aufgabe u.a. darin, die lymphpflichtigen Stoffe aus dem Interstitium aufzunehmen. Trotz einer Einteilung in definierte Gruppen, die sich an den entsprechenden anatomischen Halsregionen orientiert, besteht bezüglich Lokalisation und Anzahl der Halslymphknoten eine große Variationsbreite (Hildmann et al. 1987). Lindberg (1972) unterteilte die zervikalen Lymphknotengruppen nicht nach anatomischtopographischen Gesichtspunkten, sondern entsprechend den bevorzugten Metastasierungsmustern der im Bereich der oberen Luft- und Speisewege lokalisierten Primärtumoren. Diese von Robbins (1998) nochmals überarbeitete Klassifikation unterscheidet dabei sechs Lymphknotenstationen (sog. Level; Abb. 1), die in gewissem Umfang Rückschlüsse auf den Sitz möglicher Primartumoren gestatten Tab. 2).

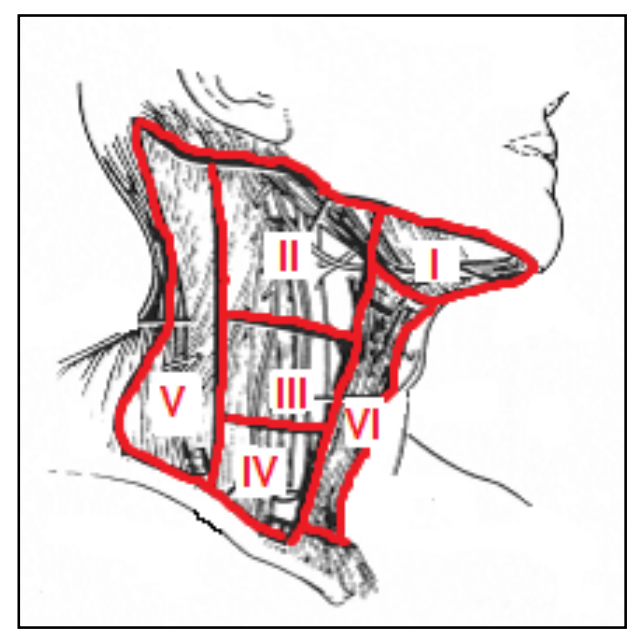

Level I - submental und submandibulär,

Level II - kranial jugular,

Level III - medial jugular,

Level IV - kaudal jugular,

Level V-dorsolateral zervikal,

Level Vl-anterior zervikal.

Abb. 1: Einteilung des zervikalen Lymphknoten systems modifiziert nach Robbins (1998), S. 640 


\begin{tabular}{|c|c|c|}
\hline $\begin{array}{l}\text { Lokalisation der } \\
\text { Lymphknotenmetastasen }\end{array}$ & $\begin{array}{c}\text { Level nach } \\
\text { Robbins } 1998\end{array}$ & $\begin{array}{l}\text { mögliche } \\
\text { Primärtumorlokalisation }\end{array}$ \\
\hline $\begin{array}{l}\text { submental } \\
\text { submandibulär }\end{array}$ & $\begin{array}{l}\text { la } \\
\text { lb }\end{array}$ & vorwiegend Mundhöhle \\
\hline kranial-jugulär & $\|$ & vorwiegend Naso-, Oropharynx \\
\hline medial-jugulär & III & $\begin{array}{l}\text { vorwiegend Oro-,Hypopharynx, } \\
\text { Larynx, Schilddrüse }\end{array}$ \\
\hline kaudal-jugulär & IV & $\begin{array}{l}\text { vorwiegend Hypopharynx, Larynx, } \\
\text { Schilddrüse, zervikaler } \\
\text { Ösophagus }\end{array}$ \\
\hline $\begin{array}{l}\text { dorsal/lateral-zervikal } \\
\text { supraklavikulär }\end{array}$ & V & vorwiegend Nasopharynx \\
\hline isoliert supraklavikulär & & $\begin{array}{l}\text { Bronchien, Lunge, Mamma, GI- } \\
\text { Trakt }\end{array}$ \\
\hline anterior-zervikal & VI & $\begin{array}{l}\text { Kopf-Hals-Tumoren: vorwiegend } \\
\text { Larynx, Trachea }\end{array}$ \\
\hline
\end{tabular}

Tab. 2: Lokalisation der Halslymphknotenmetasta se (Robbins 1998) und jeweils typische Primärtumorlokalisationen (zusammengestellt nach Zbären und Speiser 1993; Haas et al. 2002; Schmalbach und Miller 2007)

Die Metastasierungsfähigkeit eines Tumors gilt als eindeutiges Malignitätszeichen. Plattenepithelkarzinome, wie sie beim zervikalen CUP-Syndrom in der Mehrzahl vorliegen, metastasieren von wenigen Ausnahmen abgesehen, primär lymphogen. Bereits sehr kleine Primärtumoren können dabei frühzeitig Lymphknotenmetastasen setzen (Böcker et al. 2008). 


\subsection{Zervikales CUP-Syndrom}

Die zervikalen Lymphknotenmetastasen bei unbekanntem Primärtumor entsprechen ca. 2-5\% aller malignen Neuerkrankungen des Kopf-Hals-Bereiches (Grau et al. 2000; Werner und Dünne 2001; Pavlidis et al. 2009; Strojan et al. 2013a).

Im typischen Fall führt eine unspezifische, zumeist derbe und indolente Halsschwellung den betroffenen Patienten zum Arzt. Begleitet werden kann dieses oft einzige Symptom von Schmerzen, Dysphagie und Abgeschlagenheit sowie Gewichtsverlust, Nachtschweiß und Fieber als Ausdruck einer B-Symptomatik (Issing et al. 2003). Als erster diagnostischer Schritt zum Nachweis eines malignen Prozesses kann eine Feinnadelpunktion (FNP) durchgeführt werden (Pavlidis et al. 2009). Die definitive histologische Sicherung erfolgt anschließend durch Probebiopsie bzw. Probeexzision eines befallenen Lymphknotens. In 60-80\% der Fälle handelt es sich beim zervikalen CUP-Syndrom um Plattenepithelkarzinome, gefolgt von Adenokarzinomen, undifferenzierten und lymphoepithelialen Karzinomen sowie malignen Tumoren anderer Entitäten (Subramanian und Chilla 1995; Werner und Dünne 2001; Cerezo et al. 2011).

Die zugehörigen Primärtumoren werden mehrheitlich im Kopf-Hals-Bereich, vor allem in der Mundhöhle sowie Oro-, Hypo- und Nasopharynx vermutet (Issing et al. 2003; Jereczek-Fossa et al. 2004). Für Primärtumoren in diesem Bereich sprechen vor allem Metastasen des oberen und mittleren Halsabschnittes (Level I, II und III nach Robbins). Isolierte supraclavikuläre Metastasen (insbesondere im Level IV) deuten hingegen auf eine außerhalb des Kopf-Hals-Bereiches gelegene Lokalisation (z.B. intrathorakal) hin (Jereczek-Fossa et al. 2004; Cerezo et al. 2011).

Darüber hinaus kann sich der zugehörige Primärtumor auch im gastrointestinalen, gynäkologischen bzw. urologischen Gebiet befinden (Mozet et al. 2008). Die histologische Untersuchung erlaubt dabei innerhalb gewisser Grenzen Rückschlüsse auf einen möglichen Ursprung des zugehörigen Primarius (Tab. 3).

Die Entstehung von Plattenepithelkarzinomen im Kopf-Hals-Bereich wird als ein multifaktorielles Ereignis angesehen, das vielfach durch die kanzerogene Wirkung von Nikotin und Alkohol verursacht wird (Spitz 1994; Maier und Tisch 1999; Wittekind et al. 2001). Der zunehmende Konsum dieser Genussmittel ging in den letzten Jahrzehnten mit einer insgesamt steigenden Inzidenz der Plattenepithelkarzinome im Kopf-HalsBereich einher (Ambrosch 1996). 


\begin{tabular}{|l|l|}
\hline Metastasenhistologie & mögliche Primärtumorlokalisation \\
\hline \hline Plattenepithelkarzinome & $\begin{array}{l}\text { Kopf, Hals, obere-/ untere Luftwege, } \\
\text { Ösophagus, oberer Gl-Trakt, Schilddrüse, } \\
\text { Mamma, Gallenblase, Urogenitaltrakt, } \\
\text { Retroperitoneum, Haut }\end{array}$ \\
Adenokarzinome & $\begin{array}{l}\text { drüsenbildende Organe (Speicheldüsen, } \\
\text { Schilddüse, Mamma), Nasennebenhöhlen, } \\
\text { Ösophagus, Lunge, Gl-Trakt, } \\
\text { gynäkologische Organe, Urogenitaltrakt } \\
\text { Iymphoepitheliale Karzinome }\end{array}$ \\
Melanome & Haut \\
\hline
\end{tabular}

Tab. 3: Pathohistologische Tumorentitäten der zervikalen Lymphknotenmetasta sen und typische Primärtumorlokalisationen (zusammengestellt nach Arnold und Ganzer 2005; Hossfeld und Wittekind 2005)

Zusätzlich wurden in den letzten Jahren humane Papillomaviren (HPV), insbesondere Typ 16, als wichtige Risikofaktoren für die Entstehung von Plattenepithelkarzinomen des Oropharynx beschrieben (Psyrri et al. 2009; Zengel et al. 2012; Mozet et al. 2013). Die Identifizierung von HPV-DNA oder -RNA in zervikalen Lymphknotenmetastasen kann somit einen Hinweis zur Lokalisation des potentiellen Primärtumors im Oropharynx liefern (Pavlidis et al. 2009). Für einen Primärtumor im Nasopharynx gilt der EBV-Status als sensitiver Marker (Mozet et al. 2013).

\subsubsection{Diagnostik}

Der erforderliche Umfang der Routinediagnostik beim zervikalen CUP-Syndrom wird in der Literatur kontrovers diskutiert. Neben der Anamnese, die auch die prädisponierenden Faktoren wie frühere Tumorerkrankungen, genetische Disposition und Genussmittelkonsum erfasst, sind die Erhebung des HNO-Status, konventionelle und endoskopische Untersuchungen sowie die B-Scan-Sonographie des Halses obligatorisch. 
Die Routinediagnostik umfasst ferner eine Röntgen-Thorax-Untersuchung und die Abdomensonographie, um eventuelle Hinweise auf einen möglichen Primärtumor und bereits aufgetretene Fernmetastasen zu erhalten. Neuere wissenschaftliche Studien empfehlen eine intensivere Diagnostik mittels CT oder MRT der Kopf-Hals-Region sowie die CT von Thorax und Abdomen (Pavlidis et al. 2009; Waltonen et al. 2009). Neben diesen nicht-invasiven Untersuchungen ist beim zervikalen CUP-Syndrom die endoskopische Untersuchung des oberen Aero-Digestivtraktes in Vollnarkose (sog. Panendoskopie) erforderlich, einschließlich Tonsillektomie und Biopsieentnahme aus suspekten Schleimhautarealen bzw. typischen Primärtumorlokalisationsstellen wie Zungengrund und Nasopharynx.

Darüber hinaus wird in den letzten Jahren zunehmend die Positronenemissionstomographie (PET) als zusätliche Untersuchungsmethode empfohlen (Regelink et al. 2002; Rusthoven et al. 2004; Rades 2008; Cerezo et al. 2011).

Bei der Fluordesoxyglucose (FDG)- PET wird radioaktiv markierte Glukose intravenös injiziert, welche sich in den Zellen in Abhängigkeit vom Glukosestoffwechsel anreichert. Eine Vielzahl an malignen Tumoren nehmen vermehrt FDG auf (Schwenzer et al. 2012). Allerdings hat sich dieses Verfahren in der Routinediagnostik des zervikalen CUP-Syndroms aufgrund der eingeschränkten Verfügbarkeit, des Kostenaufwandes und der hohen Rate an falsch positiven Ergebnisse noch nicht flächendeckend etabliert (Kazak et al. 2003; Cerezo et al. 2011).

Pfreundner et al. (1997) schlagen bei Vorliegen eines suspekten zervikalen Lymphknotens zum weiteren Vorgehen das in Abb. 2 dargestellte Stufenschema vor.

Der Umfang der diagnostischen Maßnahmen bedarf einer individuellen, patientenbezogenen Abwägung zwischen dem zu enwartenden klinischen Benefit einerseits und dem apparativen und finanziellen Aufwand sowie der nicht zuletzt bei invasiven Untersuchungen teilweise gegebenen Patientenbelastung andererseits . 


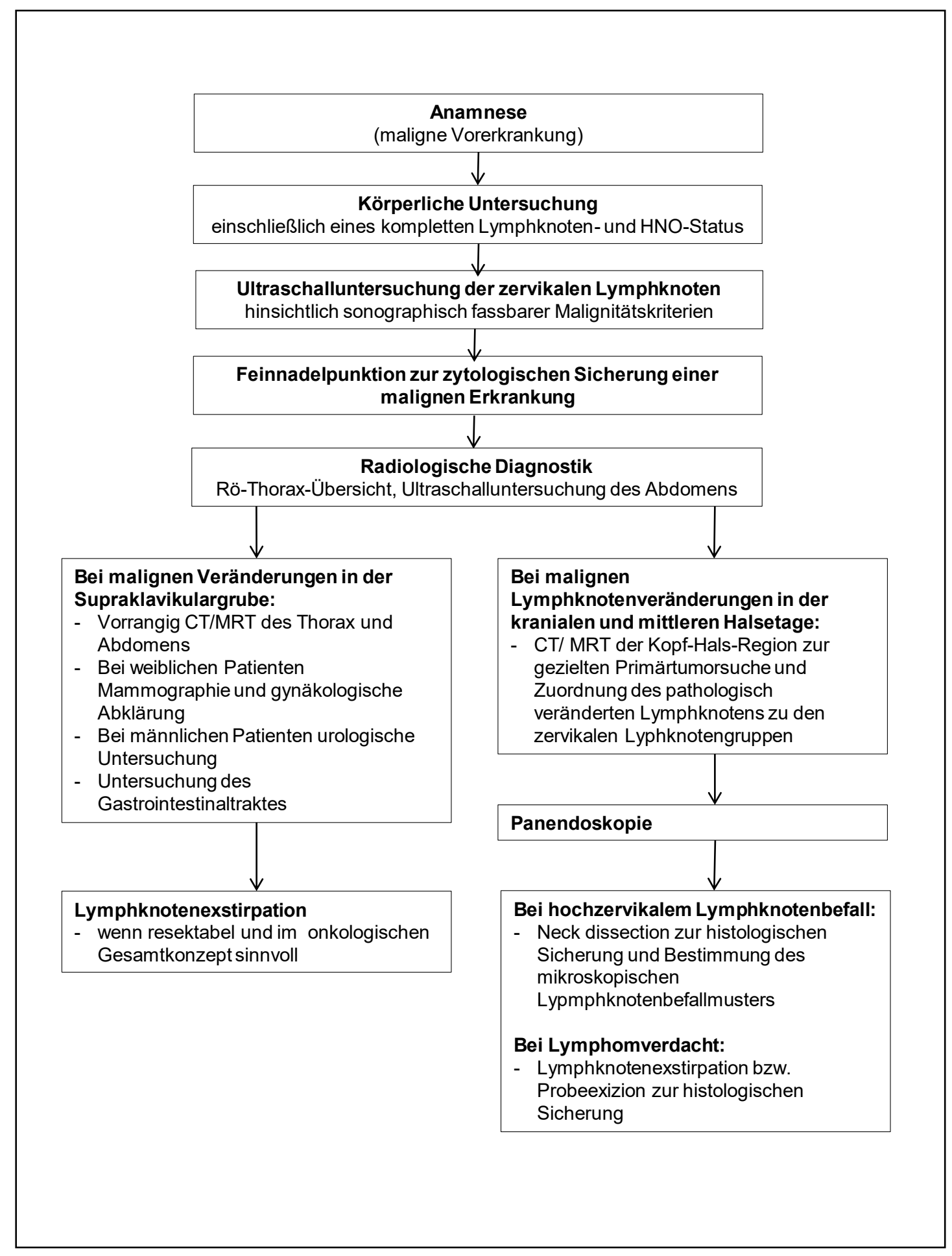

Abb. 2: Diagnostisches Stufenprogramm bei suspekten Lymphknoten in der Kopf- HalsRegion ohne bisherigen Nachweis des Primärtumors (entnommen und modifiziert aus Pfreundner et al. 1997, S. 355) 


\subsubsection{Panendoskopie}

Obligater Bestandteil in der Diagnostik des zervikalen CUP-Syndroms ist die Panendoskopie. Diese in Vollnarkose durchgeführte endoskopische Untersuchung beinhaltet eine eingehende Inspektion der einzelnen Etagen des Pharynx (Nase-, Orobzw. Hypopharynx), des Larynx, der Mundhöhle, der Trachea, des Bronchialsystems und des Ösophagus. Neben einer sorgfältigen Palpation und Entnahme von Biopsien aus suspekt imponierenden Epithelveränderungen werden auch tiefe Blindbiopsien aus Zungengrund und Nasopharynx empfohlen (sog. erweiterte Panendoskopie). Ebenfalls wird die Durchführung der ipsi- oder bilateralen Tonsillektomie gefordert, falls diese nicht bereits zuvor erfolgt ist (Koch et al. 2001; Kothari et al. 2008; Karni et al. 2011). Durch die routinemäßige Durchführung der Panendoskopie inklusive Biopsien und Tonsillektomie beim zervikalen CUP-Syndrom kann die Aufdeckungsrate gegenüber der alleinigen nicht-invasiven Diagnostik deutlich erhöht werden (Weber et al. 2001; Haas et al. 2002; Issing et al. 2003). Die Panendoskopie dient dabei nicht nur der Identifikation des Primärtumors, sondern auch dem Ausschluss von Zweittumoren, deren Auftreten die Prognose ungünstig beeinflussen kann (Dammer et al. 1999; Sharma et al. 2013).

\subsubsection{TNM-Klassifikation}

Das TNM-System gilt weltweit als Standard der UICC zur Klassifizierung maligner Tumoren. Es berücksichtigt sowohl die Ausdehnung des Primärtumors (T-Stadium), das Fehlen oder die Ausdehnung der zervikalen Lymphknotenmetastasierung ( $\mathrm{N}$ Stadium) als auch das Fehlen oder Vorhandensein von Fernmetastasen (M-Stadium). Die Standardisierung innerhalb des TNM-Systems führt zu einer einheitlichen Einteilung und Vergleichbarkeit von Patientendaten, um die Behandlungsplanung zu unterstützen, den Informationsaustausch zu erleichtern und Prognosehinweise zu geben.

Hierbei bedeuten:

„Nx: Regionärer Lymphknotenstatus kann nicht beurteilt werden

No: $\quad$ Keine regionären Lymphknotenmetastasen 
N1: $\quad$ Metastase in solitärem ipsilateralen Lymphknoten, maximal $3 \mathrm{~cm} \mathrm{im}$ größten Durchmesser .

N2a: $\quad$ Metastase in solitärem ipsilateralen Lymphknoten, zwischen 3 und $6 \mathrm{~cm}$ im größten Durchmesser.

N2b: $\quad$ Metastasen in multiplen ipsilateralen Lymphknoten mit nicht mehr als $6 \mathrm{~cm}$ im größten Durchmesser.

N2c: $\quad$ Metastasen in bi- oder kontralateralen Lymphknoten mit nicht mehr als $6 \mathrm{~cm}$ im größten Durchmesser.

N3: $\quad$ Metastasen in Lymphknoten mit mehr als $6 \mathrm{~cm}$ Durchmesser im größten Durchmesser" (Boenninghaus und Lenarz 2007, S. 321).

\subsubsection{Therapiemodalitäten}

Die optimale Therapiestrategie für Patienten mit zervikalem CUP-Syndrom wird in der Literatur kontrovers diskutiert. Übereinstimmend wird jedoch - analog zu Patienten mit fortgeschrittenem Kopf-Hals-Karzinomen - eine multimodale Behandlung angestrebt (Cerezo et al. 2011). Dies beinhaltet zumeist eine operative Halslymphknotenausräumung (Neck Dissection), gefolgt von einer adjuvanten Radio- bzw. Radiochemotherapie (Grau et al. 2000; Nieder et al. 2001; Guntinas-Lichius et al. 2006). Christiansen et al. (2005) konnten die Überlegenheit der kombinierten gegenüber einer unimodalen Therapie (ausschließlich Operation oder Strahlentherapie) darlegen. Die erforderliche Ausdehnung der Strahlenfelder sowie der Nutzen einer konkomitanten Chemotherapie werden unterschiedlich beurteilt. Die Wahl der jeweiligen Therapiestrategie richtet sich u. a. nach Lokalisation, Ausdehnung und Histologie der Lymphknotenmetastase und erfordert ein Abwägen zwischen Effektivität und möglichen Nebenwirkungen. Grundsätzlich ist die notwendige Therapie durch weiterführende diagnostische Maßnahmen möglichst frühzeitig einzuleiten mit dem Ziel einer effektiven Behandlung der Lymphknotenmetastasen und des möglichen Primärtumors (Oen et al. 1995; Weber et al. 2001). Dies erfordert eine enge interdisziplinäre Kooperation von HNO-Arzt, Pathologen und Strahlentherapeuten. Das wesentliche Therapieziel liegt in der Risikominimierung bzw. Verhinderung der 
Entwicklung von loko-regionären Rezidiven und prognoselimitierenden Fernmetastasen.

\subsubsection{Neck Dissection}

Eine Neck Dissection umfasst die „Entfernung aller Lymphknoten einschließlich des umgebenden Fett- und Bindegewebes der gesamten Halsseite oder bestimmter regionärer Lymphknotengruppen („Level“)“(Boenninghaus und Lenarz 2007, S. 32). Je nach Umfang und Ausdehnung des operativen Eingriffes existieren verschiedene Bezeichnungen der Halslymphknotenausräumung. Boenninghaus und Lenarz (2007) unterscheiden folgende Formen der Neck Dissection:

\section{Radikale Neck Dissection:}

Bei der radikalen Neck Dissection wird das gesamte Lymphknoten enthaltende Fett-Bindegewebe im Kopf-Hals-Bereich entfernt, typischerweise unter Mitnahme der V. jugularis interna, des M. sternocleidomastoideus, des $\mathrm{N}$. accessorius und des Fettgewebes bis zum Vorderrand des M. trapezius (s. Abb. 1, S. 4). Über Jahrzehnte hinweg war dies die Standardmethode zur Behandlung metastatisch besiedelter Halslymphknoten. Funktionelle Nachteile resultieren jedoch aus der konsekutiven Armheberschwäche aufgrund der N. accessorius-Parese. Ferner wirkt das eingesunkene Halsrelief kosmetisch und funktionell ungünstig.

\section{Funktionelle Neck Dissection :}

Bei der funktionellen Neck Dissection werden ebenfalls die Halslymphknoten mit dem umgebenden Fett-Bindegewebe en bloc entfernt. N. accessorius, V. jugularis interna und der $M$. sternocleidomastoideus werden jedoch typischerweise geschont. Diese Methode weist funktionell und kosmetisch bessere Resultate auf als die radikale Neck Dissection bei - eine adäquate Indikationsstellung vorausgesetzt - ähnlichen onkologischen Resultaten.

\section{Selektive Neck Dissection:}

Diese Art der Halslymphknotenausräumung beschränkt sich auf definierte Halslymphknotenlevel (s. Abb. 1, S. 4) in Abhängigkeit von Art, Lokalisation und 
Größe (T-Stadium) des Primärtumors. Soweit möglich, werden N. accessorius, V. jugularis interna, und M. sternocleidomastoideus geschont. Das Prinzip der selektiven Neck Dissection wurde in den 80er Jahren entwickelt. Die Grundlage für die Ausräumung bestimmter Halsregionen unter Erhalt nicht-lymphatischer Strukturen lieferte die Arbeit von Lindberg (1972), bei der Tumoren der oberen Luftund Speisewege bevorzugte Metastasenregionen im Halsbereich zugeordnet werden konnten.

Die Auswahl des jeweils geeigneten Operationsverfahrens zur Halslymphknotenausräumung orientiert sich insbesondere an der Ausdehnung ( $\mathrm{pN}$-Stadium) der Lymphknotenmetastasen und einer ggf. vorhandenen Kapselüberschreitung mit Infiltration des umgebenden Weichgewebes. Zur Behandlung von zervikalen Lymphknotenmetastasen bei unbekanntem Primärtumor sollte die chirurgische Intervention onkologisch angemessen unter weitest möglicher Schonung wichtiger anatomischer Strukturen erfolgen. Die Durchführung einer radikalen Neck Dissection erscheint dabei in der Mehrzahl der Fälle nur bei Infiltration von benachbarten nichtlymphatischen Strukturen, wie M. sternocleidomastoideus und V. jugularis interna, indiziert (Cerezo et al. 2011).

\subsubsection{Radiotherapie}

Die Indikationsstellung zur Durchführung einer Strahlentherapie erfolgt in Abhängigkeit von Histologie, Lokalisation und Ausdehnung des Tumors unter Berücksichtigung von Allgemeinzustand, Narkosefähigkeit und Begleiterkrankungen. Das therapeutische Vorgehen ist somit jeweils eine individuelle Entscheidung (Wannenmacher et al. 2013). Die Radiotherapie wird beim zervikalen CUP-Syndrom entweder als primäre Behandlungsmaßnahme oder als adjuvantes Therapieverfahren nach primär operativer Behandlung durchgeführt. Indikationen für eine adjuvante Radiotherapie sind u.a. extrakapsuläres Wachstum und multiple betroffene Lymphknoten (Stadium N2b und höher)(Patel et al. 2007, Pavlidis et al. 2009). Die primäre Strahlentherapie erscheint bei initial fortgeschrittenen Lymphknotenstadien (N2b oder N3) und inoperablen Befunden (z. B. Carotisinfiltration), nicht-operationsfähigen bzw. nicht-operationswilligen Patienten indiziert (Pavlidis et al. 2009). Darüber hinaus wurde in einigen wenigen Studien bei Patienten mit solitären Lymphknotenmetastasen (N1 und N2a) und fehlendem Nachweis von extrakapsulärem Wachstum über eine gute regionale 
Kontrolle bei primärer Strahlentherapie berichtet (Colletier et al. 1998; Aslani et al. 2007; Strojan et al. 2013b).

Bedingt durch Weiterentwicklungen der Bestrahlungstechniken (zwei- oder dreidimensionale Technik, intensitätsmodulierte Radiotherapie (IMRT)) resultieren für den Beobachtungszeitraum der vorliegenden Untersuchung (1986 bis 2006) im Detail unterschiedliche Therapiekonzepte, insbesondere hinsichtlich Dosis, Fraktionierung und Bestrahlungsfeld.

Die Ausdehnung der zu bestrahlenden Regionen beim zervikalen CUP-Syndrom wird in der Literatur kontrovers diskutiert. Neben der Bestrahlung der betroffenen ipsilateralen zervikalen Halsregionen (limited field radiation) besteht die Option, das Strahlenfeld auch auf die Halslymphbahnen der Gegenseite und die verschiedenen Etagen des Pharynx sowie den Larynx auszudehnen (extended field radiation), um ggf. klinisch okkulte kontralaterale Lymphknotenmetastasen sowie den bis dato unbekannten Primärtumor miteinzubeziehen (Cerezo et al. 2011).

Bisher fehlen jedoch prospektive randomisierte Studien, welche die Vorteile des ausgedehnten Strahlenfeldes belegen. Einige Autoren berichten im Rahmen retrospektiver Analysen bei Patienten mit erweitertem Strahlenfeld zwar über eine Verbesserung der regionären und lokalen Kontrolle, jedoch ohne signifikanten Einfluss auf das Gesamtüberleben (Coster et al. 1992, Colletier et al. 1998, Erkal et al. 2001a). Auch Fakhrian et al. (2012) konnten keine Verbesserung des Gesamtüberlebens oder des rezidivfreien Überlebens durch ein erweitertes Strahlenfeld darlegen. Allerdings beobachteten sie eine deutlich niedrigere Rate an akuten und chronischen Nebenwirkungen bei Patienten, bei denen das Strahlenfeld auf die betroffene Halsseite beschränkt wurde.

Akute Nebenwirkungen einer Strahlentherapie treten typischerweise während oder bis zu 90 Tage nach Abschluss der Radiotherapie auf und bestehen zumeist aus Hauterythem, Lymphödem, Infektionen, Dysphagie und Mukositis (Pavlidis et al. 2009; Fahkrian et al. 2012, Thönessen et al. 2013). Eine häufig beklagte unerwünschte Wirkung der Radiotherapie ist die Xerostomie (Fahkrian et al. 2012), welche durch eine Schädigung der Speicheldrüsen hervorgerufen wird. Darüber hinaus werden persistierende Ödeme von Haut und Larynx, Verhärtungen des Unterhautbindegewebes, Nekrosen und Larynxperichondritis als Spätfolgen beschrieben (Colletier et al. 1991; Coster et al. 1992; Erkal et al. 2001a; Beldi et al. 
2007). Der Vorteil, einen möglichen Primärtumor durch ein ausgedehntes Strahlenfeld mitzuerfassen, muss somit im Einzelfall gegen ein die Lebensqualität einschränkendes erhöhtes Risiko unerwünschter Wirkungen, wie z.B. Dysphagie und Xerostomie, abgewogen werden (Cerezo 2011).

Die Radiotherapie erfolgt analog zu den Therapie- und Dosiskonzepten für HNOTumoren mit bekannter Primärtumorlokalisation. Für die befallenen Regionen wird eine Gesamtdosis von 60 Gy angestrebt. Bei makroskopischem Nachweis (z.B. R2Resektion oder inoperablen Tumor) kann eine Boost-Bestrahlung bis 66-70 Gy sinnvoll erscheinen. Bei elektiver Bestrahlung einer Region liegt die Zieldosis bei 50 Gy. Bei konventionellem Vorgehen erfolgt eine Fraktionierung mit einer Einzeldosis von 1,8 - 2 Gy einmal pro Tag (Pavlidis et el. 2009; Thönessen et al. 2013).

Da sich extrakaspuläres Tumorwachstum nachteilig auf das Überleben des Patienten auswirkt und mit einem erhöhtem Risiko einer Rezidiventwicklung einhergeht (Coster et al. 1992), wird bei Vorliegen eines Kapseldurchbruches eine Strahlendosis von 6466 Gy empfohlen (Cerezo et al. 2011).

\subsubsection{Chemotherapie}

Die systemische Chemotherapie erfolgt beim zervikalen CUP-Syndrom als konkomitanter Bestandteil der Primärtherapie, bei Rezidivtumoren und/oder bei gegebener Palliativsituation. Die Entscheidung zur Chemotherapie wird individuell für jeden Patienten u. a. aufgrund von Histologie, Allgemeinzustand und Therapieziel getroffen (Cerezo et al. 2011).

Bisher liegen für das zervikale CUP-Syndrom keine randomisierten Studien zur Wertigkeit einer konkomitanten Chemotherapie vor. Die Therapiekonzepte basieren in erster Linie auf Ergebnissen und Erfahrungen in der Behandlung fortgeschrittener Malignome der Kopf-Hals-Region mit bekannter Primärtumorlokalisation oder retrospektiven Studien bei zervikalem CUP-Syndrom mit allerdings jeweils nur geringen Fallzahlen (Bernier et al. 2004; Shehadeh et el. 2006; Beldi et al. 2007).

In diesem Zusammenhang finden in erster Linie Zytostatika(-kombinationen) bestehend aus Cisplatin/Carboplatin (Bernier et al. 2004; Shehadeh et al. 2006) und/oder 5-Fluorouracil plus Mitomycin Anwendung (Beldi et al. 2007; Fakhrian et al. 2012). 
Bernier et al. (2004) beschrieben bei begleitender Cisplatin-Therapie lokal fortgeschrittener Kopf-Hals-Tumoren eine Verbesserung von Gesamtüberleben, krankheitsspezifischem Überleben und lokaler Kontrolle im Vergleich zu einer alleinigen Radiotherapie (Bernier et al. 2004). Shehadeh et al. 2006 sahen in ihrer retrospektiven Studie zum zervikalen CUP-Syndrom durch eine konkomitante Chemotherapie (Cisplatin) ebenfalls eine Verbesserung des Gesamtüberlebens und des Rezidiv-freien Überlebens. Auch Patel et al. (2007) befürworten, insbesondere für Patienten mit ungünstigen Risikoprofil, wie z.B. makroskopisches extrakapsuläres Wachstum und pN2/pN3- Status, die konkomitante Chemotherapie.

Demgegenüber konnten Christianen et al. (2005), Chen et al. (2011) und Fahkrian et al (2012) für Patienten mit zervikalen Lymphknotenmetastasen bei unbekanntem Primärtumor keine Verbesserung der Überlebenszeit durch eine adjuvante Radiochemotherapie im Vergleich zu einer alleinigen adjuvanten Radiotherapie darlegen. Allerdings wurde u.a. von einer höheren Inzidenz akuter Nebenwirkungen (Grad 3 und höher) - insbesondere verbunden mit Mukositis - unter begleitender Cisplatin-Therapie berichtet (Chen et al. 2011).

\subsubsection{Tumornachsorge und Prognosen}

Die Tumornachsorge beginnt mit Abschluss der Primärbehandlung. Sie ist auf ein frühzeitiges Erkennen von Rezidiven, Fernmetastasen und Zweittumoren sowie auf eine eventuellen Detektion des okkulten Primärtumors ausgerichtet (León et al. 1999). In der Praxis hat sich bewährt, die erste Kontrolluntersuchung ca. 6 Wochen nach Therapieende durchzuführen. Soweit keine besonderen Ereignisse wie z.B. Rezidive oder Fernmetastasen auftreten, werden in den ersten drei Jahren vierteljährliche bzw. im 4. und 5. Jahr halbjährliche Nachsorgeintervalle empfohlen. Ab dem 5. Jahr können die Kontrolluntersuchungen in jährlichem Abstand vorgenommen und/oder im Rahmen der Nachbetreuung durch niedergelassene Fachärzte vor Ort übernommen werden (Dellian et al. 2003).

Jede Nachsorgeuntersuchung umfasst die Endoskopie von Mundhöhle, Pharynx und Larynx, die Erhebung des lokalen Halsstatus mittels Palpation und Sonographie. Bei suspektem oder unklarem Befund werden CT- und/ oder MRT- Aufnahmen des Halses veranlasst, ergänzt ggf. durch weiterführende bildgebende Diagnostik von Thorax und Abdomen (Dellian et al 2003). Mit Rücksicht auf die Lebensqualität betroffener 
Patienten sind dabei insbesondere bei Anwendung invasiver, diagnostischer Verfahren onkologischer Nutzen und Patientenbelastung sorgfältig gegeneinander abzuwägen (Haas et al. 2001; Issing et a. 2003). 


\section{Ziel der Arbeit}

Diagnostisches Vorgehen und Therapiekonzepte bei Patienten mit zervikalem CUPSyndrom werden in der Literatur kontrovers diskutiert. Aktuelle Therapieempfehlungen beinhalten unimodale (alleinige Neck Dissection oder primäre Radio(chemo)therapie) und multimodale (Neck Dissection mit postoperativer Radio(chemo)therapie) Behandlungsansätze. In Bezug auf die Strahlentherapie werden insbesondere die Ausdehnung des Bestrahlungsfeldes sowie die Indikation einer konkomitanten Chemotherapie unterschiedlich bewertet.

Die Ziele der vorliegenden retrospektiven Studie sind:

- die Bewertung des Stellenwertes der erweiterten Panendoskopie einschließlich Tonsillektomie und histologischer Blindbiopsien bei der Primärtumoridentifikation.

- die vergleichende Gegenüberstellung verschiedener Therapiemodalitäten hinsichtlich Gesamtüberleben, krankheitsspezifischem Überleben und regionärer Kontrolle.

- die Identifikation möglicher prognostischer Faktoren, wie z.B. pN-Stadium der Lymphknotenmetastasen, extrakapsuläres Wachstum, Demaskierung des Primärtumors im Follow-up oder Auftreten von Fernmetastasen.

Die Ergebnisse dieser Studie werden anschließend den entsprechenden Literaturdaten gegenübergestellt und diskutiert. 


\section{$3 \quad$ Patienten und Methoden}

\subsection{Studienübersicht}

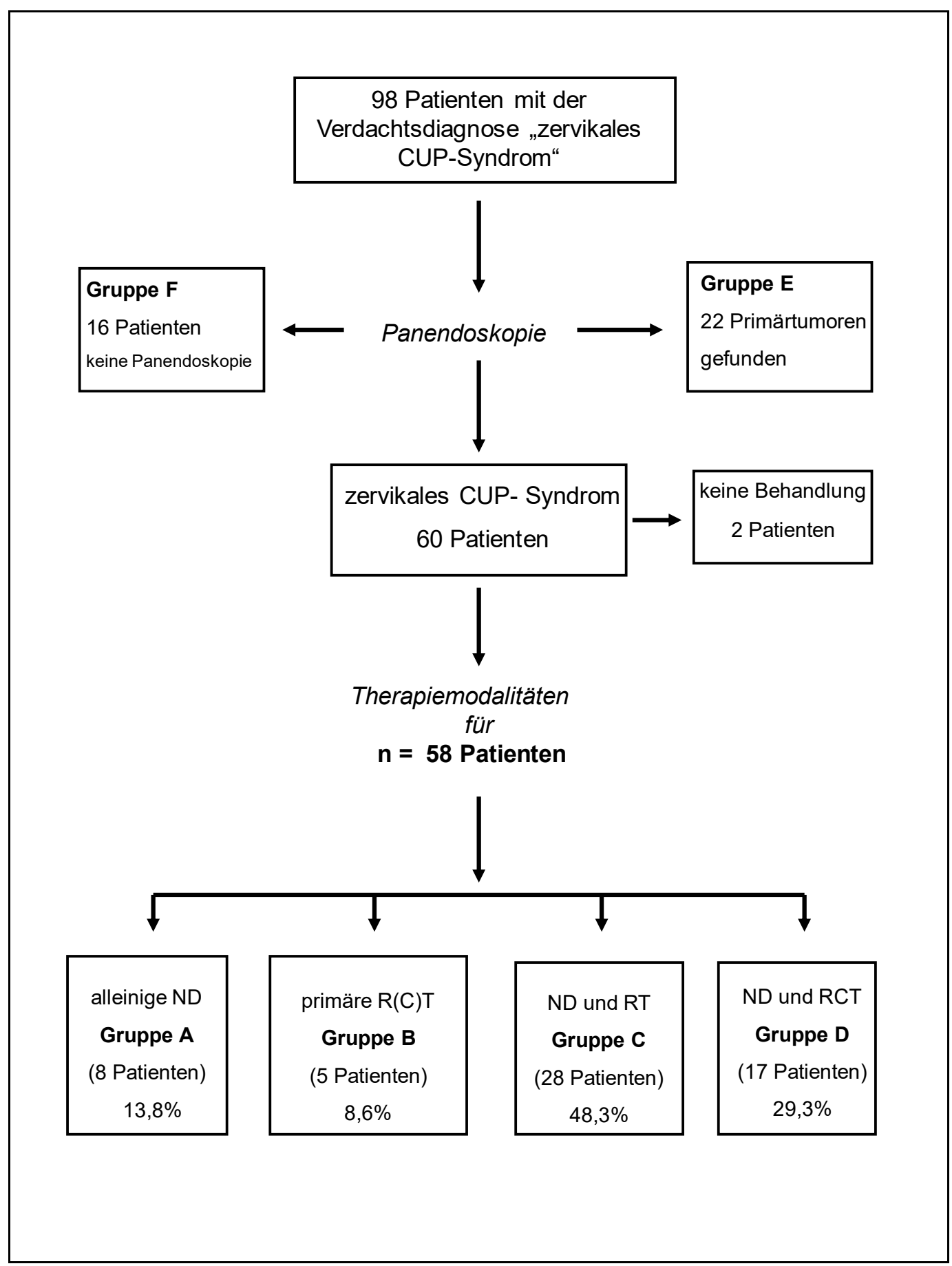

[ND= Neck Dissection, RT= Radiotherapie, $\mathrm{RCT}=$ kombinierte Radiochemotherapie $]$

Abb. 3: Studienübersicht der 98 Patienten mit initialer Verdachtsdiagnose „zervikales CUP-Syndrom" und Aufteilung in die jeweiligen Patientengruppen A-F 


\subsection{Patientenkollektiv}

Zur Auswertung wurden die Krankenakten von Patienten herangezogen, die zwischen dem 01.08.1986 und dem 18.06.2006 in der Hals-Nasen-Ohrenklinik der Universität Göttingen mit der Verdachtsdiagnose „zervikales CUP-Syndrom“ aufgenommen worden waren. Hierbei galten folgende Einschlusskriterien:

- In der Anamnese waren keine früheren malignen Tumorerkrankungen bekannt oder behandelt worden.

- Es lag ein dringender Verdacht oder eine bereits auswärts histologisch gesicherte Diagnose der Halslymphknotenmetastase vor, ohne dass bislang im Rahmen der klinischen Routineuntersuchung ein Primärtumor eindeutig identifiziert werden konnte.

- Die Malignität der Halslymphknotenmetastasen wurde im Verlauf der Diagnostik zweifelsfrei durch histopathologische bzw. zytopathologische Untersuchung belegt.

- Bei den Patienten war keine auswärtige Vorbehandlung erfolgt.

- Die Patienten wurden nach der Beendigung der Therapie mindestens über einen einjährigen Zeitraum nachbeobachtet.

- Das Follow-up wurde für die lebenden Patienten bis zum Todeszeitpunkt oder Letztkontakt weitergeführt.

Von 98 Patienten, die diesen Kriterien entsprachen, wurde im Rahmen der Diagnostik bei 82 Patienten eine erweiterte Panendoskopie durchgeführt. Bei den anderen 16 Patienten (Gruppe F) war dies nicht möglich, da diese Patienten entweder nicht narkosefähig waren oder eine Behandlung ablehnten. In 5 dieser Fälle war der Grund für die nicht durchgeführte Panendoskopie anhand der Patientenakten nicht zu ermitteln. Gruppe F wurde nicht in die weiteren Analysen der vorliegenden Studie miteinbezogen.

Im Rahmen der Primärtumorsuche mittels erweiterter Panendoskopie wurde bei weiteren 22 Patienten (Gruppe E) ein Primärtumor identifiziert (Abb. 3, S. 19). Diese 
Fälle wurden daraufhin nicht weiter als Patienten mit unbekanntem Primärtumor geführt. Stattdessen erfolgte für diese Patientengruppe eine separate Auswertung (Kapitel 4.3.2.1 und 4.11).

Bei den verbleibenden 60 Patienten wurde nach Abschluss der Diagnostik einschließlich erweiterter Panendoskopie kein Primärtumor gefunden. Bei zwei dieser Patienten wurde keine Therapie durchgeführt, so dass die Auswertung insgesamt 58 therapierten Patienten mit zervikalem CUP-Syndrom (Gruppe A-D) umfasst.

\subsection{Diagnostik und Therapie}

Die Malignitätssicherung der Halsmetastasen war bei 23 der 58 Patienten $(39,7 \%)$ bereits auswärts erfolgt. Bei 35 Patienten $(60,3 \%)$ wurde diese in domo durchgeführt.

Bei 46 (79,3\%) der 58 Patienten war zunächst eine zytopathologische Untersuchung mittels Feinnadelpunktion vorgenommen worden, welche allerdings bei 10 dieser Patienten $(17,2 \%)$ kein eindeutiges Ergebnis erbracht hatte. Die definitive histopathologische Sicherung erfolgte in diesen Fällen entweder durch eine diagnostische Halslymphknotenbiopsie oder mittels intraoperativer Schnellschnittuntersuchung im Rahmen der therapeutischen Neck Dissection. Eine Lymphknotenbiopsie ohne vorherige punktionszytologische Untersuchung wurde bei 12 Patienten $(20,7 \%)$ durchgeführt.

Anschließend wurden bei allen Patienten die erweiterte Panendoskopie mit Biopsieentnahme im Bereich von Oro-, Naso- und ggf. Hypopharynx durchgeführt. Soweit noch nicht erfolgt, wurde darüber hinaus auch die diagnostische Tonsillektomie vorgenommen. Bei operablem Halslymphknotenbefund wurde zumeist in gleicher Sitzung die operative Sanierung der Halsmetastasen angeschlossen in Form einer unioder bilateralen Neck Dissection, ggf. ergänzt durch eine adjuvante Radio- bzw. Radiochemotherapie. Bei Inoperabilität oder Ablehnung einer operativen Behandlung wurde die primäre Radio- oder Radiochemotherapie angestrebt. Die Entscheidungen wurden jeweils individuell für den jeweiligen Patienten interdisziplinär durch die betreuenden HNO-Ärzte und Radioonkologen getroffen.

Zur weiteren Primärtumorsuche und zur Identifikation von Fernmetastasen wurden die Patienten der interdisziplinären Diagnostik wie z.B. Rö-Thorax, Abdomensonographie, Abdomencomputertomographie, Skelettszintigraphie, und ggf. weiteren konsiliarische Untersuchungen (Gastroenterologie, Urologie, Gynäkologie) etc. unterzogen. 
Im Rahmen der Nachsorgeuntersuchungen wurde eine komplette HNO-ärztliche Untersuchung einschließlich Endoskopie der verschiedenen Etagen von Pharynx und Larynx durchgeführt. Der Halslymphknotenstatus wurde mittels Palpation und B-ScanSonographie erfasst. Bei Verdacht auf regionäre Rezidiventwicklung und/oder Primärtumordemaskierung wurde - in der Regel nach vorheriger CT-Diagnostik - eine histologische Sicherung angestrebt.

Hinsichtlich Epidemiologie und Anamnese wurden Datum der Erstvorstellung in der HNO-Klinik, Patientenalter bei Erstvorstellung, Geschlecht und mögliche ätiologische Einflussfaktoren (z.B. Nikotin- und Alkoholkonsum) erfasst. Die Analyse des Halslymphknotenstatus umfasste die Seite der Lymphknotenschwellung, die Kategorisierung nach Richtlinien der UICC sowie Histologie und Grading. Die Lymphknotenstadien N1, N2a wurden als „Frühstadien“ zusammengefasst und den fortgeschrittenen Stadien N2b, N2c und N3 gegenübergestellt. Bei einzelnen Patienten waren diese Angaben dem Verlaufsbogen der jeweiligen Patientenakte nicht explizit zu entnehmen und mussten dann den Operationsberichten bzw. den Befundberichten der jeweiligen bildgebenden Untersuchungen entnommen werden. Des Weiteren wurde für jeden Patienten ermittelt, welche diagnostischen Maßnahmen im Einzelnen zur Primärtumorsuche eingesetzt worden waren und nach welchem Therapieregime die jeweilige Primärtherapie erfolgte. Zur Follow-up-Analyse wurden das Auftreten von Rezidivereignissen, Fernmetastasen und Zweittumoren sowie Todesdatum und Todesursache erfasst.

\subsection{Statistische Methoden und Datenverarbeitung}

Die Krankenakten wurden retrospektiv ausgewertet. Die Tabellenerstellung und die Textverarbeitung wurden mit den Programmen „Microsoft Office Word 2003 bzw. 2010“ und „Microsoft Office Excel 2003 bzw. 2010“ durchgeführt.

Die statistische Auswertung der individuellen Patientendaten aus der Excel-Vorlage erfolgte mit wissenschaftlicher Unterstützung am Institut für Medizinische Statistik der Universität Göttingen mit dem Programm „STATISTICA“ (StatSoft Inc. 2002).

Die Endpunkte der Analyse waren regionäre Kontrolle (Abwesenheit eines Halsrezidivs), lokale Kontrolle (Abwesenheit des Primärtumors im Follow-up), 
Gesamtüberleben (Overall Survival, OS) und krankheitsspezifisches Überleben (Disease Specific Survival, DSS).

Die Überlebensstatistik wurde nach der Produkt - Limit - Methode nach Kaplan und Meier (1958) berechnet. Zur Signifikanzanalyse wurde der Logrank-Test angewandt. Alle im univariaten Verfahren positiv getesteten Analysen $(p<0.05)$ wurden einer multivariaten Analyse unterzogen. Die multivariaten Vergleiche der Untergruppen wurden mit der Cox portional hazard Regressionsanalyse durchgeführt. Das Signifikanzniveau wurde für alle Tests auf $5 \%$ festgelegt. 


\section{Ergebnisse}

\subsection{Epidemiologie und Anamnese}

\subsubsection{Geschlecht und Alter}

Von den 58 Patienten (Gruppe A-D), die in der Universitätsklinik Göttingen aufgrund von Halslymphknotenmetastasen bei unbekanntem Primärtumor behandelt wurden, waren 48 Patienten männlich (82,8\%) und 10 weiblich (17,2\%). Damit betrug das Verhältnis von Männern zu Frauen 4,8:1 (Abb. 4). Das Durchschnittsalter des Gesamtkollektivs lag bei 56,2 Jahren (Median 56,0 Jahre, $x_{\min }=37$ Jahre, $x_{\max }=77$ Jahre) (Abb. 5).

weiblich; 10;

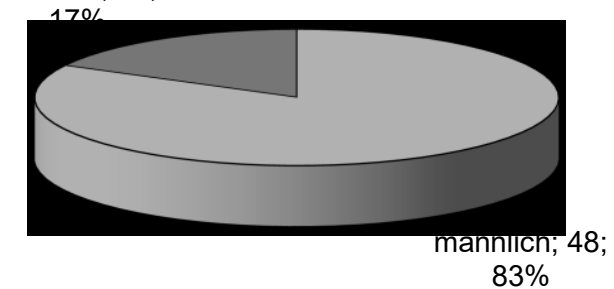

Abb. 4: Ge schlechtsverteilung im Kollektiv ( $n=58$ Patienten) 


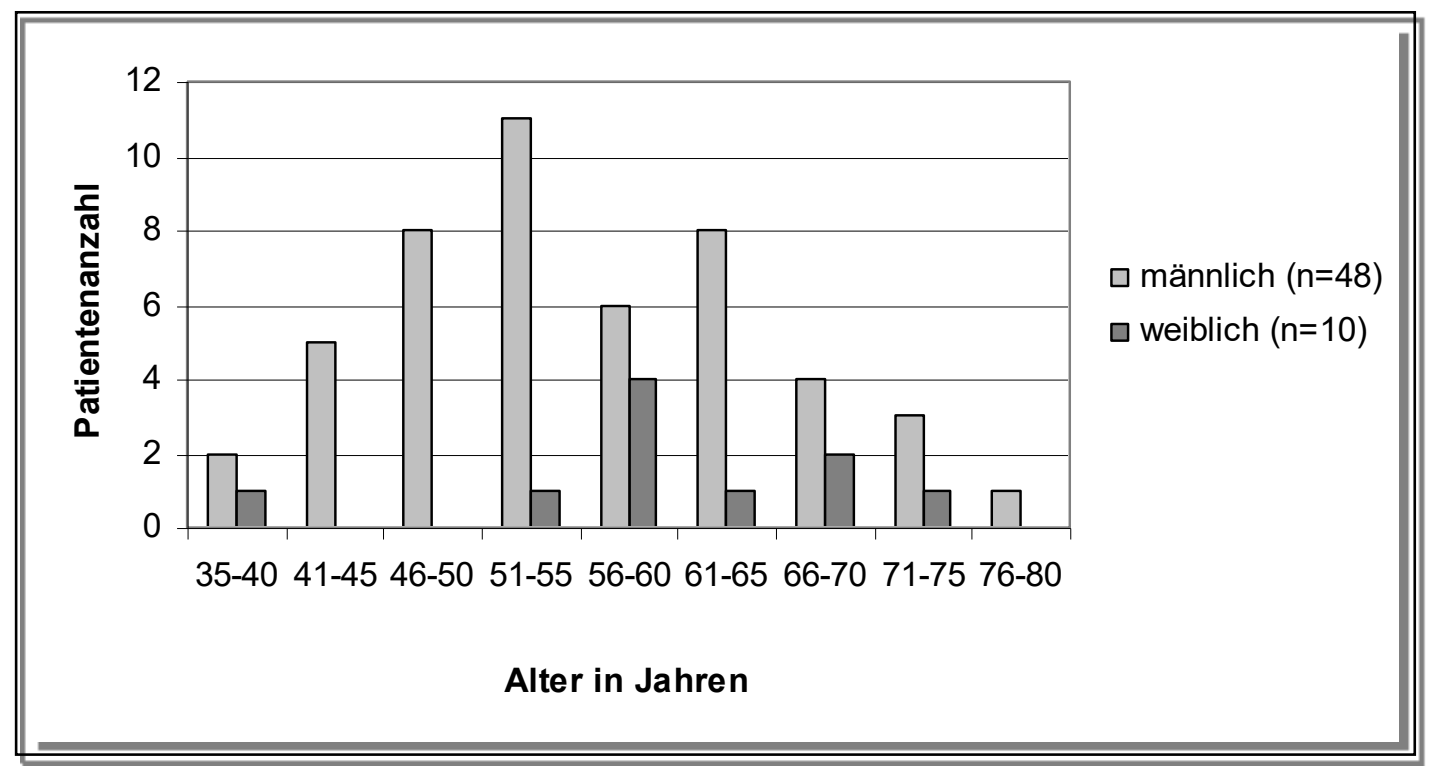

Abb. 5: Altersverteilung getrennt nach Geschlecht ( $n=58$ Patienten)

Über den Beobachtungszeitraum von 1986 bis 2006 konnte in der HNO-Klinik Göttingen eine leichte Zunahme der Anzahl der Patienten mit zervikalem CUPSyndrom beobachtet werden (Abb.6).

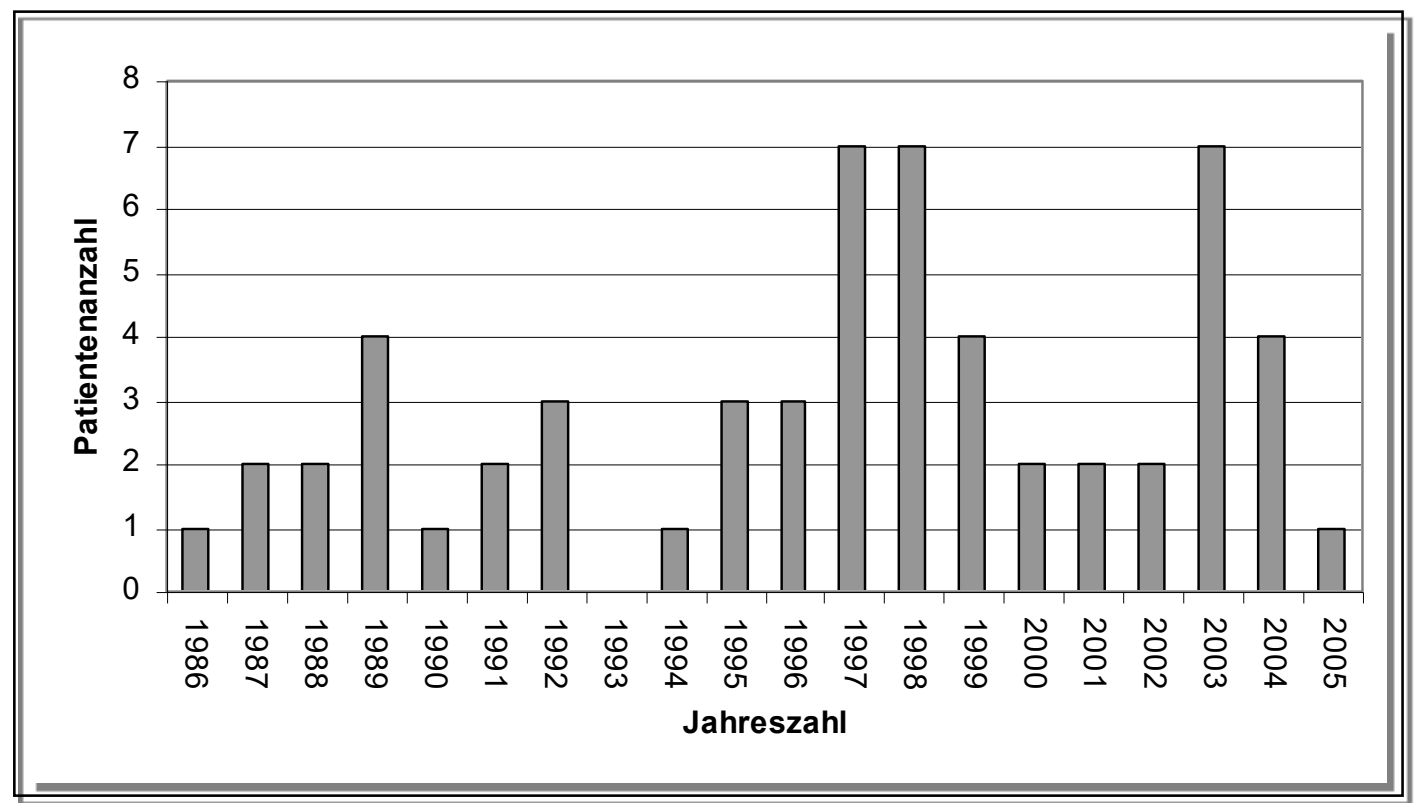


Abb. 6: Anzahl der Patienten mit therapiertem CUP-Syndrom pro Jahr Untersuchungszeitraum 1986-2006 $(n=58)$

\subsubsection{Alkohol-/ Nikotinkonsum}

31 Patienten $(53,4 \%)$ gaben an, regelmäßig Alkohol zu konsumieren und 7 Patienten (12,1\%), den Alkoholkonsum beendet zu haben. 15 Patienten (25,9\%) verneinten einen Alkoholkonsum und bei 5 Patienten $(8,6 \%)$ waren den Patientenakten diesbezüglich keine Angaben zu entnehmen.

Eine ähnliche Verteilung zeigte sich auch für den Nikotinkonsum. 42 Patienten $(72,4 \%)$ berichteten aktuell über Nikotinkonsum, 7 Patienten (12,1\%) hatten das Rauchen eingestellt, 4 Patienten (6,9\%) verneinten Nikotinkonsum und bei 5 Patienten $(8,6 \%)$ waren anhand der Akten keine Aussagen zum Nikotingenuss möglich. Insgesamt gaben 29 Patienten $(50,0 \%)$ an, sowohl regelmäßig Alkohol als auch Nikotin zu konsumieren.

Exakte Angaben zum Zeitpunkt der Einstellung des Nikotin- und/ oder Alkoholkonsums ließen sich den Unterlagen nicht entnehmen.

\subsection{Analyse der Halslymphknotenmetastasen}

\subsubsection{Lokalisation und Stadieneinteilung}

Der Halslymphknotenbefall lag bei 51 Patienten $(87,9 \%)$ unilateral und bei 7 Patienten (12,1\%) bilateral vor. Am häufigsten waren die Lymphknotenkategorien N3 (23 Patienten; 39,7\%) und N2b (15 Patienten; 25,9\%), gefolgt von N1 (9 Patienten; 15,5\%), N2a (8 Patienten; 13,8\%) und N2c (3 Patienten; 5,2\%) vertreten (Abb. 7). Die Einstufung in die jeweilige Lymphknotenkategorie erfolgte postoperativ anhand des histopathologischen Befundberichtes ( $\mathrm{pN}$-Stadium; $\mathrm{n}=53$ Patienten; 91,4\%) bzw. bei primärer Radio(chemo)therapie aufgrund der prätherapeutischen StagingUntersuchungen (cN-Stadium; $\mathrm{n}=5$ Patienten; 8,6\%).

Bei 47 Patienten (81\%) befanden sich die Metastasen in den Level II und/ oder III, und bei 3 Patienten (5\%) zusätzlich im Level IV. Weitere 8 Patienten (14\%) litten an zervikalen Tumormanifestationen, die übergreifend obere und untere Halsregionen erfassten, ohne dass nach Aktenlage eine exakte Zuordnung hinsichtlich der 
befallenen Level möglich war. Bei keinem Patienten waren die Submandibularregion (Level I) bzw. das seitliche Halsdreieck (Level V) primär isoliert befallen.

In Fällen, in denen die befallenen Lymphknoten bereits im Rahmen einer auswärtigen diagnostischen Halslymphknotenexstirpation entfernt worden waren und somit im Rahmen unserer Diagnostik bzw. Therapie kein Residualtumor mehr nachweisbar war, wurden die Angaben zur Lokalisation, N- Status und Levelangaben nach Robbins aus der Anamnese und den vorliegenden auswärtigen Befunden und OP-Berichten entnommen.

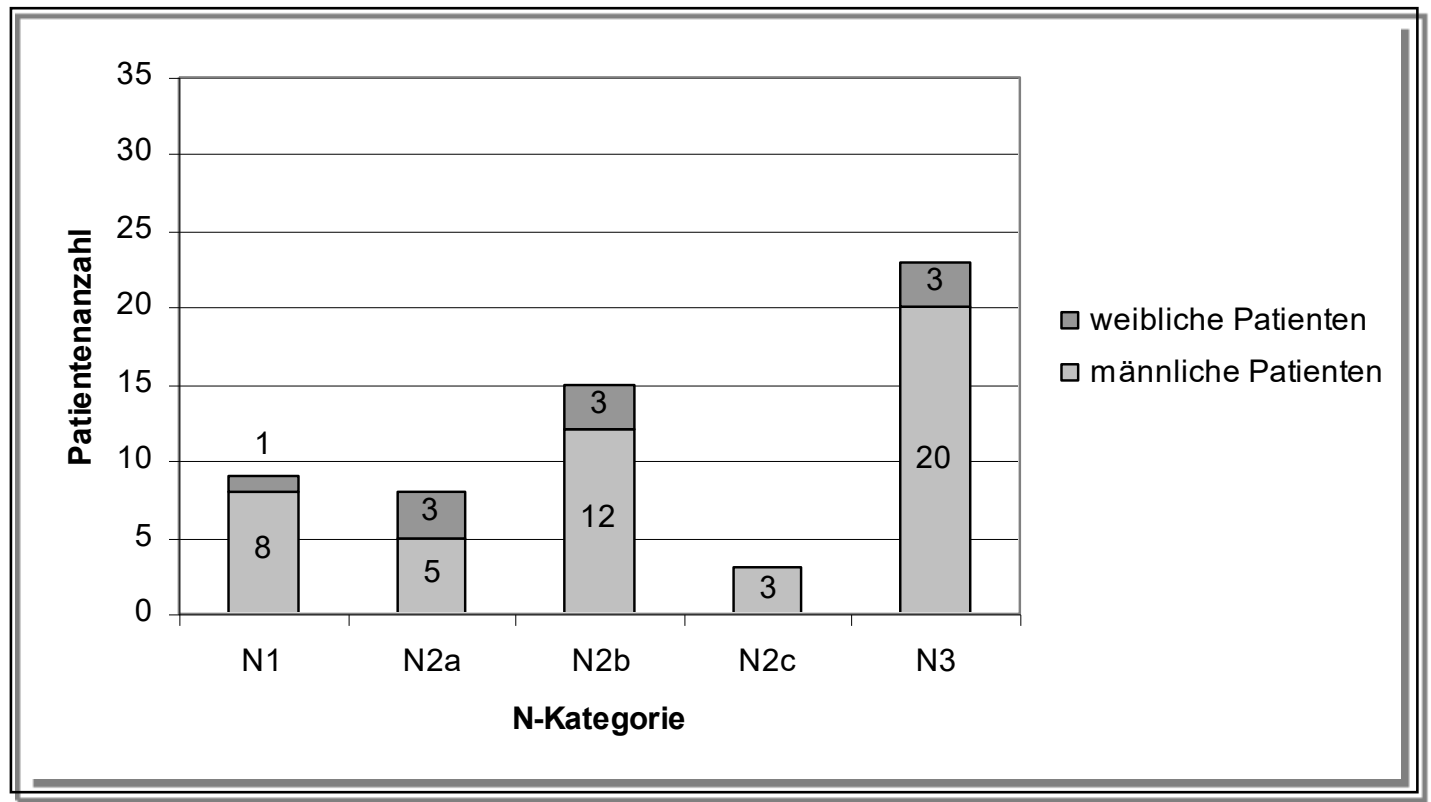

Abb. 7: N-Kategorien der 58 behandelten Patienten mit zervikalem CUP-Syndrom

\subsubsection{Histologie}

Insgesamt erbrachte die histologische Auswertung in 48 Fällen (82,8\%) ein Plattenepithelkarzinom. Bei jeweils 3 Patienten (je 5,2\%) lagen Adenokarzinome bzw. großzellige Karzinome vor. Bei 4 Patienten $(6,8 \%)$ fand sich ein lymphoepitheliales Karzinom. In Tab. 4 ist die Verteilung nach histologischer Differenzierung dargestellt. 


\begin{tabular}{|l|r|r|}
\hline histologischer Typ & Anzahl & Prozent \\
\hline \hline Plattenepithelkarzinome ingesamt & 48 & $\mathbf{8 2 , 8} \%$ \\
$\sim$ G1 & 1 & \\
$\sim$ G2 & 30 & \\
$\sim$ G3 & 13 & \\
$\sim$ G4 & 4 & \\
lymphoepitheliales Ca & 4 & $\mathbf{6 , 8} \%$ \\
Adenokarzinom & 3 & $\mathbf{5 , 2} \%$ \\
großzelliges Karzinom & 3 & $\mathbf{5 . 2} \%$ \\
\hline \hline Gesamt & $\mathbf{5 8}$ & $\mathbf{1 0 0 , 0 \%}$ \\
\hline
\end{tabular}

Tab. 4: Histologische Differenzierung der Halslymphknotenmeta sta sen ( $n=58$ Patienten)

\subsection{Diagnostische Verfahren}

\subsubsection{Bildgebende Verfahren}

Im Rahmen der Erstvorstellung wurde bei den meisten Patienten $(91,4 \%)$ eine B-Scansonographische Untersuchung der Halslymphbahnen zur Bestimmung der N-Kategorie und der Lokalisation der Halslymphknotenmetastasen durchgeführt. Im Krankheitsverlauf erfolgte bei 51 der 58 Patienten (87,9\%) eine CT bzw. bei 19 (32,8\%) eine MRT des Halses.

Ebenso wurde bei allen 58 therapierten Patienten spätestens zum Aufnahmezeitpunkt eine Röntgen-Thorax-Übersichtsaufnahme angefertigt. 50 Patienten $(86,2 \%)$ erhielten zusätzlich eine Thorax-CT. Weiterhin wurden bei $50(86,2 \%)$ der 58 Patienten eine Abdomensonographie und bei 24 Patienten (41,4\%) eine Skelettszintigraphie vorgenommen. 


\subsubsection{Panendoskopie}

\subsubsection{Stellenwert der Panendoskopie im Rahmen der Diagnostik bei zervikalem CUP-Syndrom}

Im Rahmen der Studie wurde zusätzlich der Umfang der Panendoskopie einschließlich zugehöriger Probebiopsien analysiert. Insgesamt wurde bei 82 der 98 Patienten in der Studie eine erweiterte Panendoskopie durchgeführt. 22 Patienten (Gruppe E) wurden nach Identifikation des Primärtumors durch die Panendoskopie nicht weiter als „CUPPatienten“ eingestuft, sondern separat von den 58 therapierten Patienten (Gruppe A-D) bzw. den 2 nicht-therapierten Patienten mit zervikalem CUP-Syndrom ausgewertet (s. Übersicht Abb. 3, S. 19).

Bei 17 dieser 22 Patienten wurde der Primärtumor visuell im Rahmen der Panendoskopie identifiziert. In 5 Fällen erfolgte jedoch erst durch die histopathologische Aufarbeitung der im Rahmen der Panendoskopie entnommenen Biopsate (4x Tonsille, 1x Nasopharynx) die Primärtumordiagnose bei intraoperativ zunächst unauffälligem Befund. Hierbei überwogen frühe Primärtumorstadien.

Die Primärtumorlokalisationen der 22 bei Panendoskopie identifizierten Primarien sind in Tab. 5 näher dargestellt. Bezogen auf die Gesamtzahl von 82 durchgeführten Panendoskopien ergibt sich somit eine Primärtumor-Detektionsrate von $26,8 \%$.

\begin{tabular}{|c|c|c|}
\hline Lokalisation & Patientenanzahl & pT-Stadium \\
\hline Oropharynx & $10(46,0 \%)$ & \\
\hline Tonsille & 6 & $4 \mathrm{~T}^{* \star *} ; 1 \mathrm{~T} 2^{*} ; 1 \mathrm{~T} 3$ \\
\hline Zungengrund & 3 & $1 \mathrm{~T} 1 ; 1 \mathrm{~T} 2 ; 1 \mathrm{~T} 3$ \\
\hline Seitenwand & 1 & T3 \\
\hline Hypopharynx & $8(36,0 \%)$ & 3 T1; 2 T2; 3 T3 \\
\hline Larynx & $1(5,0 \%)$ & $\mathrm{T} 1$ \\
\hline Nasopharynx & $1(5,0 \%)$ & $\mathrm{T} 1^{*}$ \\
\hline Ösophagus & $1(5,0 \%)$ & $\mathrm{T} 1$ \\
\hline Lunge & $1(5,0 \%)$ & $\mathrm{T} 1$ \\
\hline Gesamt & 22 & $12 \mathrm{~T} 1 ; 4 \mathrm{~T} 2,6 \mathrm{~T} 3$ \\
\hline
\end{tabular}

*erst im Rahmen der his topathologischen Aufarbeitung identifizierte Primärtumoren $(n=5)$

Tab. 5: Lokalisation und pT-Stadien der im Rahmen der Panendoskopie identifizierten Primärtumoren (Gruppe E, n=22 Patienten) 
Im Rahmen der erweiterten Panendoskopie wurde bei 6 Patienten ein Tonsillenkarzinom diagnostiziert. In der Mehrzahl $(n=4)$ wurden diese Tumoren erst bei der histopathologischen Aufarbeitung identifiziert (Tab. 5). Alle bei der Panendoskopie diagnostizierten Tonsillenkarzinome $(n=6)$ waren ipsilateral zum initialen Halslymphknotenbefall ( $4 \mathrm{x}$ rechte und $2 \mathrm{x}$ linke Halsseite) lokalisiert.

\subsection{Therapie der Halslymphknotenmetastasen}

Aufgrund der Weiterentwicklungen sowohl der operativen als auch der radioonkologischen Therapieverfahren innerhalb des 20jährigen Beobachtungszeitraumes variierten sowohl die Indikationsstellungen als auch die jeweiligen Therapiekonzepte, insbesondere auch hinsichtlich Strahlendosis und Bestrahlungsfeld. 8 der 58 Patienten, bei denen auch durch die erweiterte Panendoskopie kein Primärtumor identifiziert werden konnte (Gruppe $\boldsymbol{A} ; 13,8 \%$ ), erhielten eine alleinige Neck Dissection, 28 Patienten (Gruppe C; 48,3\%) eine Neck Dissection mit adjuvanter Radiotherapie, 17 Patienten (Gruppe $D ; 29,3 \%$ ) eine Neck Dissection mit adjuvanter kombinierter Radiochemotherapie und 5 Patienten (Gruppe B; 8,6\%) eine primäre Radio- bzw. Radiochemotherapie (Abb. 8).

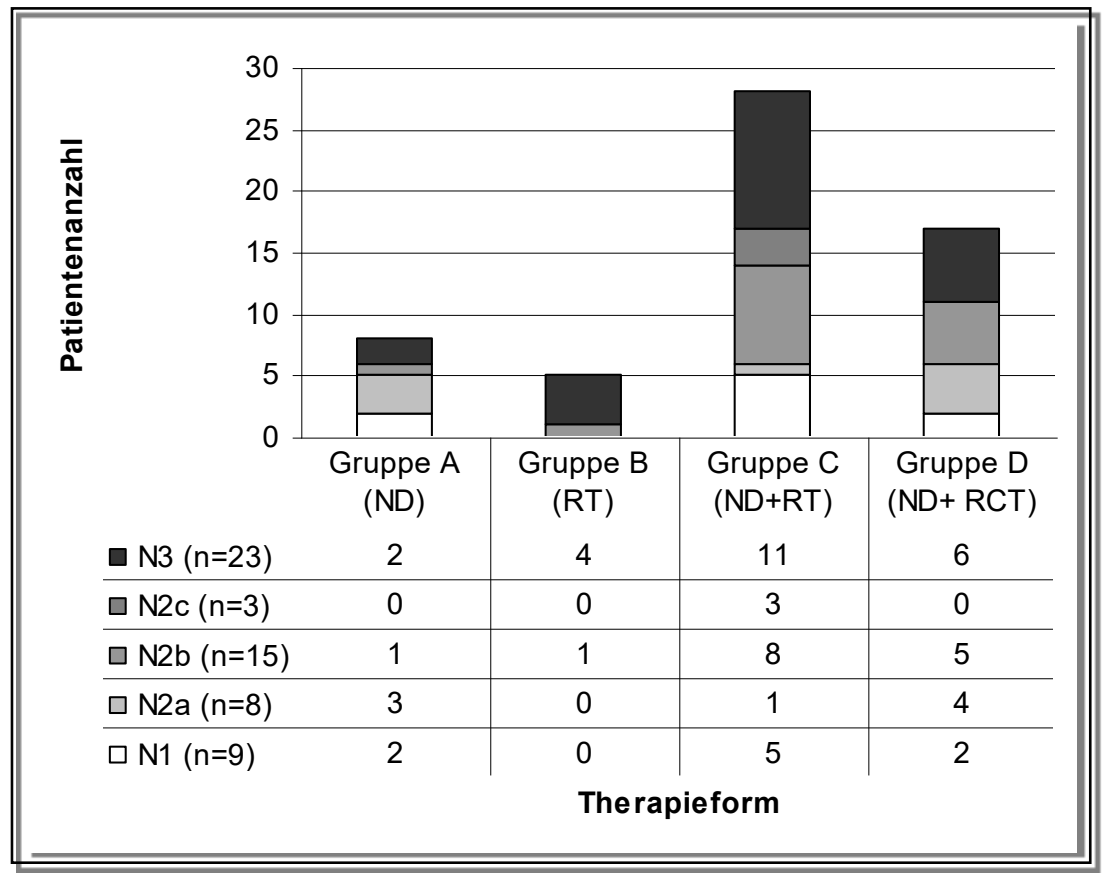

Abb. 8: Durchgeführte Therapieformen (Gruppe A-D) bei $n=58$ Patienten mit zervikalem CUP - Syndrom aufgeteilt nach $\mathrm{N}$-Kategorien ( $\mathrm{pN}$ bzw. cN) 


\subsubsection{Neck Dissection}

Bei insgesamt 53 Patienten (91,4\%) wurde eine Neck Dissection als operative Behandlungsmaßnahme vorgenommen. Der Eingriff wurde je nach Erfordernis als selektive oder radikale Neck Dissection ausgeführt (14x radikal, 39x selektiv). Im Fall einer bilateralen Metastasierung wurde zumindest einseitig eine funktionserhaltende selektive Neck Dissection vorgenommen. Alle operativ versorgten Patienten konnten im Sinne einer R0-Resektion behandelt werden. Die histologischen Aufarbeitungen der Operationspräparate ergaben, dass bei 27 Präparaten (46,6\%) ein Kapseldurchbruch vorlag.

\subsubsection{Radiotherapie}

Bei 50 Patienten $(86,2 \%)$ erfolgte eine Strahlentherapie mit einer durchschnittlichen Dosis von 59,1 Gy (Median $60 \mathrm{~Gy} ; \mathrm{x}_{\min }=46,8 ; \mathrm{x}_{\max }=72 \mathrm{~Gy}$ ). Die Radiotherapie erfolgte bei 10 Patienten (20,0\%) begrenzt auf den Bereich der jeweils betroffenen zervikalen Lymphabflusswege (limited field radiation) und bei 40 Patienten $(78,0 \%)$ an beiden Halsseiten unter Einbeziehung möglicher Primärtumorlokalisationen (extended field radiation).

\subsubsection{Primäre Radiotherapie}

5 Patienten (Gruppe B, 8,6\%) wurden primär bestrahlt. In diesen Fällen lag entweder eine inoperable Infiltration der A. carotis interna vor oder es handelte sich um Patienten in deutlich reduziertem Allgemeinzustand bzw. mit fortgeschrittener, narkoselimitierender Grunderkrankung. Geplant war initial eine kumulative Dosis von ca. 70 Gy, die jedoch bei 3 Patienten nicht erreicht werden konnte. Bei einem Patienten wurde eine schlechte Compliance als Ursache für den vorzeitigen Bestrahlungsabbruch beschrieben, bei den anderen beiden Patienten fanden sich diesbezüglich im Aktenmaterial keine Angaben. Die minimale applizierte Dosis lag in diesen Fällen bei ca. 50 Gy.

Bei 2 der 5 primär bestrahlten Patienten beschränkte sich das Bestrahlungsfeld auf die ipsilaterale zervikale Metastasenregion (limited field radiation). Bei 3 Patienten wurden sowohl die Metastasenregion als auch die vermeintlichen Primärtumorlokalisationen bestrahlt (extended field radiation) (Tab. 6). 


\subsubsection{Adjuvante Radiotherapie}

45 Patienten $(77,6 \%)$ erhielten im Anschluss an die operative Behandlung eine adjuvante Strahlentherapie, wobei eine kumulative Dosis von 60-64 Gy angestrebt wurde.

Diese vorgesehene Zieldosis wurde jedoch bei 14 Patienten nicht vollständig erreicht (minimal 46,8 Gy). Die Ursache für die Dosisreduzierung war jedoch anhand der Aktenlage nicht im Einzelfall dokumentiert bzw. ausgewertet worden. Die durchschnittliche Strahlendosis des adjuvant bestrahlten Kollektivs lag ca. 6-10 Gy niedriger als die Dosis in der primär bestrahlten Patientengruppe (Tab. 6). Die adjuvante Bestrahlung erfolgte bei 8 Patienten als limited field radiation beschränkt auf die zervikale Metastasenregion. Bei 37 der postoperativ bestrahlten Patienten wurde zusätlich zur Metastasenregion die mögliche Primärtumorlokalisation in das Strahlenfeld miteinbezogen (extended field radiation). Die Auswertung der Strahlentherapiedaten erfolgte unabhängig von einer ggf. begleitenden Chemotherapie.

\begin{tabular}{|c|c|c|c|c|}
\hline 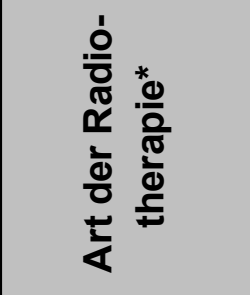 & 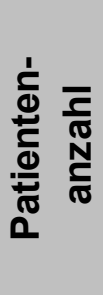 & 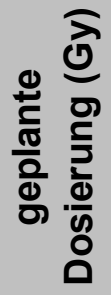 & 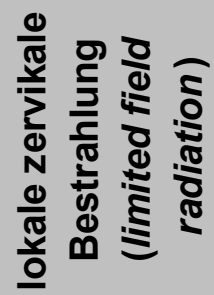 & 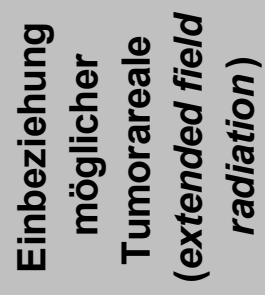 \\
\hline \multirow{2}{*}{$\begin{array}{l}\text { primäre } \\
\text { Radiotherapie } \\
\text { adjuvante } \\
\text { Radiotherapie }\end{array}$} & 5 & 70 & 2 & 3 \\
\hline & 45 & $60-64$ & 8 & 37 \\
\hline $\begin{array}{l}\text { Radiotherapie } \\
\text { insgesamt }\end{array}$ & 50 & & 10 & 40 \\
\hline
\end{tabular}

Tab. 6: Patienten mit primärer/ adjuvanter Radiotherapie ( $n=50$ Patienten)

\subsubsection{Konkomitante Chemotherapie}

Insgesamt erhielten 20 (34,5\%) der insgesamt 58 therapierten Patienten zusätzlich zur Radiotherapie eine begleitende Chemotherapie. Bei 17 Patienten erfolgte diese im 
Rahmen einer adjuvanten Radiochemotherapie nach vorheriger operativer Halssanierung (Gruppe D), bei 3 Patienten im Rahmen einer primären Radiochemotherapie.

Als Chemotherapeutikum wurde bei 6 der insgesamt 20 Patienten Cisplatin $(30,0 \%)$ und bei 3 Patienten Carboplatin (15,0\%) appliziert. Des Weiteren fanden Kombinationen aus Carboplatin plus 5-FU (2 Patienten; 10,0\%) und Cisplatin plus 5-FU (3 Patienten; 15,0\%) sowie Mitomycin und 5-FU (5 Patienten; 25,0\%) Anwendung. Bei einem Patienten (5,0\%) erfolgte die alleinige Gabe von 5-FU.

\section{5 Überleben und Todesursachen}

Am Ende der Nachbeobachtungszeit waren von den 58 behandelten Patienten 22 Patienten (37,9\%) am Leben. Für diese Patienten lag die Nachbeobachtungszeit bei durchschnittlich 83,5 Monaten ( $x_{\min }=24$ Monate, $x_{\max }=162$ Monate). Bei 16 dieser Patienten $(72,7 \%)$ konnte ein Follow-up über mindestens 5 Jahre durchgeführt werden. Das durchschnittliche Todesalter der 36 verstorbenen Patienten lag bei 58,7 Jahren (Median 60,0 Jahre; $x_{\min }=39$ Jahre, $x_{\max }=79$ Jahre). Die mittlere Überlebenszeit der 36 verstorbenen Patienten zwischen der Erstvorstellung in der Universitätsklinik Göttingen und dem Todeszeitpunkt belief sich auf 31,5 Monate (Median 36,5 Monate; $x_{\min }=3$ Monate, $x_{\max }=179$ Monate).

19 Patienten (32,7\%) verstarben aufgrund von Fernmetastasen und 4 Patienten $(6,9 \%)$ erlagen regionären Rezidiven. Bei 2 Patienten (3,4\%) war ein im Nachbeobachtungszeitraum demaskierter Primärtumor todesursächlich. 11 Patienten $(19,0 \%)$ verstarben interkurrent (Abb. 9). 


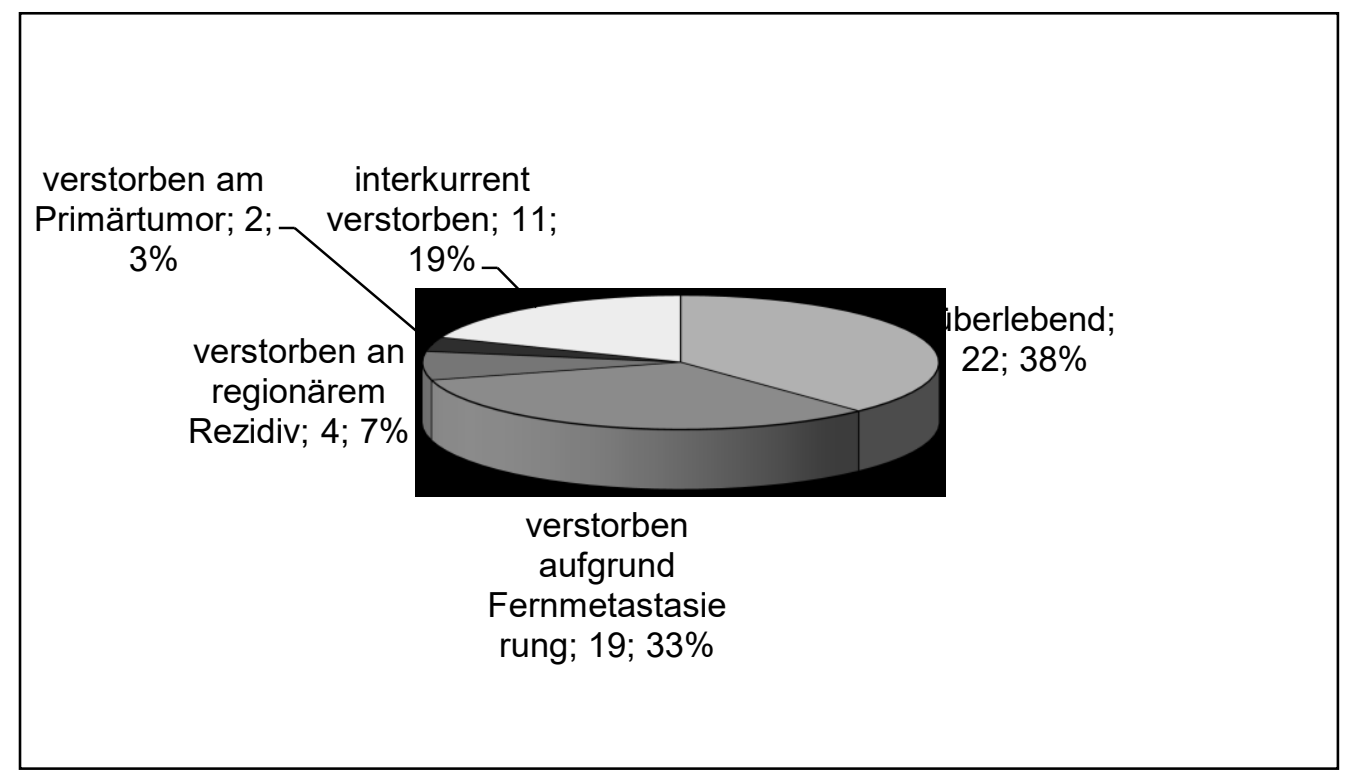

Abb. 9: Überleben bzw. Todesursachen der 58 behandelten Patienten mit zervikalem CUP-Syndrom

Das 3-Jahresgesamtüberleben (Overall Survival) lag für das Gesamtkollektiv von 58 Patienten bei $52,9 \%$, das 5-Jahresgesamtüberleben bei 40,9\% (Abb. 10) und das 3bzw. 5 Jahres krankheitsspezifische Überleben (DSS) bei 50,9\% bzw. 39,7\% (Abb. 11). 


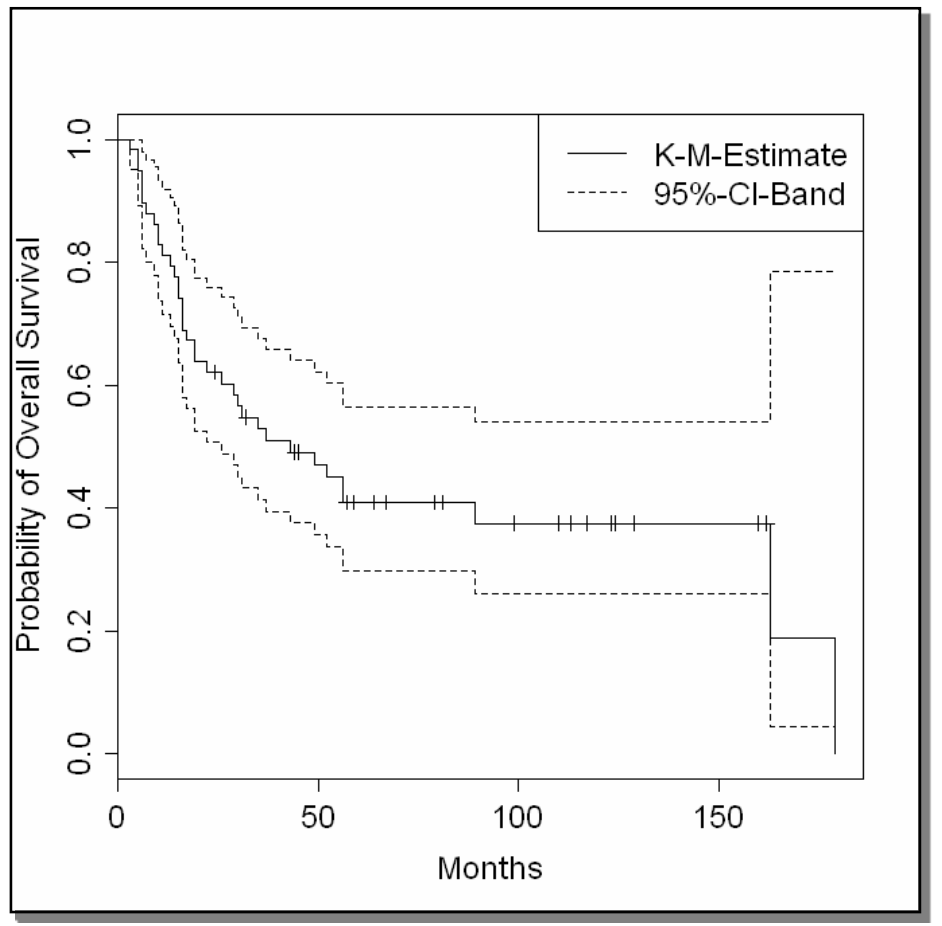

Abb. 10: Ge samtüberleben (Overall Survival) für alle therapierte Patienten ( $n=58$ Patienten) 


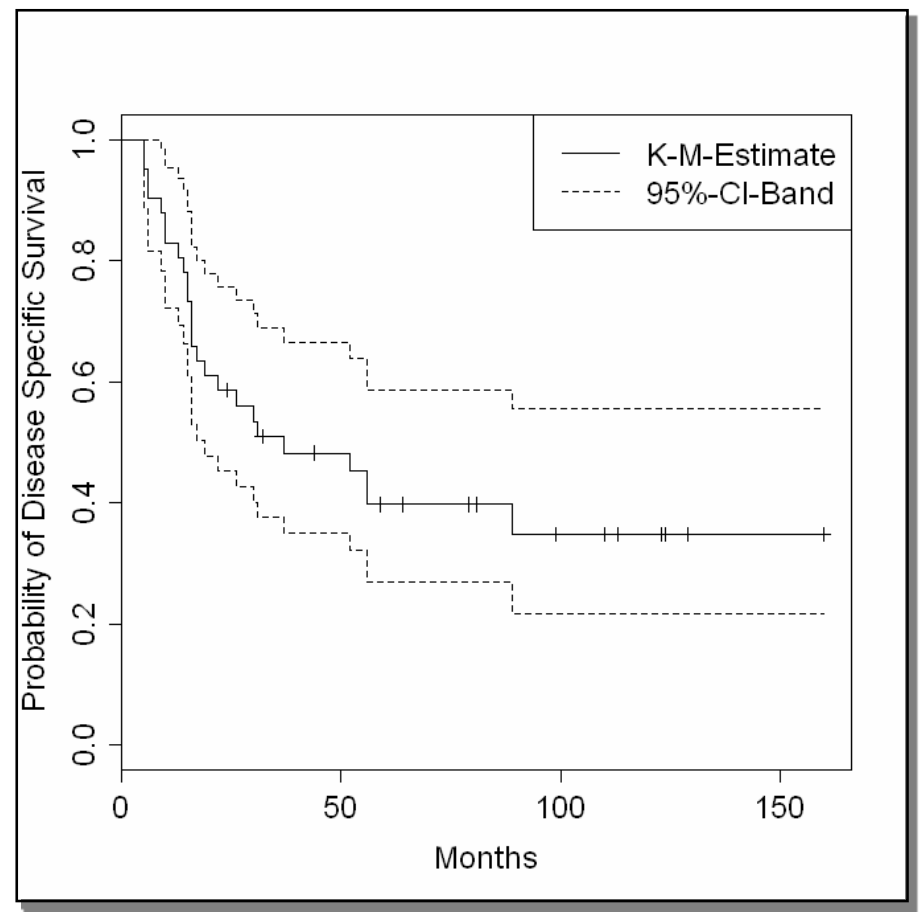

Abb. 11: Das krankheitsspezifische Überleben (Disease Specific Survival) für alle therapierte Patienten ( $\mathrm{n}=58$ Patienten)

\subsection{Regionäre (nodale) Kontrolle}

Im Laufe der Nachsorge wurden bei 15 Patienten Halslymphknotenrezidive (25,9\%) diagnostiziert. Der Zeitraum zwischen durchgeführter Primärtherapie und Diagnose des Halsrezidivs lag durchschnittlich bei 14,2 Monaten (Median 10,2 Monate; $x_{\min }=2$ Monate, $x_{\max }=43$ Monate). Innerhalb des ersten Jahres nach der Primärtherapie wurden $66,7 \%$ der Halsrezidive diagnostiziert.

Bei 5 Patienten konnten die aufgetretenen Rezidive erfolgreich operativ und, falls dies nicht bereits im Rahmen der Primärtherapie erfolgt war, mit adjuvanter Radio- oder Radiochemotherapie behandelt werden. Für alle 58 therapierten Patienten betrug die 3- bzw. 5-Jahresrate der regionären Kontrolle 73,7\% bzw. 67,3\% (Abb. 12). 


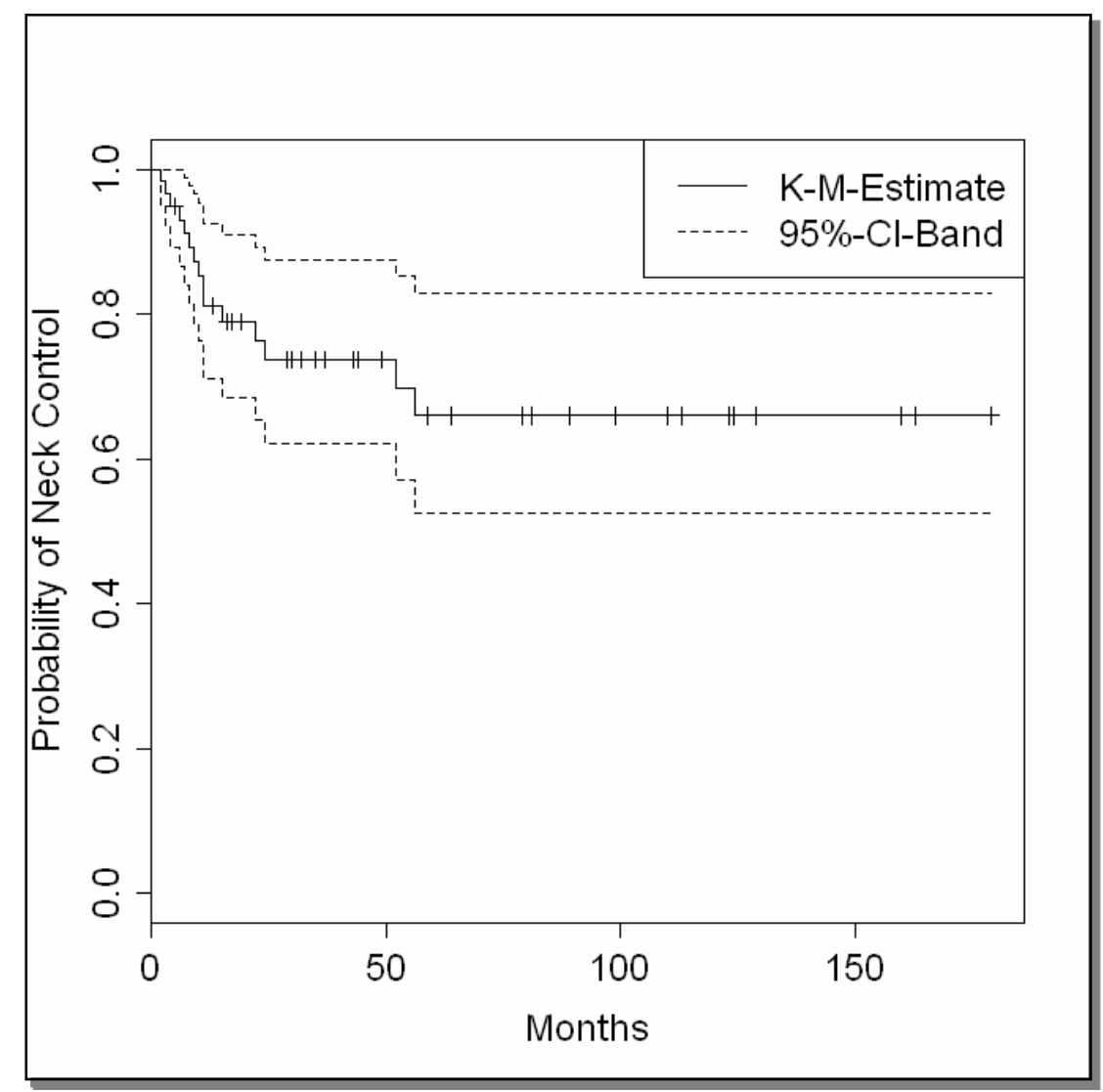

Abb. 12: Regionäre Kontrolle für alle 58 therapierten Patienten

Die regionäre Kontrolle war unabhängig vom N-Stadium $(p=0.36)$. Es zeigte sich ein statistisch signifikanter Zusammenhang zwischen regionärer Kontrolle und krankheitsspezifischem Überleben ( $p=0.02$ univariater Analyse; $p=0.54$ multivariate Analyse), jedoch nicht zwischen regionärer Kontrolle und Gesamtüberleben $(p=0.96)$ (Tab. 9, S. 47).

Die Analyse der regionären Kontrolle in Abhängigkeit von der Behandlungsmodalität ergab die höchste Rezidivrate (62,5\%) für Patienten, bei denen als primäre Therapiemaßnahme ausschließlich eine Neck Dissection ohne Nachbestrahlung (Gruppe A) durchgeführt worden war. In den anderen Behandlungsgruppen (Gruppen B-D) lag die Rezidivquote bei jeweils etwa 20\% (Abb. 13).

Die Analyse der regionären Rezidive in Abhängigkeit vom jeweiligen N-Stadium des Ausgangsbefundes ergab die höchste Rezidivrate für Solitärmetastasen der Kategorie 
N1 (Abb. 14). Allerdings bestand die Patientengruppe A, die mit $62,5 \%$ die höchste Rezidivrate aufwies, zu 62,5\% (5 Patienten) aus den Solitärstadien N1 und N2a.

Die 5 Patienten der Gruppe A, welche ein Halsrezidiv nach alleiniger vorheriger Operation erlitten hatten, wurden anschließend einer weiteren Therapie zugeführt. Bei 4 Patienten erfolgte eine erneute operative Therapie, wobei 3 Patienten zusätzlich mit einer adjuvanten Radiotherapie behandelt wurden. Bei einem Patienten wurde das Halsrezidiv primär bestrahlt.

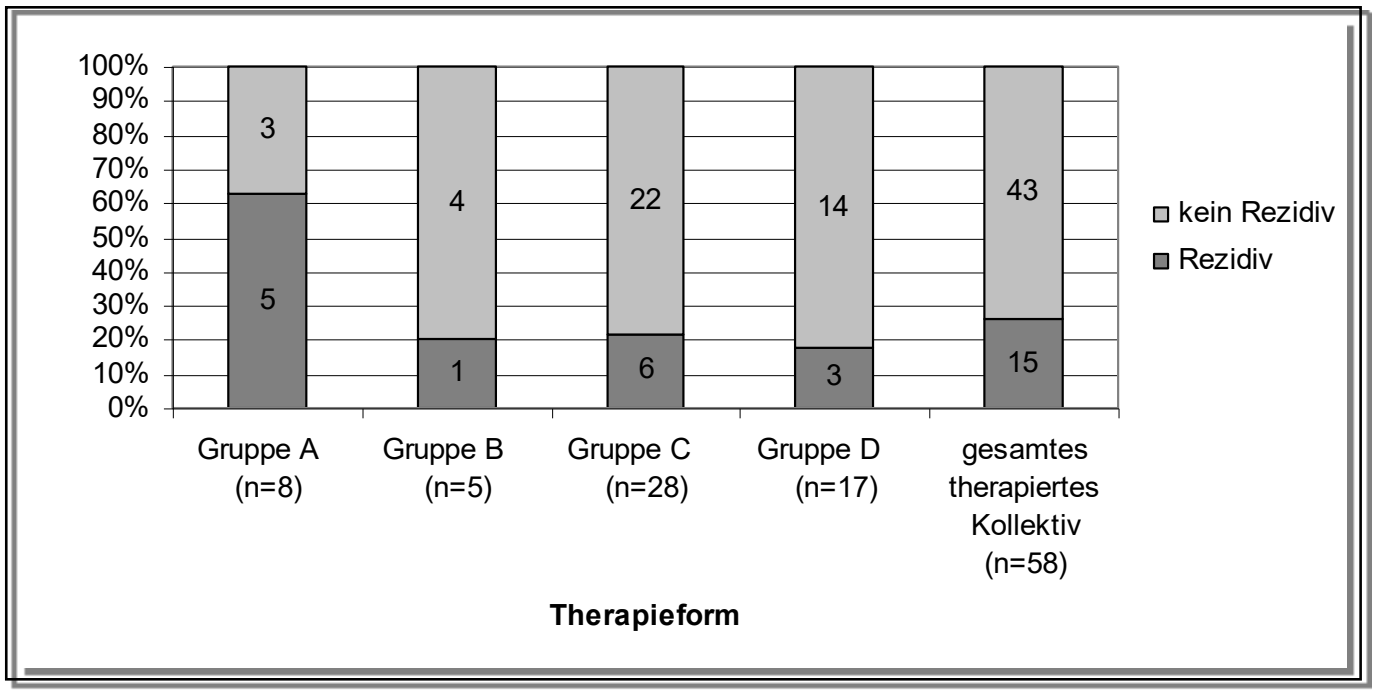

Abb. 13: Entwicklung regionärer Rezidive in Abhängigkeit von der vorausgegangenen Therapieform bei allen therapierten Patienten ( $n=58$ Patienten) 


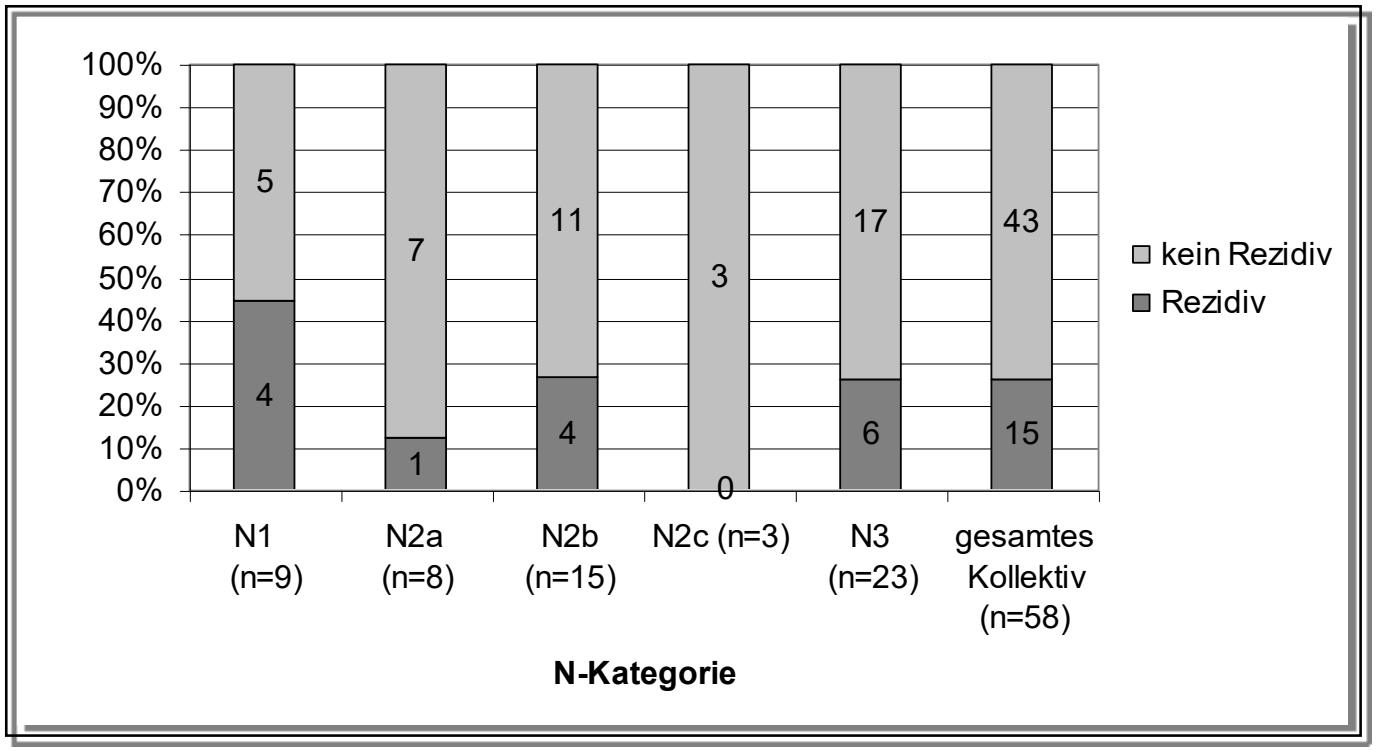

Abb. 14: Halsrezidive bezogen auf den N-Status vor Primärbehandlung ( $n=58$ Patienten)

\subsection{Lokale Kontrolle und späte Primärtumordemaskierung}

Nach Abschluss der Primärtherapie konnte bei 4 (6,9\%) der 58 therapierten Patienten im Rahmen der Nachuntersuchungen der Primärtumor diagnostiziert werden. Im Durchschnitt wurde dieser 32,5 Monate nach Primärbehandlung (Median 29,5; $x_{\min }=8$ Monate, $x_{\max }=63$ Monate) festgestellt. Bei 3 der 4 demaskierten Primärtumoren lagen fortgeschrittene Stadien vor $(\mathrm{T} 3=2 ; \mathrm{T} 4=1)$. In einem Fall war ein exaktes Tumorstaging nicht möglich, da der betroffene Patient jegliche weitere Diagnostik verweigerte.

Am Ende der Nachbeobachtungszeit blieb der Primärtumor noch bei 54 Patienten $(93,1 \%)$ des Gesamtkollektivs ( $n=58,100 \%)$ unbekannt. Hinsichtlich Gesamtüberleben $(p=0.56)$, krankheitsspezifischem Überleben $(p=0.61)$ und regionärer Kontrolle $(p=0.62)$ ergab sich für die späte Primärtumordemaskierung kein statistisch signifikanter Einfluss gegenüber Patienten ohne Primärtumordemaskierung. Jedoch erscheint die Aussagekraft statistischer Untersuchungen bei lediglich 4 Patienten eingeschränkt.

\subsubsection{Lokalisation der demaskierten Primärtumoren}

Die 4 während des Follow-up demaskierten Primärtumoren befanden sich in 3 Fällen $(75,0 \%)$ im HNO-Bereich (Hypopharynx $n=2$; Larynx $n=1)$. Bei 2 dieser Patienten lag 
der Primärtumor innerhalb der im Rahmen der Erstbehandlung bestrahlten Region (extended field radiation). Der eine außerhalb des HNO-Bereiches lokalisierte Primärtumor wurde im rechten zentralen Lungenflügel diagnostiziert.

\subsubsection{Therapie der demaskierten Primärtumoren}

Alle 4 Patienten, bei denen im Laufe der Nachuntersuchung der Primärtumor diagnostiziert wurde, wurden einer Therapie zugeführt. Bei 2 Patienten erfolgte in kurativer Absicht eine laserchirurgische Primärtumorresektion. Da bei den anderen 2 Patienten weder eine chirurgische Intervention noch eine erneute Radiatio möglich war, wurden diese palliativ behandelt. Alle vier Patienten verstarben innerhalb von 9 bis 32 Monaten nach Primärtumordemaskierung.

\subsection{Fernmetastasen}

Bei 21 der 58 behandelten Patienten (36,2\%) wurden während des Follow-up Fernmetastasen diagnostiziert (Abb. 15).

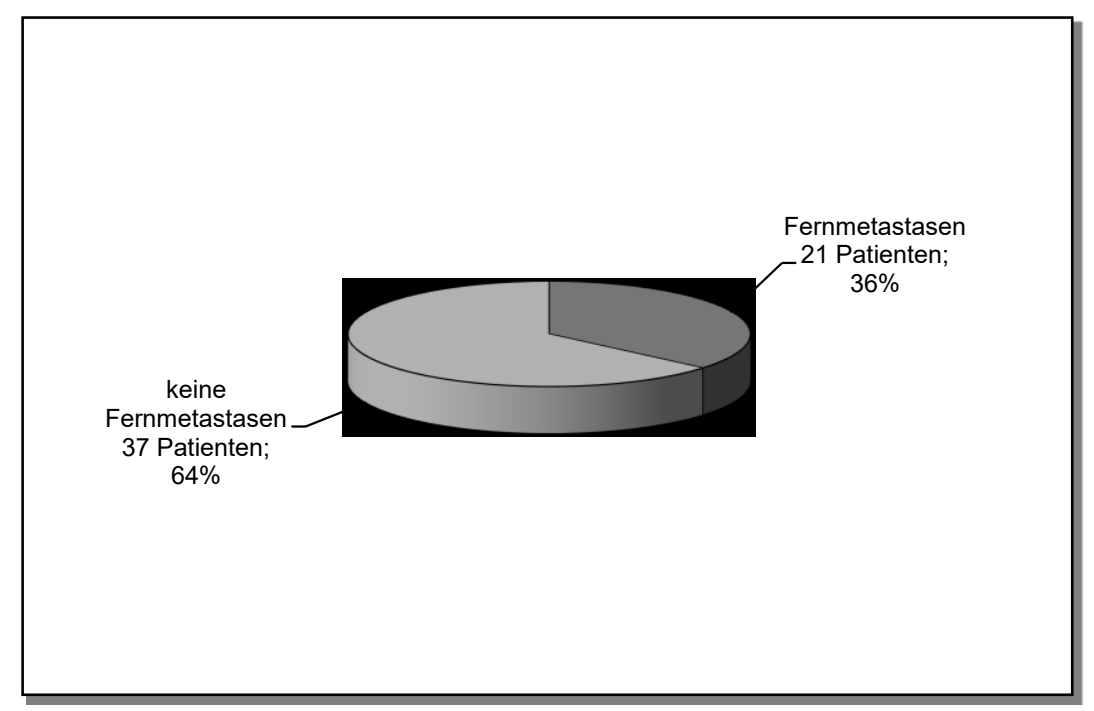

Abb. 15: Auftreten von Fernmetastasen ( $n=58$ Patienten)

Die Fernmetastasen waren in Lunge, Skelett, mediastinalen/ axillären Lymphknoten, Leber und Gehirn lokalisiert (Tab. 7). 
Bei 11 der 21 Patienten (52,4\%) erschien eine Therapie der Fernmetastasen nicht sinnvoll. Bei 4 Patienten (19,1\%), deren Metastasenherde im Mediastinum und Leber lokalisiert waren, erfolgte eine operative Behandlung. Eine Radiotherapie wurde bei 2 Patienten $(9,4 \%)$ mit Metastasen im Bereich des Skelettsystems und des Gehirns durchgeführt. Weitere 4 Patienten (19,1\%) erhielten eine palliative Chemotherapie.

\begin{tabular}{|l|c|}
\hline Fernmetastasenlokalisation & Anzahl \\
\hline \hline Lunge & 9 \\
Skelett & 6 \\
Leber & 3 \\
mediastinale/ axilläre & 2 \\
Lymphknoten & 3 \\
\hline
\end{tabular}

Tab. 7: Lokalisation von Fernmetastasen (Mehrfachnennungen möglich) bei 21 Patienten mit aufgetretenen Fernmetastasen

Innerhalb des Beobachtungszeitraumes verstarben 19 der 21 Patienten (90,5\%) an den Folgen der Fernmetastasen. Bei 16 der 21 Patienten mit Fernmetastasen (76,2\%) waren bei der initialen histologischen Aufarbeitung der Lymphknotenpräparate Kapseldurchbrüche diagnostiziert worden.

Im Hinblick auf das primäre N-Stadium zeigte sich, dass Fernmetastasen vermehrt bei Patienten mit fortgeschrittenen Halslymphknotenmetastasen auftraten, die nach Abschluss der Primärbehandlung in die Kategorien N3, N2b und N2c eingestuft worden waren (Abb. 16). 


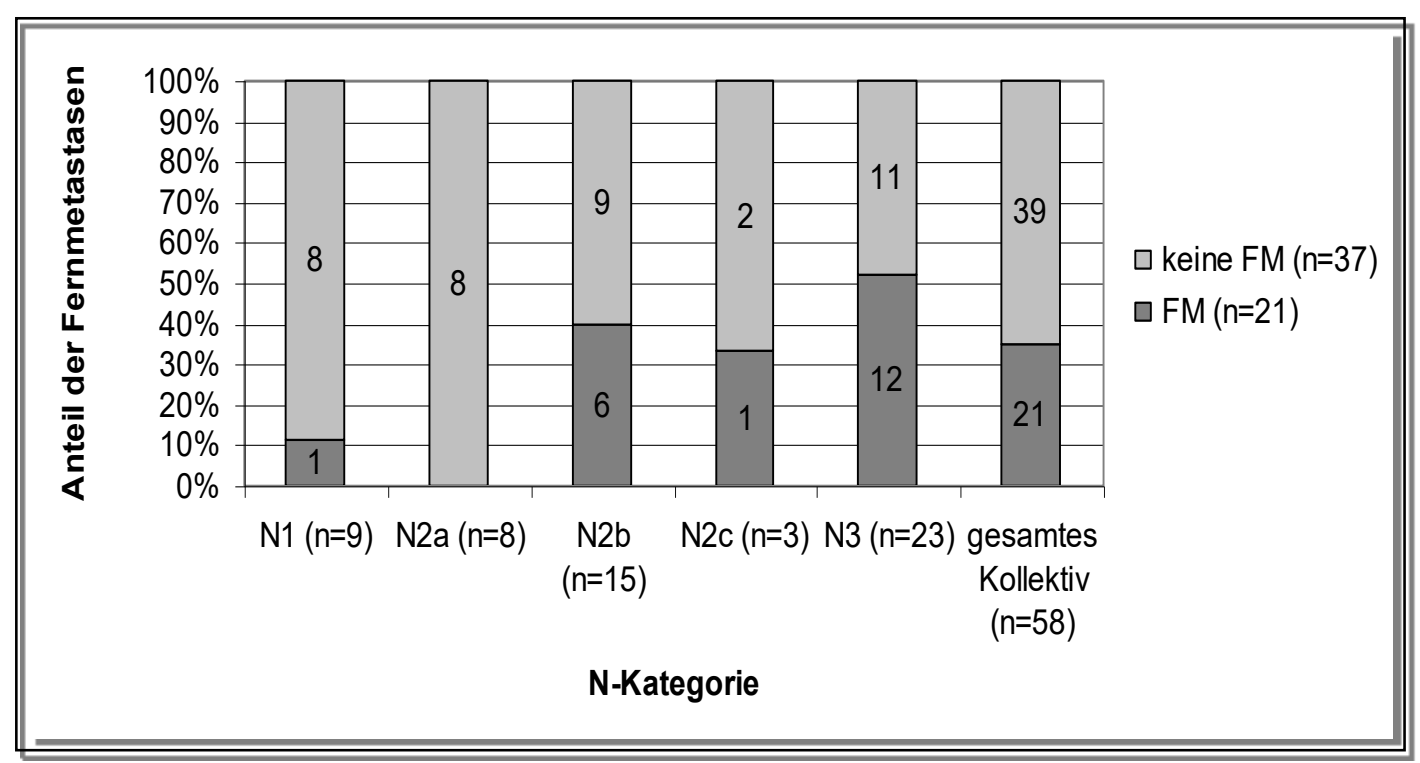

Abb. 16: Fernmetasta sen in Abhängigkeit von der initialen N-Kategorie ( $n=58$ Patienten)

13 Patienten $(61,9 \%)$, bei denen im Verlauf Fernmetastasen diagnostiziert wurden, waren primär durch Neck Dissection und adjuvanter Radiotherapie (Gruppe C) behandelt worden. Demgegenüber entwickelten lediglich 5 Patienten (23,8\%) Fernmetastasen nach initialer Operation und adjuvanter kombinierter Radiochemotherapie (Abb. 17).

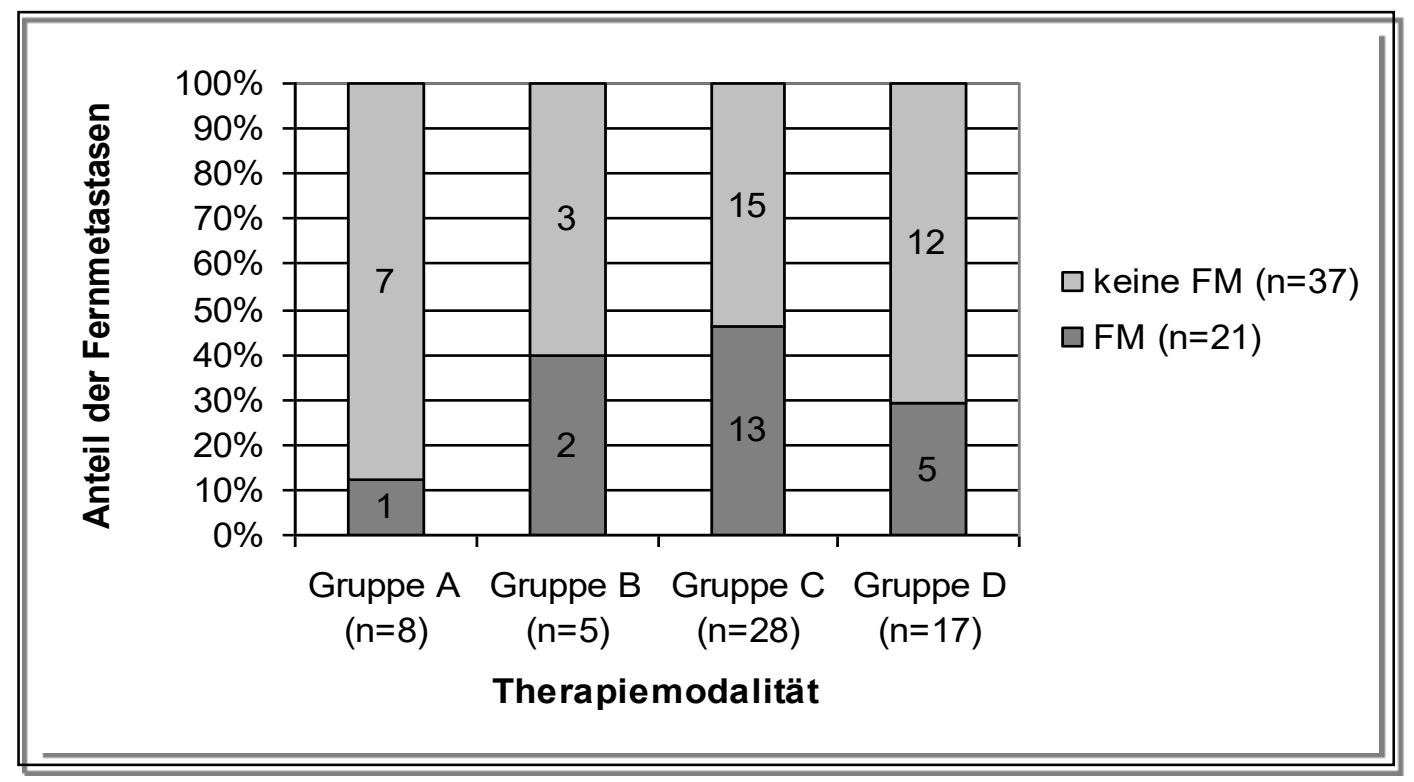

Abb. 17: Fernmetasta sen in Abhängigkeit von der Art der Primärbehandlung ( $n=58$ Patienten) 
Patienten mit Fernmetastasen wiesen ein deutlich schlechteres 3- bzw. 5Jahresgesamtüberleben (22\% bzw. 6\%), krankheitsspezifisches Überleben (20\% bzw. $5 \%$ ) und regionäre Kontrolle (57\% bzw. 38\%) auf im Vergleich zu Patienten ohne Fernmetastasen (3- bzw. 5-Jahresgesamtüberleben $70 \%$ bzw. $61 \%$; krankheitsspezifisches Überleben $81 \%$ bzw. $75 \%$ und regionäre Kontrolle $82 \%$ bzw. 77\%). Insgesamt ging die Entwicklung von Fernmetastasen im Follow-up mit einer signifikanten Reduktion von Gesamtüberleben $(p<0.0001$ univariat; $p=0.001$ multivariat), krankheitsspezifischem Überleben ( $p<0.001$ univariat; $p=0.001$ multivariat) und regionärer Kontrolle ( $p=0.03$ univariat) einher (Tab. 9, S. 47).

\subsection{Zweittumoren}

Während des Nachbeobachtungszeitraumes konnte bei $9(15,5 \%)$ der 58 Patienten ein Zweittumor diagnostiziert werden. Beobachtete Zweittumorlokalisationen waren die Lunge $(n=2,22,2 \%)$, die Prostata, die Tonsille, die Uvula, die Haut, die Mamma, der Alveolarfortsatz des Unterkiefers und ein neuroendokriner Tumor (jeweils $n=1 ; 11,1 \%$ ) (Tab. 8).

\begin{tabular}{|l|c|}
\hline Lokalisation von Zweittumoren & Anzahl \\
\hline \hline Lunge & 2 \\
Prostata & 1 \\
Tonsille & 1 \\
Uvula & 1 \\
Haut & 1 \\
Mamma & 1 \\
Alveolarfortsatz des Unterkiefers & 1 \\
neuroendokriner Tumor & 1 \\
\hline \hline Gesamtanzahl & $\mathbf{9}$ \\
\hline
\end{tabular}

Tab. 8: Lokalisation der Zweittumoren im Beobachtungszeitraum (n=9 Patienten) 


\subsection{Andere prognostische Faktoren}

Die weitere Subgruppenanalyse umfasste Geschlecht, Therapiemodalität, N-Status, Vergleiche zwischen uni- und bilateraler Metastasierung, Histologie, Art der Neck Dissection, extrakapsuläres Wachstum, späte Primärtumordemaskierung, regionäre Kontrolle, Entwicklung von Fernmetastasen und Strahlenfeld (Tab. 9, S. 47).

\subsubsection{Geschlecht}

Es zeigte sich für die weiblichen Patienten $(n=10)$ ein tendenziell $(p=0.14)$ besseres Gesamtüberleben, jedoch keine Verbesserung für das krankheitsspezifische Überleben $(p=0.27)$ und die regionäre Kontrolle $(p=0.85)$. Die 3- bzw. 5-Jahresgesamtüberlebensrate betrug für weibliche Patienten $70 \%$ bzw. $60 \%$ und für die männlichen Patienten 49\% bzw. 37\% (Tab. 9, S. 47).

\subsubsection{Therapiemodalität}

Für die Art der Primärtherapie (Gruppen A-D) ergab sich eine statistisch signifikante Relevanz im Hinblick auf das Gesamtüberleben ( $p=0.02$ univariat; $p=0.11$ multivariat). So wiesen Patienten mit alleiniger Neck Dissection (Gruppe A) mit einem 3- bzw. 5Jahresgesamtüberleben (Overall Survival) von $88 \%$ bzw. $75 \%$ die höchsten Überlebensraten auf. Diese Patientengruppe umfasste jedoch lediglich 8 Patienten mit überwiegend frühen Lymphknotenstadien N1 und N2a. Demgegenüber wies die ebenfalls kleine Patientengruppe $B$ (primäre $R(C) T ; n=5$ Patienten) das niedrigste 3bzw. 5-Jahresgesamtüberleben auf (jeweils 20\%) auf. Diese Gruppe bestand allerdings überwiegend aus Patienten mit fortgeschrittenen und z.T. inoperablen Lymphknotenstadien (N3=4 Patienten).

Im Vergleich der Patientengruppen mit multimodalen Therapiekonzepten wiesen Patienten mit adjuvanter Radiochemotherapie (Gruppe D) ein besseres 3- bzw. 5Jahresgesamtüberleben (64\% bzw. 54\%) auf als Patienten mit adjuvanter alleiniger Radiotherapie nach vorheriger Neck Dissection (Gruppe C, 43\% bzw. 29\%). Ebenso ergab sich für Patienten mit adjuvanter Radiochemotherapie (Gruppe D) ein höheres krankheitsspezifische Überleben (67\% bzw. 53\%) und eine bessere regionäre Kontrolle (88\% bzw. 76\%) gegenüber Patienten mit adjuvanter Radiotherapie (Gruppe C). Das krankheitsspezifische Überlegen lag bei diesen Patienten bei $45 \%$ nach 3 Jahren und 
$32 \%$ nach 5 Jahren und die regionäre Kontrolle bei $76 \%$ bzw. $68 \%$ nach 3 bzw. 5 Jahren (Tab. 9, S. 47). Insgesamt zeigte sich sich jedoch sowohl für das krankheitsspezifische Überleben $(p=0.32)$ als auch die regionäre Kontrolle $(p=0.13)$ keine statistisch signifikanter Unterschied (Tab. 9, S. 47).

\subsubsection{Halslymphknotenstatus}

Für den Halslymphknotenstatus ergab sich in der univariaten Analyse ein allenfalls tendenzieller Einfluss auf das Gesamtüberleben $(p=0.07)$ und das krankheitsspezifische Überleben $(p=0.07)$, was sich bei der multivariate Analyse jedoch nicht bestätigte. Auf die regionäre Kontrolle $(p=0.36)$ zeigte der Halslymphknotenstatus keinen statistisch signifikanten Einfluss (Tab. 9, S. 47).

Wurden die Stadien N1 und N2a als Frühstadien zusammengefasst und den fortgeschrittenen Stadien (N2b, N2c und N3) gegenübergestellt, ergab sich für die Frühstadien ein signifikant besseres Gesamtüberleben ( $p=0.02$ univariat) gegenüber den fortgeschrittenen Stadien. Das Gesamtüberleben der Frühstadien betrug nach 3 Jahren 74,7\% bzw. nach 5 Jahren 60,3\% im Vergleich zu 43,9\% bzw. 33,1\% bei den fortgeschrittenen Stadien (Abb. 18).

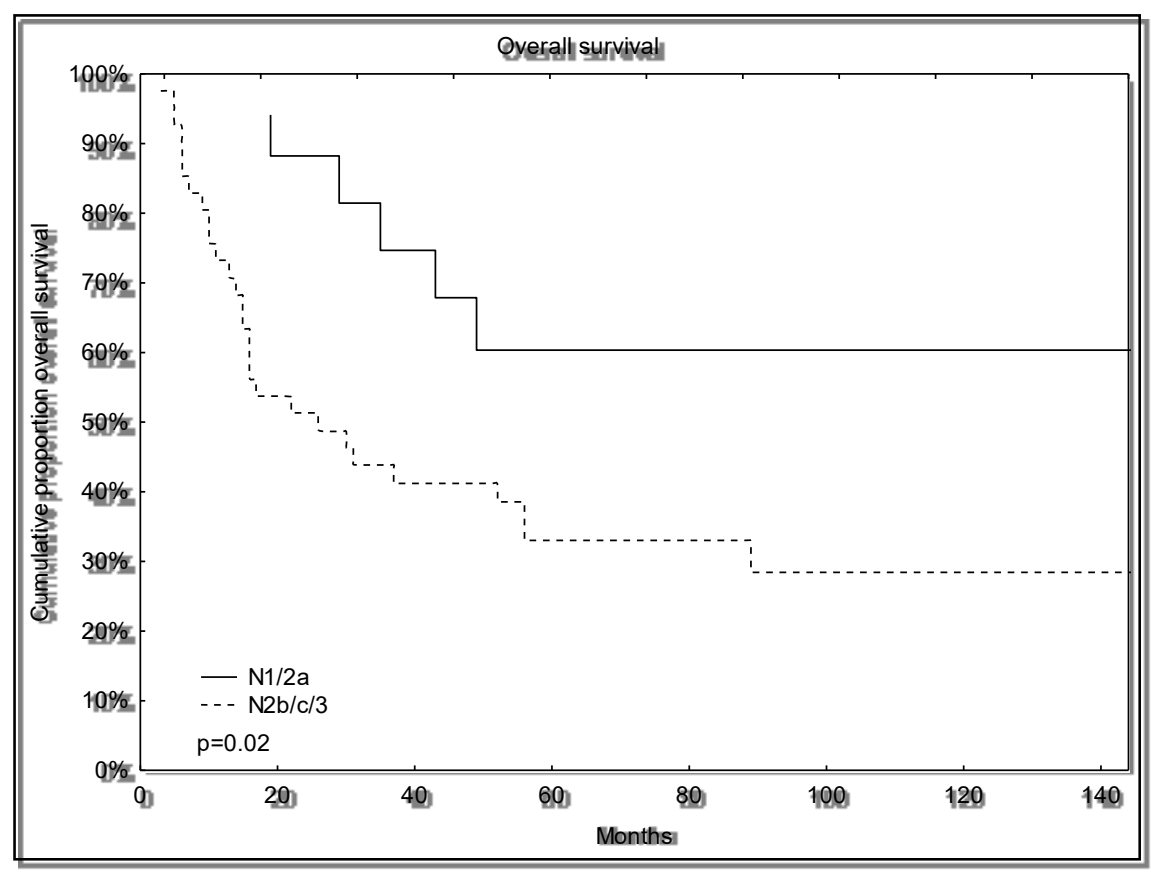

Abb. 18: Ge samtüberleben von Patienten mit Halslymphknotenfrühstadien (N1, N2a; $n=17$ ) vs. Patienten mit fortge schrittenen Halslymphknoten stadien (N2b, N2c, N3; n=41) 


\subsubsection{Extrakapsuläres Wachstum}

Das Auftreten von extrakapsulärem Wachstum beeinflusste sowohl das Gesamtüberleben als auch das krankheitsspezifische Überleben statistisch signifikant (jeweils $p=0.04$ in univariater Analyse). Die 3- bzw. 5-Jahresgesamtüberlebensrate betrug bei Patienten mit nachgewiesenem extrakapsulären Wachstum 35,9\% bzw. 22,8\%. Im Vergleich dazu lag diese ohne Nachweis von extrakapsulärem Wachstum bei $67,6 \%$ bzw. 56,6\% (Abb. 19). Das krankheitsspezifische Überleben lag bei Patienten mit nachgewiesenem extrakapsulärem Wachstum bei 37,0\% nach 3 Jahren bzw. 19,0\% nach 5 Jahren gegenüber $63,0 \%$ bzw. 58,0\% bei fehlendem Nachweis von extrakapsulärem Wachstum. In der multivariaten Analyse konnte dieser Einfluss hingegen nicht bestätigt werden.

Bezüglich der regionären Kontrolle ergab der Nachweis von extrakapsulärem Wachstum keinen statistisch signifikanten Einfluss ( $p=0.74$ ) (Tab. 9, S. 47).

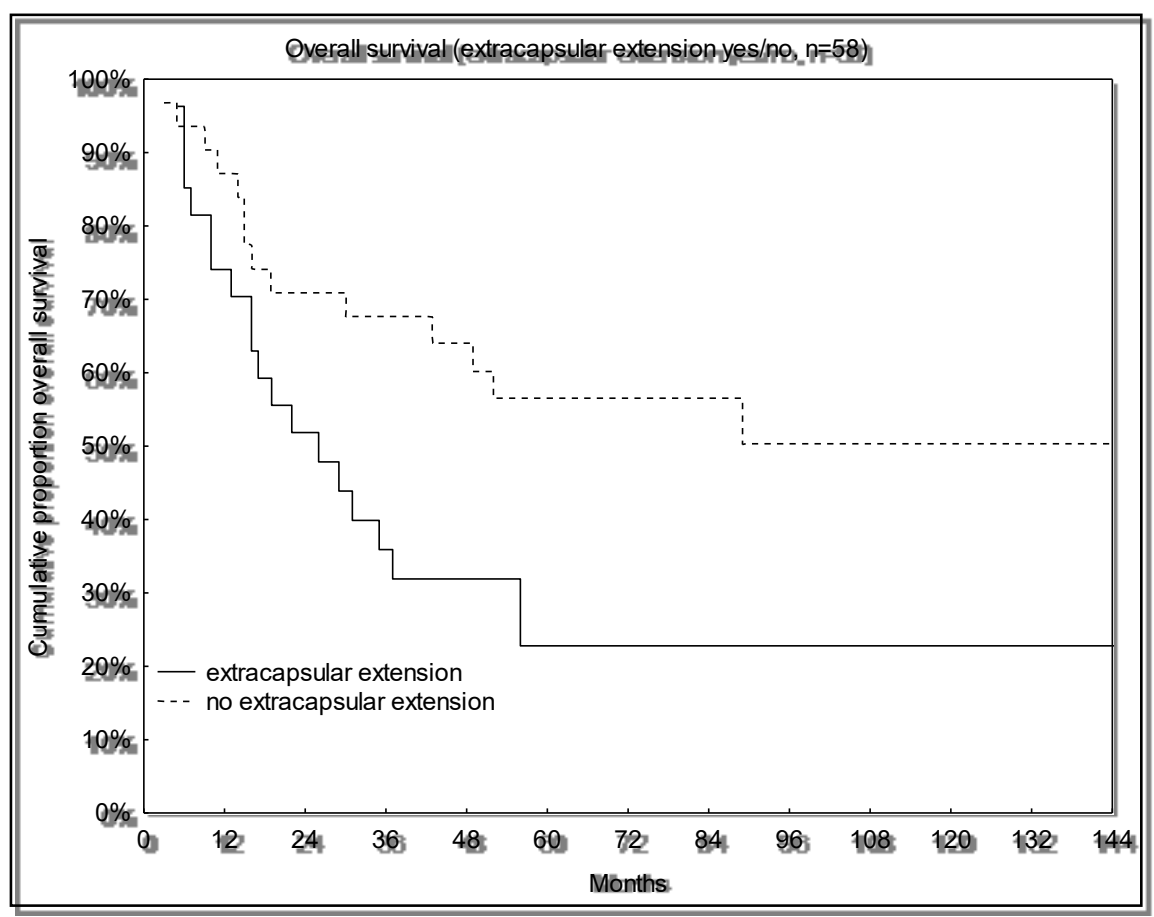

Abb. 19: Ge samtüberleben für Patienten mit Halsmetasta sen ohne $(n=31)$ und mit Kapseldurchbruch $(n=27)$ 


\begin{tabular}{|c|c|c|c|c|c|c|c|}
\hline \multirow[t]{2}{*}{ Parameter } & \multirow[b]{2}{*}{ Anzahl } & \multicolumn{2}{|c|}{ Gesamtüberleben (\%) } & \multicolumn{2}{|c|}{$\begin{array}{c}\text { krankheitsspezfisches } \\
\text { Überleben (\%) }\end{array}$} & \multicolumn{2}{|c|}{ regionäre Kontrolle (\%) } \\
\hline & & 3-Jahre & 5-Jahre & 3-Jahre & 5-Jahre & 3-Jahre & 5-Jahre \\
\hline \multicolumn{8}{|l|}{ Geschlecht } \\
\hline männlich & 48 & 49 & 37 & 47 & 36 & 75 & 64 \\
\hline weiblich & 10 & 70 & 60 & 71 & 57 & 68 & 68 \\
\hline$p$ (uni-/multivariat) & & \multicolumn{2}{|c|}{$0.14 /-$} & \multicolumn{2}{|c|}{$0.27 /-$} & \multicolumn{2}{|c|}{$0.85 /-$} \\
\hline \multicolumn{8}{|l|}{ Therapiemodalität } \\
\hline A & 8 & 88 & 75 & 67 & 67 & 38 & 38 \\
\hline B & 5 & 20 & 20 & 25 & 25 & 50 & 50 \\
\hline C & 28 & 43 & 29 & 45 & 32 & 76 & 68 \\
\hline D & 17 & 64 & 54 & 67 & 53 & 88 & 76 \\
\hline$p$ (uni-/multivariat) & & \multicolumn{2}{|c|}{$0.02 / 0.11$} & \multicolumn{2}{|c|}{$0.32 /-$} & \multicolumn{2}{|c|}{$0.13 /-$} \\
\hline \multicolumn{8}{|l|}{ N-Status } \\
\hline 1 & 9 & 76 & 61 & 100 & 100 & 53 & 53 \\
\hline $2 a$ & 8 & 88 & 73 & 80 & 80 & 88 & 88 \\
\hline $2 b$ & 15 & 33 & 20 & 40 & 20 & 75 & 56 \\
\hline $2 c$ & 3 & 67 & 67 & 67 & 67 & 100 & 100 \\
\hline 3 & 23 & 43 & 33 & 43 & 31 & 72 & 62 \\
\hline$p$ (uni-/multivariat) & & & 07/- & & & & \\
\hline \multicolumn{8}{|l|}{ Halsseite } \\
\hline bilateral & 7 & 43 & 29 & 43 & 29 & 80 & 80 \\
\hline unilateral & 51 & 54 & 43 & 52 & 42 & 73 & 64 \\
\hline$p$ (uni-/multivariat) & & \multicolumn{2}{|c|}{$0.19 /-$} & \multicolumn{2}{|c|}{$0.21 /-$} & \multicolumn{2}{|c|}{$0.52 /-$} \\
\hline Histologie & & & & & & & \\
\hline Plattenepithelkarzinom & 48 & 51 & 39 & 51 & 41 & 73 & 63 \\
\hline lymphoepitheliales Karzinom & 4 & 25 & 25 & 33 & 33 & 100 & 100 \\
\hline Adenokarzinom & 3 & 67 & 67 & 100 & 0 & 67 & 67 \\
\hline anaplastisches Karzinom & 3 & 67 & 67 & 50 & 50 & 50 & 50 \\
\hline$p$ (uni-/multivariat) & & & $59 /-$ & & & & \\
\hline Neck Dissection & & & & & & & \\
\hline radikal & 14 & 43 & 34 & 40 & 27 & 67 & 51 \\
\hline selektiv & 39 & 60 & 46 & 59 & 46 & 77 & 72 \\
\hline $\begin{array}{l}\text { primäre Radio- oder } \\
\text { Radiochemotherapie }\end{array}$ & 5 & 20 & 20 & 25 & 25 & 50 & 50 \\
\hline$p$ (uni-/multivariat) & & & $12 /-$ & & & & \\
\hline extrakapsuläres Wachstum & & & & & & & \\
\hline Nein & 31 & 68 & 56 & 63 & 58 & 70 & 59 \\
\hline $\mathrm{Ja}$ & 27 & 36 & 23 & 37 & 19 & 75 & 70 \\
\hline$p$ (uni-/multivariat) & & & $1 / 0.56$ & & 62 & & \\
\hline PT im Follow-Up & & & & & & & \\
\hline Nein & 54 & 51 & 43 & 48 & 42 & 71 & 71 \\
\hline $\mathrm{Ja}$ & 4 & 75 & 24 & 75 & 25 & 100 & 100 \\
\hline$p$ (uni-/multivariat) & & & $56 /-$ & & & & \\
\hline nodale Kontrolle & & & & & & & \\
\hline Nein & 15 & 53 & 43 & 22 & 0 & & \\
\hline $\mathrm{Ja}$ & 43 & 52 & 35 & 59 & 52 & & \\
\hline$p$ (uni-/multivariat) & & & $96 /-$ & & 54 & & \\
\hline Fernmetastasen & & & & & & & \\
\hline Nein & 37 & 70 & 61 & 81 & 75 & 82 & 77 \\
\hline $\mathrm{Ja}$ & 21 & 22 & 6 & 20 & 5 & 57 & 38 \\
\hline$p$ (uni-/multivariat) & & $<0.0$ & $1 / 0.001$ & $<0.0$ & .001 & & \\
\hline Strahlenfeld & & & & & & & \\
\hline extended field radiation & 40 & 53 & 42 & 50 & 40 & 74 & 64 \\
\hline limited field radiation & 10 & 50 & 33 & 56 & 37 & 74 & 74 \\
\hline$p$ (uni-/multivariat) & & & 89/- & & & & \\
\hline
\end{tabular}

Tab. 9: Subgruppenanalyse für Ge samtüberleben, krankheitsspezifisches Überleben und regionäre Kontrolle ( $n=58$ Patienten) 


\subsubsection{Lokalisation der Lymphknotenmetastasen, Histologie, Art der Neck Dissection, Ausdehnung des Strahlenfeldes}

Ein- vs. beidseitiges Auftreten der Lymphknotenmetastasen, Histologie, Art der Neck Dissection, späte Primärtumordemaskierung und Ausdehnung des Strahlenfeldes waren ohne statistisch signifikanten Einfluss auf Gesamtüberleben, krankheitsspezifisches Überleben und regionäre Kontrolle (Tab. 9).

\subsection{Gesamtüberleben und regionäre Kontrolle bei Patienten mit Primärtumoridentifikation im Rahmen der erweiterten Panendoskopie (Gruppe E)}

Bei 22 Patienten war im Rahmen der erweiterten Panendoskopie ein Primärtumor gefunden worden (Tab. 5, S. 29). Dieser wurde bei 18 Patienten $(81,8 \%)$ operativ behandelt. Bei den verbleibenden 4 Patienten erfolgte eine primäre Radio- und/oder Chemotherapie.

Zur Behandlung der zervikalen Lymphknotenmetastasen wurden bei 17 der Patienten $(77,3 \%)$ eine Neck Dissection durchgeführt (13 x einseitig und $4 x$ beidseitig). Eine Strahlentherapie erfolgte bei insgesamt 14 Patienten $(63,6 \%)$ mit einer durchschnittlichen Dosis von 63,2 Gy (Median 63,5 Gy, $x_{\min }=56 \mathrm{~Gy}, \mathrm{x}_{\max }=70 \mathrm{~Gy}$ ), wobei bei 10 Patienten diese als adjuvante Radiotherapie durchgeführt wurde.

Am Ende der Nachbeobachtungszeit waren von den 22 behandelten Patienten 10 Patienten (45,5\%) am Leben. Für diese Patienten lag die Nachbeobachtungszeit bei durchschnittlich 72,7 Monaten (Median=43 Monate; $x_{\min }=27$ Monate, $x_{\max }=231$ Monate). Während des Follow-up verstarben 12 Patienten, davon mindestens 11 Patienten tumorabhängig, während bei einem Patienten die genaue Todesursache retrospektiv nicht eruiert werden konnte. Die mittlere Überlebenszeit der 12 verstorbenen Patienten zwischen der Erstvorstellung in der Universitätsklinik Göttingen und dem Todeszeitpunkt belief sich auf 20,6 Monate (Median 16 Monate; $x_{\min }=3$ Monate, $x_{\max }=$ 82 Monate). Die nach Kaplan-Meier geschätzte 3- bzw. 5-Jahresrate für das Gesamtüberleben lag bei jeweils 50\% (Abb. 20). 


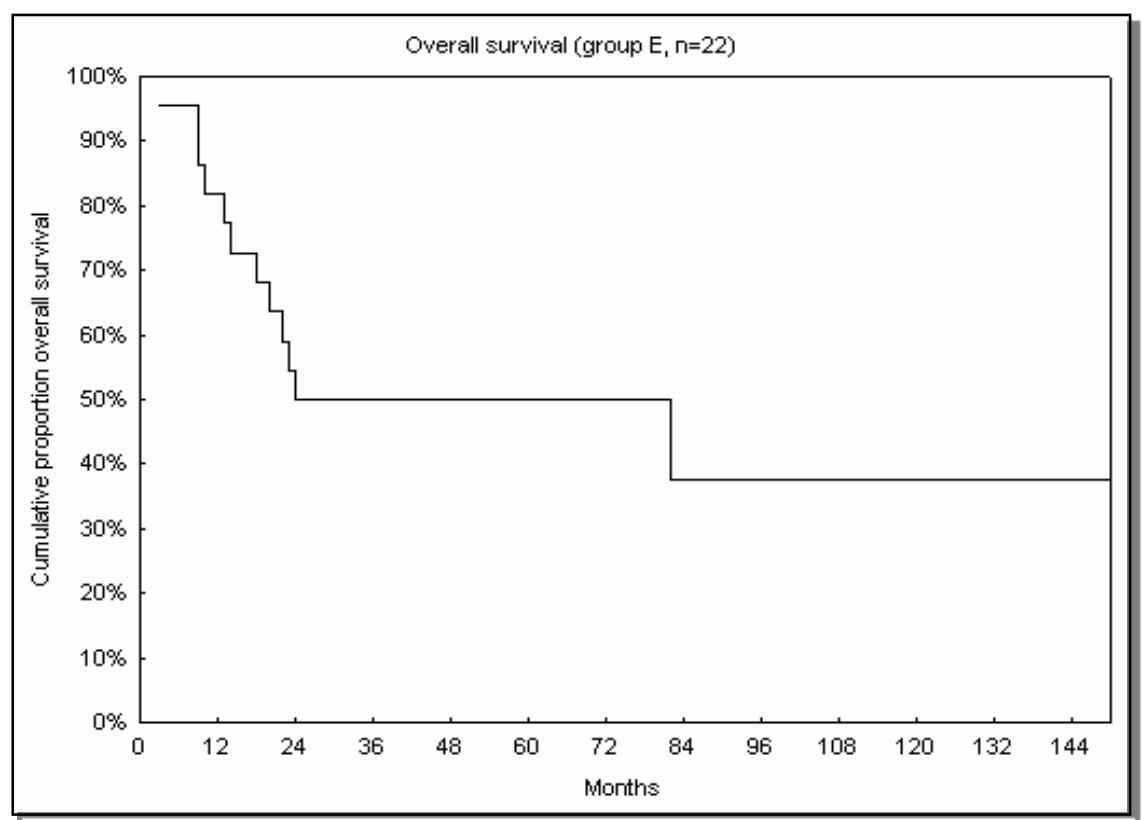

Abb. 20: Ge samtüberleben der Gruppe $E$ ( $n=22$ Patienten), bei der im Rahmen der Primärdiagnostik ein Primärtumor gefunden wurde

Innerhalb des Nachbeobachtungszeitraumes entwickelten 5 Patienten innerhalb einer Zeitspanne von durchschnittlich 10 Monaten ein regionäres bzw. lokoregionäres Rezidiv (Median 7 Monate; $x_{\min }=5$ Monate, $x_{\max }=19$ Monate). Dieses war $4 x$ ipsilateral und 1 x kontralateral zur den ursprünglichen zervikalen Metastasen lokalisiert. Bei einem Patienten erfolgte keine Therapie des Rezidivs. Bei zwei Patienten wurde eine alleinige operative Therapie durchgeführt. Ein Patient wurde nach operativer Resektion bestrahlt und ein weiterer Patient erhielt postoperativ eine Chemotherapie. Die regionäre Kontrolle nach 3 und 5 Jahren lag bei jeweils 73,3\%.

Damit liegen sowohl Gesamtüberleben als auch regionäre Kontrolle dieser Patientengruppe in ähnlicher Größenordnungen wie bei den Patienten mit zervikalem CUP-Syndrom dieser Studie (Abb. 10, S. 35). 


\section{Diskussion}

\subsection{Epidemiologie und Anamnese}

Zervikale Lymphknotenmetastasen von Plattenepithelkarzinomen bei unbekanntem Primärtumor werden bei 2-5\% aller Karzinome mit unbekanntem Primärtumor beobachtet (Jereczek-Fossa et al. 2004) und entsprechen 3-5\% aller malignen Erkrankungen im Kopf-Hals-Bereich (Werner und Dünne 2001, Pavlidis et al. 2009; Strojan et al. 2013a). Dieses eher seltene Vorkommen des zervikalen CUP-Syndroms bedingt in den einschlägigen Studien vielfach nur kleine Patientenkollektive bzw. große Beobachtungszeiträume mit wechselnden Therapiemodalitäten (Tab. 10).

\subsubsection{Geschlecht und Alter}

Das durchschnittliche Alter bei Erstvorstellung wird in der Literatur zwischen 55 und 64 Jahren angegeben, wobei das männliche Geschlecht wesentlich häufiger betroffen ist. Die Angaben zum Verhältnis vom männlichen zum weiblichen Geschlecht schwanken zwischen 2,4:1 und 11,7:1 (Tab. 10).

\begin{tabular}{|c|c|c|c|c|c|c|}
\hline \multirow{2}{*}{$\begin{array}{c}\text { Autoren (Beispiele)/ } \\
\text { [Jahreszahl] }\end{array}$} & \multicolumn{3}{|c|}{$\begin{array}{l}\text { untersuchtes } \\
\text { Patientengut }\end{array}$} & \multirow{2}{*}{$\begin{array}{c}\text { Geschlechts- } \\
\text { verhältnis } \\
\text { m:w }\end{array}$} & \multicolumn{2}{|c|}{$\begin{array}{c}\text { Altersangaben } \\
\text { (in Jahren) }\end{array}$} \\
\hline & & w & gesamt & & $\begin{array}{l}\text { Durch- } \\
\text { schnitt }\end{array}$ & $\begin{array}{l}\text { Spann- } \\
\text { weite }\end{array}$ \\
\hline Barrié et al.[1970] & 109 & 14 & 123 & $7,8: 1$ & k.A. & $19-89$ \\
\hline Dunst et al. [1988] & 25 & 7 & 32 & $3,6: 1$ & 55 & $28-83$ \\
\hline Lefebvre et al. [1990] & 175 & 15 & 190 & $11,7: 1$ & k.A. & k.A. \\
\hline Subramanian und Chilla [1995] & 43 & 15 & 58 & $2,9: 1$ & 56,6 & k.A. \\
\hline Grau et al. [2000] & 248 & 104 & 352 & $2,4: 1$ & k.A. & k.A. \\
\hline Issing et al. [2003] & 134 & 33 & 167 & $4,1: 1$ & 55 & $29-86$ \\
\hline Huang et al. [2008] & 35 & 13 & 48 & $2,7: 1$ & 63 & $36-84$ \\
\hline Wallace et al. [2011] & 157 & 22 & 179 & $7,1: 1$ & 61 & $26-89$ \\
\hline Fakhrian et al. [2012] & 52 & 13 & 64 & $4,0: 1$ & 60 & $39-90$ \\
\hline Nagel et al. [2015] & 47 & 5 & 52 & $9,4: 1$ & 59 & k.A. \\
\hline Eigene Studie & 48 & 10 & 58 & $4,8: 1$ & 56 & $37-77$ \\
\hline
\end{tabular}

Tab. 10: Alters- und Geschlechtsverteilung des vorliegenden Patientenkollektivs im Vergleich mit ausgewählten Literaturangaben 
Dies steht im Einklang mit unserer Studie, bei der das Alter des vorliegenden Patientenkollektivs bei Erstvorstellung bei durchschnittlich 56 Jahren lag, mit einem Verhältnis von männlichen zu weiblichen Patienten von 4,8:1. Es zeigte sich in der vorliegenden Studie für die weiblichen Patienten ein allenfalls tendenziell $(p=0.14)$ besseres Gesamtüberleben, ähnlich den Ergebnissen früherer Studien (Subramanian und Chilla 1995; Grau et al. 2000; Issing et al. 2003). Habermalz et al. (1972) beschrieben in ihrer Studie sogar ein signifikant schlechteres Gesamtüberleben bei Männern. Demgegenüber beobachteten Huang et al. (2008) keinen Zusammenhang zwischen Geschlecht und Überleben.

\subsubsection{Alkohol-/ Nikotinkonsum}

Als wesentlicher Risikofaktor für das Entstehen von Plattenepithelkarzinomen im KopfHals-Bereich gilt der übermäßige Genuss von Alkohol und Nikotin (Steiner 1993; Ambrosch 1996; Maier und Tisch 1999; Hoffman et al. 2002). Es besteht dabei ein multiplikativer Effekt, bei dem sich durch einen mehrstufigen Prozess ein Plattenepithelkarzinom entwickeln kann (Weber und Tannapfel 2002). In den Studien über Halslymphknotenmetastasen bei unbekanntem Primärtumor lassen sich - analog zu der vorliegenden - bei zahlreichen Patienten diese beide Noxen nachweisen (Weber et al. 2001; Issing et al. 2003; Huang et al. 2008; Fakhrian et al. 2012).

\subsubsection{Humane Papillomaviren und weitere Risikofaktoren}

Bei Patienten, die keinen Alkohol und/oder Nikotin konsumiert haben, und bei denen nach bildgebender Diagnostik und Panendoskopie kein Hinweis für einen Primärtumor besteht, wird neuerdings zusätlich ein Nachweis auf humanes Papillomavirus (HPV) und Epstein-Barr-Virus (EBV) empfohlen (Strojan et al. 2013a).

Humane Papillomaviren (HPV), vor allem Typ 16, wurden in den letzten Jahren als wichtiger Risikofaktor für eine Untergruppe der Plattenepithelkarzinome des Oropharynx, insbesondere für diejenigen ausgehend von Tonsilla lingualis und palatina, identifiziert (Psyrri et al. 2009; Zengel et al. 2012; Mozet et. al. 2013). Somit könnte die Identifizierung von HPV-DNA oder -RNA in zervikalen Lymphknotenmetastasen einen Hinweis zur Lokalisation des Primärtumors im Oropharynx liefern (Pavlidis et al. 2009). Zengel et al. (2012) wiesen in ihrer Studie ebenfalls darauf hin, dass ein positiver HPV-Nachweis der Halslymphknotenmetastase in erster Linie auf 
eine Primärtumorlokalisation im Oropharynx (insbesondere Tonsillae palatinae und Zungengrund) hinweist, verbunden mit der Notwendigkeit einer sorgfältigen Diagnostik in diesen Bereichen. Die in ihrer Studie identifizierten Primärtumoren waren zumeist und vielfach submukös lokalisiert, wodurch derartige Primärtumoren endoskopisch leicht übersehen werden können und somit bei frühzeitiger lymphogener Metastasierung zunächst als zervikales CUP-Syndrom eingestuft werden (Zengel et al. 2012). Eine HPV-Diagnostik scheint nicht nur für die Suche nach einem Primärtumor sinnvoll, sondern auch im Hinblick auf Prognose und Therapie. Ang et al. (2010) konnten in ihrer retrospektiven Studie den HPV Status als unabhängigen und starken prognostischen Faktor bei Plattenepithelkarzinomen im Oropharynx identifizieren. Ein positiver HPV-Status war gegenüber einem HPV-negativen Status mit einem besseren Gesamtüberleben assoziiert.

Fakhry et al. (2008) zeigten in ihrer prospektiven Studie ebenfalls eine verbesserte Prognose und einen Überlebensvorteil für Patienten mit HPV-positiven gegenüber HPV-negativen Plattenepithelkarzinomen im Oropharynx auf. Weiterhin berichteten sie in ihrer multizentrischen klinischen Studie über ein besseres Ansprechen der HPVpositiven Tumoren auf Chemotherapie und Strahlentherapie im Vergleich zu HPVnegativen Tumoren (Fakhry et al. 2008).

Eine systematische Bestimmung von HPV- bzw. EBV-Status war in der vorliegenden Studie zum Zeitpunkt der Datenerhebung leider nicht durchgeführt worden. Im Hinblick auch evtl. zukünftiger prospektiver Studien erscheint dies jedoch als wichtiger diagnostischer und prognostischer Faktor relevant.

Des Weiteren wird der Einfluss von beruflichen Noxen, diätischen Faktoren und Mundhygiene auf die Entwicklung eines Plattenepithelkarzinomen im Kopf-HalsBereich im Sinne eines multifaktoriellen Geschehens in der Literatur diskutiert (Maier und Tisch 1999; Wittekind et al. 2001), was jedoch in dieser Arbeit ebenfalls nicht näher untersucht wurde. 


\subsection{Analyse des Halslymphknotenstatus}

\subsubsection{Lokalisation und Lymphknotenstatus}

Die zervikalen Lymphknotenmetastasen bei unbekanntem Primärtumor traten im vorliegenden Kollektiv ( $n=58$ Patienten) mit einer Häufigkeit von 53,3\% ( $n=32$ Patienten) initial im Bereich der rechten Halsseite und bei 21 Patienten (35,0\%) auf der linken Halsseite auf. Bei 7 Patienten (11,7\%) waren beide Halsseiten involviert. Über eine ähnliche Präferenz der rechten Halsseite berichten auch Barrie et al. (1970) und Lefebvre et al. (1990) in ihren Studien. Demgegenüber weisen Koscielny et al. (2000) und Guntinas-Lichius et al. (2006) auf eine Prädominanz der linken Halsseite hin. In der Literatur finden sich keine näheren Angaben zu einem möglichen Zusammenhang zwischen Seitenlokalisation und Tumorkontrolle bzw. Überleben. Übereinstimmend besteht jedoch ein deutliches Überwiegen des einseitigen Auftretens der Lymphknotenmetastasen (Tab. 11).

Gemäß der Klassifikation der zervikalen Lymphknotenmetastasen nach UICCRichtlinien wurden in der vorliegenden Studie zum besseren Vergleich die Kategorien N1 und N2a als „singuläre Stadien“ bzw. „Frühstadien“ den Kategorien N2b, N2c und N3 als „fortgeschrittene Stadien“ gegenübergestellt. In Übereinstimmung mit weiteren Autoren (Reddy und Marks 1997; Weber et al. 2001; Iganej et al. 2002; Hauswald et al. 2008; Huang et al. 2008; Fakhrian et al. 2012) lagen auch in unserem Kollektiv zum Zeitpunkt der Primärbehandlung überwiegend fortgeschrittene Lymphknotenmetastasierungen vor $(n=44,73,3 \%)$.

\begin{tabular}{|l|c|c|c|c|}
\hline \multicolumn{1}{|c|}{$\begin{array}{c}\text { Autoren (Quelle) } \\
\text { [Jahreszahl] }\end{array}$} & $\begin{array}{c}\text { Anzahl der } \\
\text { untersuchten } \\
\text { Patienten }\end{array}$ & $\begin{array}{c}\text { Anzahl der } \\
\text { Patienten mit } \\
\text { rechtsseitig } \\
\text { lokalisierter } \\
\text { Halsmetastase }\end{array}$ & $\begin{array}{c}\text { Anzahl der } \\
\text { Patienten mit } \\
\text { linksseitig } \\
\text { lokalisierter } \\
\text { Halsmetastase }\end{array}$ & $\begin{array}{c}\text { Anzahl der } \\
\text { Patienten mit } \\
\text { beidseitig } \\
\text { lokalisierten } \\
\text { Halsmetastasen }\end{array}$ \\
\hline \hline Barrie et al. [1970] & $114(100 \%)$ & $64(56,1 \%)$ & $46(40,4 \%)$ & $4(3,5 \%)$ \\
Lefebvre et al. [1990] & $190(100 \%)$ & $106(55,8 \%)$ & $75(39,5 \%)$ & $9(4,7 \%)$ \\
\hline Koscienly et al. [2000] & $99(100 \%)$ & $39(39,4 \%)$ & $48(48,5 \%)$ & $12(12,1 \%)$ \\
Guntinas-Lichius et. al [2006] & $69(100 \%)$ & $29(42 \%)$ & $39(57 \%)$ & $1(2 \%)$ \\
\hline Eigene Studie & $58(100 \%)$ & $31(53,4 \%)$ & $20(34,5 \%)$ & $7(12,1 \%)$ \\
\hline
\end{tabular}

Tab. 11: Seitenlokalisation der Halslymphknotenmetasta sen bei Patienten mit zervikalem CUP-Syndrom 
Beim zervikalem CUP-Syndrom gilt der N-Status als wichtiger prognostischer Faktor (Marcial-Vega et al. 1990; Nguyen et al. 1994; Oen et al. 1995), wobei für fortgeschrittene Stadien eine schlechtere Prognose angegeben wird (Grau et al. 2000; Huang et al. 2008, Fakhrian et al. 2012). Demgegenüber beobachteten Strojan und Anicin (1998) und Christiansen et al. (2005) keinen statistisch signifikanten Einfluss des Lymphknotenstatus auf das Gesamtüberleben. Zusätzlich wird das Auftreten von extrakapsulärem Wachstum (Kapselruptur) als prognostisch ungünstiger Faktor für Gesamtüberleben bzw. regionäre Kontrolle gewertet (Iganej et al. 2002; Christiansen et al. 2005; Hauswald et al. 2008; Fakhrian et al. 2012). In unserem Kollektiv zeigt sich in der univariaten Analyse zumindest ein tendenziell besseres Gesamtüberleben und krankheitsspezifisches Überleben für Patienten mit singulären Halsmetastasen gegenüber Patienten mit fortgeschrittenen Halslymphknotenstatus. Für die regionäre Kontrolle konnte ein solcher Zusammenhang allerdings nicht belegt werden. Hinsichtlich des extrakapsulären Wachstums konnte unsererseits ein statistisch signifikanter Einfluss auf Gesamtüberleben und krankheitsspezifisches Überleben allerdings nur bei univariater Analyse gefunden werden.

Zur orientierenden feingeweblichen Beurteilung auffälliger Halslymphknoten wird im Allgemeinen die Feinnadelpunktion (FNP) favorisiert, die einen ersten Hinweis zur Dignität liefern kann (Lefebvre et al. 1990; Thierauf et a. 2015). Das Risiko einer Fehlpunktion im Rahmen einer Feinnadelpunktion kann durch Ultraschallkontrolle minimiert werden (Schmalbach und Miller 2007). So zeigten van den Brekel et al. (1993), dass die Ultraschall-gesteuerte FNP die beste Sensitivität, Spezifität und Genauigkeit zur Auffindung von Lymphknotenmetastasen aufwies.

In unserem Patientengut wurde zunächst bei 46 Patienten (79,3\%) eine Feinnadelpunktion der vergrößerten Halslymphknoten zur Dignitätsbestimmung durchgeführt. Bei 10 dieser Patienten war in der zytopathologischen Beurteilung allerdings keine sichere Aussage zur Dignität möglich, so dass der Malignitätsnachweis erst im Rahmen der operativen Halslymphknotenprobeexzision gelang. Diese erfolgte entweder durch eine isolierte Halslymphknotenbiopsie oder im Rahmen einer intraoperativen Schnellschnittdiagnostik bei der erweiterten Panendoskopie und anschließender Neck Dissection in gleicher Sitzung. 


\subsubsection{Histologie der Lymphknotenmetastasen}

In Übereinstimmung mit zahlreichen Studien (Issing et al. 2003; Hauswald et al. 2008; Huang et al. 2008) überwogen im vorliegenden Patientenkollektiv die Plattenepithelkarzinommetastasen $(83,3 \%)$, insbesondere die hoch- und mittelgradig differenzierten Formen. Deutlich seltener fanden sich Adenokarzinome $(5,0 \%)$, lymphoepithelialen Karzinome (6,7\%) und Tumoren anderer Histologie (5,0\%). In der Literatur wird der Anteil der Plattenepithelkarzinome (PECA) für das zervikale CUPSyndrom zwischen 60 und $80 \%$ angegeben, gefolgt von Adenokarzinomen, malignen Melanomen, undifferenzierten Karzinomen und anderen malignen Tumoren (Cerezo et al. 2011) (Tab. 12).

\begin{tabular}{|l|c|c|c|c|}
\hline \multicolumn{1}{|c|}{$\begin{array}{c}\text { Autoren (Quelle) } \\
\text { [Jahreszahl] }\end{array}$} & $\begin{array}{c}\text { Anzahl } \\
\text { untersuchte } \\
\text { Patienten }\end{array}$ & PECA & Adenokarzinome & andere \\
\hline \hline Oen et al. [1995] & $66(100 \%)$ & $44(66,7 \%)$ & $7(10,6 \%)$ & $15(22,7 \%)$ \\
\hline Weber et al. [2001] & $75(100 \%)$ & $60(80,0 \%)$ & $6(8,0 \%)$ & $9(12,0 \%)$ \\
Hauswald et al. [2008] & $84(100 \%)$ & $58(69 \%)$ & k.A. & $26(31 \%)$ \\
Eigene Studie & $58(100 \%)$ & $48(82,8 \%)$ & $3(5,2 \%)$ & $7(12,0 \%)$ \\
\hline
\end{tabular}

Tab. 12: Pathohistologie der zervikalen Lymphknotenmetasta sen

Der hohe Anteil der Plattenepithelkarzinommetastasen ist dabei mit dem häufig vorkommenden Genuss von Nikotin und Alkohol assoziiert (Ambrosch 1996; Maier und Tisch 1999).

Für Adenokarzinome wird von manchen Autoren ein niedrigeres Gesamtüberleben gegenüber Patienten mit Plattenepithelkarzinomen beschrieben (Spiro et al. 1983; Koscielny et al. 2000), was jedoch in anderen Studien (Kirschner et al. 1997; Hauswald et al. 2008) nicht bestätigt werden konnte. Aufgrund der kleinen Anzahl der NichtPlattenepithelkarzinome $(n=10)$ erschien eine statistische Analyse hinsichtlich der histopathologischen Tumorentität, ähnlich wie in zahlreichen anderen Untersuchungen, in der vorliegenden Studie nicht sinnvoll. 


\subsection{Diagnostik, bildgebende Verfahren und Panendoskopie}

Die Primärtumorsuche bei Patienten mit zervikalem CUP-Syndrom stellt sowohl für den Arzt als auch für den betroffenen Patienten nicht selten eine Herausforderung zwischen Primärtumoridentifikation und Patientenbelastung dar, zumal die Primärtumorsuche mit z.T. invasiven und belastenden Untersuchungsverfahren verbunden sein kann. Die Diagnostik des zervikalen CUP-Syndroms beinhaltet dabei neben der Primärtumorsuche das Halslymphknotenstaging (N-Status) und den Ausschluss bzw. Nachweis von Fernmetastasen (M-Status).

\subsubsection{Bildgebende Verfahren}

Die Routinediagnostik umfasst Anamnese, HNO-ärztliche Spiegeluntersuchung, Histologiesicherung der Halsmetastasen, Halssonographie und Computertomographie (Schädelbasis bis Zwerchfell) mit Kontrastmittel. Ergänzend, sowie insbesondere auch bei CT-Kontrastmittelunverträglichkeit, kommt die Magnetresonanztomographie in Betracht (Nieder et al. 2001).

Zur Einstufung des Halslymphknotenstatus ist die palpatorische Untersuchung des Halses noch weit verbreitet, ergänzt durch die genannten bildgebenden Verfahren (Mende et al. 1996). Der Stellenwert bildgebender Verfahren wird allerdings kontrovers diskutiert. Feinmesser et al. (1987) beschrieben in diesem Zusammenhang keinen Vorteil der Computertomographie gegenüber der Palpation. Nach Mende et al. (1996) besitzt die Halssonographie eine mit der CT vergleichbare Sensitivität. Obwohl die Aussagekraft der Sonographie nicht unwesentlich von der Erfahrung des Untersuchers abhängig ist, ermöglicht sie bei geringer Belastung und schneller Verfügbarkeit aussagekräftige Angaben zum Halslymphknotenstatus im Rahmen des präoperativen Staging, bei der Therapieplanung sowie während des Follow-up. Die Magnetresonanztomographie erlaubt eine gegenüber der Computertomographie bessere Weichteildarstellung und somit prinzipiell eine genauere Bestimmung der Ausdehnung von Lymphknotenmetastasen (Jungehülsing et al. 1997). Bis heute kommt in der Schnittbilddiagnostik allerdings überwiegend die Computertomographie zum Einsatz, was unter anderem auf eine größere Verbreitung von CT-Geräten sowie auf die im Vergleich zur MRT geringeren Untersuchungskosten zurückzuführen ist. Darüber hinaus erfordert die MRT zur Untersuchung mehrerer Körperregionen (z.B. Kopf-Hals-Thorax) jeweils separate Untersuchungsgänge. Die Domäne der 
Schnittbilddiagnostik durch CT bzw. MRT liegt beim zervikalen CUP-Syndrom nicht nur im Halslymphknotenstaging, sondern auch in der Visualisierung klinisch okkulter, evtl. submuköser Primärtumoren, so dass bildmorphologisch verdächtige Bezirke auch bei submuköser Lokalisation im Rahmen der Panendoskopie gezielt biopsiert bzw. exzidiert werden können (Nieder et al. 2001). Darüber hinaus liefert die prätherapeutische CT-Untersuchung wichtige Daten zur Festlegung bzw. Dimensionierung der Strahlenfelder für die primäre bzw. adjuvante Radiotherapie.

Weitere Bestandteile der Routinediagnostik sind die Röntgenaufnahme des Thorax in zwei Ebenen sowie die Abdomensonographie, um Anhaltspunkte für einen möglichen Primärtumor außerhalb des Kopf-Hals-Gebietes oder für das Vorliegen von Fernmetastasen zu erhalten. Bei diesbezüglich suspekten Befunden ist eine weitere Abklärung mittels Thorax- bzw. Abdomen-CT indiziert. Aufgrund der höheren Sensitivität hinsichtlich suspekter intrathorakaler Veränderungen empfehlen Subramanian und Chilla (1995) grundsätzlich neben der Kopf-Hals-CT auch die routinemäßige Erstellung einer Thorax-CT. Daher gehört aktuell die Spiral-CTUntersuchung von Schädelbasis bis Zwerchfell in unserer Klinik zum diagnostischen Standardprogramm bei Patienten mit zervikalem CUP-Syndrom zur Primärtumorsuche, Halslymphknotenstaging, Fernmetastasen- und Zweittumorsuche.

In der vorliegenden Studie wurden die Patienten, bei denen im Rahmen des Staging (HNO-Untersuchung, Röntgen Thorax, Sonographie, CT Abdomen oder MRT) ein Primärtumor vor Durchführung einer Panendoskopie lokalisiert werden konnte, nicht in das Kollektiv eingeschlossen. Die Beurteilung der Wertigkeit dieser bildgebenden Untersuchungen bezüglich der Primärtumorlokalisation war daher auch nicht Gegenstand unserer Analyse.

\subsubsection{Positronenemissionstomographie (PET)}

Zur Detektion von Primärtumoren, sowie Zweittumoren, loko-regionäre Rezidiven und Fernmetastasen wird zunehmend die Positronenemissionstomographie (PET) in der Diagnostik des zervikalen CUP-Syndroms eingesetzt und von einigen Autoren als routinemäßiger Bestandteil der Diagnostik bei zervikalem CUP-Syndrom empfohlen (Steiner 2003; Waltonen et al. 2009; Cerezo et al. 2011).

Die diagnostische Wertigkeit dieses Verfahrens ist jedoch nicht unumstritten. Nach Regelink et al. (2002) weist die FDG (Fluordesoxyglucose)-PET eine höhere 
Sensitivität für die Darstellung von Primärtumor und Fernmetastasen auf als herkömmliche bildgebende Verfahren oder Panendoskopie. Die Autoren berichten über eine Identifikationsrate von $32 \%$ für den bis dato okkulten Primärtumor mittels FDG PET und empfehlen daher die FDG-PET als diagnostisches Standardverfahren beim zervikalen CUP-Syndrom. Eine ähnliche Aufdeckungsrate (25\%) konnten Rusthoven et al. (2004) in ihrer durchgeführten Metaanalyse aufzeigen. Jedoch wiesen sie auch auf die geringe Spezifität als größten Schwachpunkt der FDG-PET hin (Rusthoven et al. 2004). Stoeckli et al. (2003) konnten demgegenüber keinen Vorteil der FDG-PET in der Primärtumoridentifikation des Primärtumors sehen. Ein weiterer Nachteil der FDG-PET ist die fehlende anatomische Information über die FDG-anreichernde Lokalisation. Um eine bessere Wertigkeit $\mathrm{zu}$ erreichen, wird eine Kombination der diagnostischen Möglichkeiten als FDG-PET/CT oder -MRT angewendet (Pavlidis et al. 2009). Waltonen et al. (2009) und Keller et al. (2011) konnten durch die Fusion von FDG-PET und CT eine bessere Aufdeckungsrate an Primärtumoren gegenüber alleiniger FDGPET erzielen. Zusätzlich ist zu beachten, dass es durch vorherige Biopsieentnahmen, z.B. im Rahmen einer Panendoskopie u. a. aufgrund postoperativ-entzündlicher Gewebeveränderungen zu vermehrt falsch-positiven Ergebnissen kommen kann. Dementsprechend wird eine FDG-PET/CT generell vor Endoskopie oder Biopsien empfohlen (Fakhrian et al. 2012).

Aufgrund der hohen Rate an falsch-positiven Befunden (20-46\%), der niedrigen Sensitivität und der hohen Kosten (ca. 600-1000 Euro pro Sitzung) wird die PET zumindest beim zervikalen Plattenepithelkarzinom bislang noch nicht routinemäßig bei allen Patienten angewandt, zumal auch die Kostenerstattung von einigen Krankenkassen restriktiv gehandhabt wird und im Einzelfall einer gesonderten Genehmigung bedarf (Kazak et al. 2003; Kothari et al. 2008). In aktuelleren Studien zum zervikalen CUP-Syndrom wird die FDG-PET als diagnostisches Verfahren jedoch zunehmend eingesetzt (Fakhrian et al. 2012, Perkins et al. 2012). In unserem Patientengut fand die PET keine Anwendung, so dass wir zum Stellenwert dieser Untersuchung keine eigenen Daten beitragen können.

\subsubsection{Erweiterte Panendoskopie}

Im Rahmen der Primärtumorsuche kommt der endoskopischen Untersuchung des oberen Aerodigestivtraktes wesentliche Bedeutung zu. Diese erfolgt zunächst im Rahmen der routinemäßigen HNO-Spiegeluntersuchung mittels Lupenlaryngoskop, $30^{\circ}$ 
bzw. $70^{\circ}$-Staboptik und flexiblem Fiberendoskop. Ergänzt werden diese Untersuchungen durch bildgebende Diagnostik mittels CT bzw. MRT. Findet sich nach Abschluss der konventionellen und bildgebenden Diagnostik kein Primärtumor, wird die Primärtumorsuche im Rahmen einer erweiterten Panendoskopie in Allgemeinnarkose fortgeführt (Mendenhall et al. 1998; Nieder et al. 2001; Huang et al. 2008; Kothari et al. 2008). Hierbei erfolgt die direkte Endoskopie von Naso-, Oro- und Hypopharynx, Larynx, Tracheobronchialsystem und Ösophagus mit der Entnahme von Probebiopsien aus suspekt imponierenden Schleimhautarealen. Der Stellenwert von Blindbiopsien aus oberflächlich unauffällig erscheinenden Schleimhautarealen wird dabei kontrovers diskutiert. Mistry et al. (2008) stellen den Nutzen derartiger randomisierter Biopsien aus makroskopisch unauffälligen Arealen zur Aufdeckung möglicher Primärtumoren grundsätzlich in Frage. Demgegenüber werden von zahlreichen anderen Autoren Probebiopsien aus dem Oropharynx, hier insbesondere aus dem Zungengrundbereich sowie die diagnostische Tonsillektomie, auch bei unauffälligem Lokalbefund befürwortet (Marcial-Vega et al. 1990; Mendenhall et al. 1998; Haas et al. 2002; Schmalbach und Miller 2007; Kothari et al. 2008; Waltonen et al. 2009).

Die Notwendigkeit der Entnahme von randomisierten Nasopharynxbiopsien (aus unauffälligen Schleimhautarealen) im Rahmen der Panendoskopie beim zervikalen CUP-Syndrom wird in einschlägigen Studien unterstrichen (Haas et al. 2002; Waltonen et al. 2009; Keller et al. 2011). Allerdings finden sich über Stellenwert und Sensitivität nur wenige Literaturdaten. Haas et al. (2002) wiesen bei 5 von 57 durchgeführten randomisierten Nasopharynxbiopsien (8,8\%) ein Nasopharynxkarzinom nach. Guntinas-Lichius et al. (2006) berichteten bei 40 durchgeführten randomisierten Biopsien aus dem Nasopharynx von lediglich 2 detektierten Primärtumoren (5\%) und beschrieben eine Sensitivität von lediglich $9 \%$.

In unserem Patientenkollektiv konnte durch Blindbiopsien des Nasopharynx lediglich in einem Fall ein klinisch okkultes Nasenrachenkarzinom identifiziert werden. In allen anderen Fällen waren die Probebiopsien aus Nasopharynx negativ. Ein möglicher Grund für die niedrige Aufdeckungsrate an Primärtumoren im Nasopharynx besteht unter Umständen in der Tatsache, dass Raumforderungen in diesem Bereich nicht selten bereits bei der routinemäßigen endoskopischen Untersuchung erkennbar sind bzw. durch eine Tubenventiliationsstörung mit konsekutiver Ohrsymptomatik auffällig werden, noch bevor eine Panendoskopie in Vollnarkose durchgeführt wird (Mendenhall et al. 1998). 
Zur Häufigkeit klinisch okkulter submuköser Zungengrundmalignome finden sich in der Literatur ebenfalls nur wenige Daten. Mehta et al. (2013) konnten in ihrer kürzlich veröffentlichen Studie zum diagnostischen und therapeutischen Vorgehen beim zervikalen CUP-Syndrom bei 9 von 10 untersuchten Patienten ein Zungengrundkarzinom mittels Transoral Robotic Surgery (TORS) ${ }^{1}$ diagnostizieren, nachdem sich zuvor weder inspektorisch noch palpatorisch noch im Rahmen der Routinediagnostik (Bildgebung, PET/CT, Panendoskopie und beidseitige Tonsillektomie) malignomverdächtige Befunde ergeben hatten. Karni et al. (2011) verglichen in ihrer retrospektiven Studie zum zervikalem CUP-Syndrom die Detektionsrate von bis dato unbekannten Primärtumoren zwischen der traditionell gebräuchlichen starren Pharyngolaryngoskopie mit Knipsbiopsien ( $n=12$ Patienten) und transoraler lasermikrochirurgischer bioptischer Gewebeentnahme ( $n=19$ Patienten). Hierbei erwies sich die lasermikrochirurgische Gewebeentnahme als vorteilhaft, da bei 94\% (17 von 18) der Patienten ein bis dato okkulter Primärtumor im Oropharynx, überwiegend im Zungengrund, identifiziert werden konnte. Demgegenüber konnte mittels Knipsbiopsie lediglich in 25\% der Fälle (3 von 12 Patienten) ein Primärtumor identifiziert werden (jeweils einmal im Nasopharynx, Zungengrund und Tonsilla palatina). Fasst man zusammen, so identifizierten die Autoren durch beide Verfahren bei insgesamt 12 von 30 Patienten (40,0\% der Gesamtpopulation) einen bis dato unbekannten Primarius im Zungengrund. Allerdings wurde nicht explizit beschrieben, inwieweit die Gewebeentnahmen jeweils aus inspektorisch unauffälligen Arealen - im Sinne einer Blindbiopsie - erfolgten.

Da es sich sowohl bei der Studie von Mehta et al. (2013) als auch bei Karni et al. (2011) um eher kleine Fallzahlen (10-18 Patienten) handelt, sind weitere Ergebnisse in größeren Studien diesbezüglich abzuwarten.

In unserer Untersuchung konnte bei zumindest 3 der insgesamt 82 panendoskopierten Patienten (3,7\%) ein Zungengrundkarzinom identifiziert werden, so dass der Anteil der Zungengrundmalignome an allen im Rahmen der Panendoskopie identifizierten Primarien bei $13,6 \%$ liegt. Bei klinisch und endoskopisch unauffälligem Zungengrund wird gegenwärtig empfohlen, die Zungengrund-Probeexzision im Sinne einer großzügigen transoralen laserchirurgischen Zungengrundteilresektion durchzuführen,

\footnotetext{
${ }^{1}$ TORS (Transoral Robotic Surgery) ist ein neues roboterassistiertes Verfahren aus den USA. Durch die Verwendung einer 3D-HD-Optik und zwei robotergesteuerten Instrumenten erlaubt es dem Operateur einen erleichterten Zugang zum Oropharynx. Dies verbessert die funktionellen Ergebnisse (Lörincz et al. 2013).
} 
da diese im Gegensatz zu kleinen randomisierten Biopsien eine höhere Aufdeckungsrate für okkulte Plattenepithelkarzinome besitzen soll (Werner und Dünne 2001; Nagel et al. 2014).

Als weiterer Bestandteil der Panendoskopie bei Patienten mit zervikalem CUPSyndrom gilt die Tonsillektomie. Nach Literaturangaben kann hierdurch in bis zu $35 \%$ der Fälle ein bis dato okkulter Primärtumor gefunden werden (Jones et al. 1993; Lapeyre et al. 1997; McQuone et al. 1998; Mendenhall et al. 1998; Haas et al. 2002; Kazak et al. 2003; Schmalbach und Miller 2007; Kothari et al. 2008; Nagel et al. 2014). In unserem Kollektiv konnte bei 6 der 82 Patienten (7,3\%) durch die diagnostische Gaumenmandelentfernung im Rahmen der Panendoskopie ein Tonsillenkarzinom als Primärtumor identifiziert werden, was einem Anteil von 27,3\% an allen im Rahmen der Panendoskopie identifizierten Primarien entspricht. Darunter befanden sich 4 Tonsillenmalignome, die bei intraoperativ augenscheinlich unauffälligem Befund erst durch die histopathologische Aufarbeitung der entfernten Gaumenmandeln diagnostiziert wurden. Die Frage, inwieweit im Rahmen der Panendoskopie die bilaterale oder lediglich die einseitige, ipsilaterale Tonsillektomie indiziert ist, wird kontrovers diskutiert. In unserem Patientengut waren alle 6 Tonsillenkarzinomen, welche im Rahmen der Panendoskopie makroskopisch bzw. histopathologisch als Primärtumor identifiziert wurden, ipsilateral zum Halslymphknotenbefall lokalisiert, so dass in Übereinstimmung mit Lapeyre et al. (1997), Mendenhall et al. (1998) und Randall et al. (2000) prinzipiell die Beschränkung auf die ipsilaterale Tonsillektomie gerechtfertigt erscheint. Demgegenüber erwähnen Nagel et al. (2014) in ihrer Untersuchung bei insgesamt 11 durch Tonsillektomie diagnostizierten Tonsillenkarzinomen einen Fall von synchronen Primärtumoren in beiden Gaumenmandeln. Wir befürworten gegenwärtig analog zu zahlreichen anderen Untersuchern (Koch et al. 2001; Kothari et al. 2008; Pavlidis et al. 2009; Waltonen et al. 2009; Cerezo et al. 2011; Mozet et al. 2013) noch die bilaterale Tonsillektomie, zumal für Tonsillenkarzinome in bis zu $10 \%$ der Fälle kontralaterale Metastasierungswege beschrieben sind. Bei lediglich 6 nachgewiesenen Tonsillenkarzinomen in unserer Analyse erscheint die Fallzahl jedoch für hinreichend repräsentative Aussagen zu gering.

Aufgrund unserer Untersuchungsergebnisse werden in unserer Abteilung im Rahmen der erweiterten Panendoskopie bei Patienten mit zervikalem CUP-Syndrom - neben Probebiopsien aus suspekt imponierenden Arealen und neben der diagnostischen 
Tonsillektomie - randomisierte Biopsien routinemäßig nur aus Nasopharynx und Zungengrund gewonnen. In Übereinstimmung mit anderen Autoren (Mendenhall et al. 1998; Weber et al. 2001; Schmalbach und Miller 2007, Nagel et al. 2015) waren die im Rahmen der erweiterten Panendoskopie identifizierten Primärtumoren bevorzugt im Zungengrund- und Tonsillenbereich lokalisiert, was den Stellenwert für die Primärtumorsuche zumindest von Tonsillektomie und Zungengrundteilresektion auch bei klinisch unauffälligem Befund unterstreicht.

Die von wenigen Autoren (de Braud et al. 1989; Mendenhall et. al 1998) angeführten Hypopharynx-Blindbiopsien werden von uns demgegenüber nicht routinemäßig durchgeführt, zumal deren Nutzen auch in der Literatur nicht eindeutig belegt werden konnte. Waltonen et al. (2009) führten in ihrer Studie zum zervikalen CUP-Syndrom Hypopharynx-Blindbiospien durch. Aufgrund einer niedrigen Aufdeckungsrate sehen die Autoren jedoch von einer diesbezüglichen Empfehlung ab. Auch Strojan et al. (2013a) erachten Blindbiopsien aus unauffälliger Schleimhaut der Sinus piriformes als nicht obligat. Angesichts der unterschiedlichen Teilbereiche des Hypopharynx (Sinus piriformes, Postcricoidregion, Hypopharynxhinterwand) und der Ausdehnung seiner Schleimhaut über eine Oberfläche von mehreren Quadratzentimetern stellt sich ohnehin die Frage nach dem repräsentativen bzw. bevorzugten Ort derartiger Hypopharynx-Blindbiopsien. Wir führen entsprechende Hypopharynx-Biopsien daher nur aus suspekt erscheinenden Schleimhautarealen bzw. bei bildmorphologischem begründetem Verdacht (CT, MRT) auf submuköses Tumorwachstum in dieser Region durch.

Aufgrund der oben diskutierten eher niedrigen Primärtumoraufdeckungsraten bei Blindbiospien im Hypo- und Nasopharynx ist abzuwägen, inwieweit Blindbiopsien in diesen Bereichen den Patienten durch mögliche Komplikationen, wie z.B. Blutungen bzw. durch zusätzliche postoperative Morbidität belasten, ohne letztlich zu einer Prognoseverbesserung beizutragen.

Insgesamt konnte in der vorliegenden Studie bei 22 der 82 panendoskopierten Patienten (26,8\%; Gruppe E) im Rahmen der Narkoseuntersuchung ein Primärtumor detektiert werden (Abb. 3, S. 19). Die von uns ermittelte Aufdeckungsrate von Primärtumoren durch Panendoskopie liegt dabei mit 26,8\% deutlich unter dem von Durmus et al. (2014) beschriebenen Wert von 77,3\%, jedoch basierten deren 
Untersuchungen auf einem wesentlich kleineren Patientenkollektiv ( $n=22$ Patienten). Weiterhin wurden von den Autoren solche Patienten, bei denen der Verdacht auf eine maligne Läsion bereits präoperativ im PET/CT gestellt und in der anschließenden Panendoskopie bestätigt wurde, nicht aus dem Gesamtkollektiv ausgeschlossen (Durmus et al. 2014). Nach Nagel et al. (2014) kann die Primärtumoraufdeckungsrate bei der Panendoskopie durch Zuhilfenahme eines hochauflösenden Mikroskops und intraoperativen Schnellschnittuntersuchungen auf Werte über $80 \%$ gesteigert werden.

In unserer Studie wurden nur solche Patienten berücksichtigt, bei denen sich nach Abschluss der präoperativen Diagnostik einschließlich radiologischer Bildgebung kein Hinweis auf einen Primärtumor ergeben hatte. Mendenhall et al. (1998) und GuntinasLichius et al. (2006) berichteten über eine Aufdeckungsrate von $17 \%$ bzw. 33\% durch Panendoskopie mit Biopsieentnahme, ohne dass zuvor im Rahmen der präoperativen Diagnostik Hinweise auf einen Primarius gegeben waren.

Die Identifikation des okkulten Primärtumors erscheint im Rahmen der Primärdiagnostik bzw. -behandlung bei Patienten mit zervikalem CUP-Syndrom prognostisch relevant, da sich hierdurch prinzipiell die Möglichkeit einer Lokalbehandlung in kurativer Intention eröffnet (Haas et al. 2002). Sowohl Haas et al. (2002) als auch Mehta et al. (2013) beobachteten durch die Aufdeckung und nachfolgender Therapie des Primärtumors, zumindest für dessen Lokalisation im Oropharynx, einen Überlebensvorteil. Demgegenüber berichteten Guntinas-Lichius et al. (2006) eine deutlich niedrigere 5-Jahresgesamtüberlebensrate bei Patienten mit detektiertem Primärtumor (22\%) im Vergleich zu den Patienten mit weiterhin okkultem Primarius (52\%).

In der vorliegenden Studie konnten wir für die Aufdeckung des Primarius durch erweiterte Panendoskopie keinen eindeutigen prognostischen Vorteil belegen. So war die 3-Jahresgesamtüberlebensrate für Patienten mit identifiziertem Primärtumor $(50,0 \%)$ annähernd identisch gegenüber Patienten ohne nachgewiesenem Primarius (52,9\%). Auch hinsichtlich des 5-Jahresgesamtüberlebens ergab sich lediglich ein leichter Vorteil für Patienten mit detektiertem Primärtumor $(50,0 \%)$ gegenüber Patienten ohne Hinweis auf einen Primarius (40,9\%).

Wie aus unseren Daten hervorgeht, geht die Identifikation des Primärtumors durch erweiterte Panendoskopie demnach nicht zwingend mit einer Prognoseverbesserung einher. 


\subsection{Therapie der Halslymphknotenmetastasen}

Eine einheitlich standardisierte Therapieempfehlung zur Behandlung des zervikalen CUP-Syndroms existiert bis zum heutigen Tage nicht. Bisher folgten die dazu durchgeführten Studien - wie auch die vorliegende Arbeit - einem retrospektivem Design. Eine erstmalig angestrebte prospektive randomisierte Studie der European Organization for Research on Treatment of Cancer und Radiation Therapy Oncology Group zur Evaluation der Behandlungsstrategie bei zervikalem CUP-Syndrom musste aufgrund mangelnder Patientenrekrutierung beendet werden (Perkins et al. 2012).

\subsubsection{Therapiemodalitäten}

Als therapeutische Optionen stehen Operation, Radiotherapie und kombinierte Radiochemotherapie zur Wahl. Die Therapiemodalität richtet sich einerseits nach der Ausdehnung der zervikalen Lymphknotenmetastasierung (Sandherr et al. 1997), andererseits beeinflussen auch Alter, Allgemeinzustand, Komorbidität und Therapiewunsch des Patienten die Therapiewahl (Seeber und Strumberg 2006). Soweit möglich wird bei Patienten mit zervikalen Lymphknotenmetastasen ein kurativer Therapieansatz angestrebt. In Fällen mit ausgedehnter Tumormanifestation bzw. tiefer Halsweichteil- bzw. Gefäßinfiltration erscheint nur eine palliative Therapie, bestehend z.B. aus Radio- und/oder Chemotherapie, mit der Intention einer Verbesserung bzw. Erhaltung der Lebensqualität möglich.

In der Literatur variiert die 5-Jahresgesamtüberlebensrate (Overall Survival) bei Patienten mit zervikalem CUP-Syndrom zwischen 11 und 63\% (Koscielny et al. 2000; Nguyen et al. 1994). Diese große Spannweite ist nach unserer Einschätzung u. a. auch unterschiedlichen Therapiemodalitäten und Patienteneinschlusskriterien geschuldet, zumal die optimale Therapiestrategie im Detail noch kontrovers diskutiert wird (Christiansen et al. 2005). Die in der vorliegenden Studie ermittelte 5Jahresgesamtüberlebensrate von 40,9\% erscheint mit den Ergebnissen anderer Untersucher vergleichbar (Oen et al. 1995; Christiansen et al. 2005; Huang et al. 2008; Fakhrian et al. 2012).

\subsubsection{Neck Dissection}

Wesentlicher Bestandteil eines kurativen Therapieansatzes ist die operative Entfernung der Halslymphknotenmetastasen (Dunst et al. 1988), die heutzutage meist 
in Form einer individuell angepassten, selektiven bzw. funktionellen Neck Dissection durchgeführt wird (Jungehülsing et al. 1997). So erscheint die Durchführung einer radikalen Neck Dissection derzeit nur noch bei offensichtlicher Infiltration von benachbarten, nicht lymphatischen Strukturen, wie des M. sternocleidomastoideus und der V. jugularis interna, indiziert (Jungehülsing et al. 1997; Werner und Dünne 2001; Cerezo et al. 2011). Die operative Behandlung von zervikalen Lymphknotenmetastasen bei unbekanntem Primärtumor soll eine angemessene onkologische Radikalität anstreben bei weitgehender Schonung funktioneller und kosmetisch relevanter Strukturen (Cerezo et al. 2011).

Umstritten ist die Behandlung der kontralateralen Halsseite, sofern dort keine Hinweise für Lymphknotenmetastasen vorliegen. In Anlehnung an Werner und Dünne (2001) sollte in diesem Fall die kontralaterale Neck Dissection nur bei ipsilateral fortgeschrittener Lymphknotenmetastasierung der oberen Halsregion erfolgen. Bei fortgeschrittenen Metastasen im Bereich der latero-kaudalen Halsregionen (Level IV und V) erscheint demgegenüber die prophylaktische Neck Dissection der Gegenseite fragwürdig, da in diesen Fällen von einer erhöhten Fernmetastasierungsrate bzw. einer reduzierten Gesamtüberlebensrate als limitierende Faktoren auszugehen ist (Werner und Dünne 2001). Zur Frage der Notwendigkeit der kontralateralen Halssanierung konnten in der vorliegenden Studie keine statistisch abgesicherten Daten gewonnen werden.

Für Patienten mit zervikalem CUP- Syndrom scheint sich die operative Behandlung günstig auf die Gesamtprognose auszuwirken, da sich in der vorliegenden Studie ein tendenziell besseres Gesamtüberleben für Patienten mit operativer Therapie (Gruppen A, C und D) gegenüber primär bestrahlten Patienten (Gruppe B) ergab (Tab. 9, S. 47). Dies steht im Einklang mit der Untersuchung von Huang et al. (2008). Allerdings erscheint insofern ein gewisser Selektionseffekt gegeben, als es sich sowohl in der genannten als auch unserer Studie bei den nicht-operierten Patienten (Gruppe B) jeweils um sehr kleine Kollektive mit überwiegend fortgeschrittenem und inoperablem Lymphknotenstatus handelte.

Übereinstimmend berichten aktuelle Studien über eine insgesamt bessere Prognose für Patienten mit kombinierter chirurgisch-strahlentherapeutischer Primärbehandlung gegenüber Patienten, die unimodal, d.h. ausschließlich chirurgisch oder radiotherapeutisch, behandelt wurden (Strojan und Anicin 1998; Koscielny et al. 2000; Guntinas-Lichius et al. 2006). Dies konnte in unserer Studie zwar bezüglich der regionären Kontrolle jedoch nicht für das Gesamtüberleben bestätigt werden. So hatten 
die 13 Patienten, die einer unimodalen Therapie zugeführt wurden (Gruppe AVB), eine signifikant schlechtere regionäre Kontrolle gegenüber Patienten mit multimodalen Therapieansätzen (Gruppe C/D).

Nach Sandherr et al. (1997) ist eine alleinige radikale Operation mit Rezidivraten zwischen 20 und 40\% einer multimodalen Behandlung mit Rezidivraten zwischen 5 und $10 \%$ unterlegen. Nach Ansicht weiterer Untersucher kann eine alleinige Neck Dissection ausschließlich in Fällen mit Solitärstadien von zervikalen Plattenepithelkarzinommetastasen ( $\mathrm{pN1a}$ ) ohne extrakapsuläres Wachstum angezeigt sein (MarcialVega et al. 1990; Coster et al. 1992). In der vorliegenden Studie erhielten 8 Patienten ausschließlich eine Neck Dissection (Gruppe A), wobei bei 5 Patienten (62,5\%) Solitärstadien (N1/ N2a) vorlagen. Demgegenüber ist jedoch zu beachten, dass in unserer Studie, trotz des hohen Anteils an Frühstadien in der Gruppe A ( $n=8$ Patienten), die regionäre Rezidivrate nach alleiniger Neck Dissection mit $62,5 \%$ ( $n=5$ Patienten) deutlich höher lag als bei der kombinierten Therapie mit ca. 20,0\%. Diese 5 Patienten mit Halsrezidiv nach alleiniger vorheriger Operation wurden anschließend einer weiteren Therapie zugeführt. Bei 4 Patienten wurde eine erneute operative Therapie durchgeführt, von denen 3 Patienten mit einer zusätzlichen Radiotherapie behandelt wurden. Bei einem Patienten wurde das Halsrezidiv primär bestrahlt.

Die operative Therapie im Sinne einer Neck Dissection hat aufgrund der nachfolgenden histopathologischen Aufarbeitung des Neck Dissection - Präparates im Gegensatz zum rein konservativen Therapieansatz (primäre Radio- bzw. Radiochemotherapie) nicht nur den Vorteil einer genauen Einstufung der Lymphknotenkategorie durch den Pathologen (pN-Staging), sondern ermöglicht auch eine differenzierte Aussage zum extrakapsulären Wachstum mit entsprechender prognostischer Relevanz (Olsen et al. 1994; Pfreundner et al. 1997; Strojan und Anicin 1998).

\subsubsection{Radio-bzw. Radiochemotherapie}

Bei Patienten mit fortgeschrittenen Kopf-Hals-Karzinomen bekannter Primärtumorlokalisation bewirkt die konkomitante Chemotherapie sowohl bei primärer als auch bei adjuvanter Radiotherapie eine Verbesserung von Tumorkontrolle und Gesamtüberleben (Wendt et a. 1998; Bernier et al. 2004). 
Für das zervikale CUP-Syndrom wird nach primär operativer Therapie die Effektivität einer kombinierten adjuvanten Radiochemotherapie im Vergleich zur alleinigen adjuvanten Radiotherapie in der Literatur demgegenüber noch kontrovers diskutiert, wobei diesbezüglich noch immer keine prospektiven randomisierten Studien vorliegen, welche die verschiedenen Therapiemodalitäten vergleichen. Cerezo et al. (2011) schlagen für Patienten mit zervikalem CUP-Syndrom ein multimodales Behandlungskonzept unter Einschluss einer konkomitanten Chemotherapie vor analog zu Patienten mit lokal fortgeschrittenen Kopf-Hals-Tumoren. Allerdings ist das therapeutische Vorgehen stets auch eine individuelle Entscheidung abhängig von der klinischen Situation und dem Allgemeinzustand des jeweiligen Patienten.

Andere Autoren (Christiansen et al 2005; Hauswald et al. 2008; Chen et al. 2011; Fakhrian et al. 2012) konnten durch eine konkomitante Chemotherapie keine Verbesserung von Gesamtüberleben bzw. loko-regionärer Kontrolle beobachten. Allerdings wurde bei kombinierter Radiochemotherapie ein statistisch signifikanter Anstieg von Nebenwirkungen bzw. ein vermehrtes Auftreten von Therapieunterbrechungen und Hospitalisation beschrieben (Chen et al. 2011). Aufgrund der sehr kleinen Fallzahlen wurde in den oben erwähnten Studien jedoch keine weitere Differenzierung vorgenommen, ob die konkomitante Chemotherapie im Rahmen einer postoperativen oder primären Radiotherapie erfolgte.

In unserer Studie erscheinen die Ergebnisse der Neck Dissection mit anschließender kombinierter Radiochemotherapie (Gruppe D) günstiger als nach Neck Dissection und alleiniger adjuvanter Radiotherapie (Gruppe C), so dass von uns derzeit das multimodale Therapiekonzept, bestehend aus Operation und adjuvanter Radiochemotherapie, favorisiert wird. Inhomogenitäten bezüglich Lymphknotenstatus und die jeweils nur kleine Patientenzahl ( $n=28$ Patienten in Gruppe C, n= 17 Patienten in Gruppe D) limitieren die Vergleichbarkeit zwischen den beiden Untergruppen ( $C$ und D), so dass keine statistisch signifikanten Unterschiede belegt werden konnten.

Die für den jeweiligen Patienten möglichst geeignete Behandlungsmodalität muss individuell unter Berücksichtigung patientenspezifischer Parameter, wie Lymphknotenstatus, Risikoprofil, Allgemeinzustand, Sicherheitsbedürfnis usw. interdisziplinär festgelegt werden.

Für die postoperative Strahlentherapie variieren die Dosisangaben für die betroffene Halsseite zwischen durchschnittlich 50-70 Gy, die über mindestens 5 Wochen in Einzeldosen von 1,8-2 Gy appliziert werden (Dunst et al. 1988; Snow 1995; Christiansen et al. 2005; Chen et al. 2011; Fakhrian et al. 2012), wobei man sich an 
den Dosiskonzepten zu Radiotherapie bei Kopf-Hals-Tumoren mit bekannter Primärtumorlokalisation orientiert.

Die Wahl der Gesamtdosis wird u.a. vom Nachweis eines kapselüberschreitendem Wachstums beeinflusst, bei dessen Auftreten in der Regel eine erhöhte Dosis von 6466 Gy befürwortet wird (Cerezo et al. 2011). Die Angaben über die Höhe der zu applizierenden Strahlendosis unterliegen in der vorliegenden Literatur jedoch zum Teil großen Schwankungen, was nicht zuletzt auf Veränderungen im Therapieregime und auf technische Verbesserungen im zeitlichen Verlauf zurückzuführen ist (Fakhrian et al. 2012).

Ein weiterer Diskussionspunkt bei der Radiotherapie von Patienten mit zervikalem CUP-Syndrom ist die Ausdehnung des Strahlenfeldes. Neben einer alleinigen Bestrahlung der betroffenen Halsregion(en) (limited field radiation) besteht die Option, auch die kontralaterale Halsseite sowie den Pharynxschlauch und den Larynx (extended field radiation) einzubeziehen. Dabei sollte sich das Strahlenfeld auch auf Tonsillenlogen und Zungengrund erstrecken, um unentdeckte Primärtumoren an diesen Lokalisationen zu erfassen (Thönissen et al. 2013) mit dem Ziel einer Verbesserung von Gesamtüberleben bzw. loko-regionärer Kontrolle (Kirschner et al. 1997; Strojan und Anicin 1998; Grau et al. 2000; Beldi et al. 2007).

Andere Autoren (Glynne-Jones et al. 1990; Weir et al 1995; Sinnathamby et al. 1997; Koscielny et al. 2000) hingegen sehen im erweiterten Strahlenfeld keinen prognostisch günstigen Einfluss und favorisieren ein limitiertes Bestrahlungsfeld im Hinblick auf das geringere Nebenwirkungsrisiko (Fakhrian et al. 2012). Hierbei wird das Strahlenfeld auf die betroffene Halsseite beschränkt (limited field radiation).

In unserem Patientenkollektiv wurden insgesamt 48 (80,0\%) der bestrahlten Patienten einer extended field radiation zugeführt. Es zeigte sich jedoch in den durchgeführten univariaten Analysen kein signifikanter Einfluss des Strahlenfeldes auf das Gesamtüberleben $(p=0.89)$, das krankheitsspezifische Überleben $(p=0.77)$ und die regionäre Kontrolle $(p=0.57)$. Jedoch ist darauf hinzuweisen, dass aufgrund des kleinen Patientenkollektivs keine weitere Differenzierung innerhalb der beiden Gruppen (extended vs. limited field radiation) z. B. nach Lymphknotenstatus durchgeführt wurde, so dass diesbezüglich keine sicheren Aussagen getroffen werden können.

Um den Nutzen eines ausgedehnten Strahlenfeldes beim zervikalen CUP-Syndrom hinreichend zu belegen, sind prospektive randomisierte Studien erforderlich (Thönissen et al. 2013). 
In den letzten Jahren hat zunehmend die intensitätsmodulierte Radiotherapie (IMRT) bei der Bestrahlung von Karzinomen im Kopf-Hals-Bereich Anwendung gefunden. Der Gebrauch der IMRT ermöglicht eine Reduzierung der Nebenwirkungen, da die Intensität der verwendeten Strahlendosen innerhalb eines Bestrahlungsfeldes an Tumorlokalisation und -ausdehnung angepasst werden kann (Tribius et al. 2010). Durch die IMRT soll eine möglichst hohe homogene Strahlendosis im Tumorgewebe aufgebaut werden, während nicht befallenes Nachbargewebe sowie Risikoorgane (wie z.B. Speicheldrüsen oder Rückenmark) geschont werden (Thönissen et al. 2013). Dies verringert strahleninduzierte Nebenwirkungen bzw. verbessert die Lebensqualität. Weiterhin lässt sich z.B. bei Oropharynxkarzinomen durch die IMRT gegenüber einem konventionellen Vorgehen eine höhere lokale Tumorkontrolle erreichen (Thönissen et al. 2013). Trotz zunehmender Anwendung der IMRT bei bekannten Kopf-HalsKarzinomen gibt es bisher nur wenig Literatur über den Stellenwert der IMRT bei der Therapie des zervikalen CUP-Syndroms.

Ligey et al. (2009) untersuchten in ihrer Studie den Einfluss unterschiedlicher Bestrahlungstechniken auf die loko-regionäre Kontrolle und das Gesamtüberleben bei Patienten mit unilateralen zervikalen Lymphknotenmetastasen bei unbekanntem Primärtumor. Sie konnten eine signifikant verbesserte loko-regionäre Kontrolle und ein signifikant verbessertes Gesamtüberleben bei 3D-konformaler Strahlentherapie und IMRT gegenüber der zweidimensionalen Technik nachweisen.

Einschränkend ist jedoch hinzuzufügen, dass die Gruppengrößen bei den einzelnen Bestrahlungstechniken stark variierten. Auch Beldi et al. (2007) befürworten aufgrund eines besseren Gesamtüberlebens in ihrer Studie eine multimodalen Therapiestrategie bei zervikalen CUP-Syndrom, bestehend aus Neck Dissection und erweitertem Strahlenfeld (bilateraler Hals und pharyngeale Mukosa) durch eine dreidimensionale Radiotherapie. Demgegenüber konnten Madani et al. (2008) keinen signifikanten Einfluss der IMRT auf das 2-Jahresgesamtüberleben gegenüber der konventionellen Radiotherapie (zweidimensional) nachweisen. Sie beobachteten jedoch eine statistisch signifikante Reduktion der akuten und längerfristigen Nebenwirkungen.

Zusammenfassend gesagt, existiert gegenwärtig für die optimale Therapiestrategie bei Patienten mit zervikalem CUP-Syndrom im Detail keine einheitliche Empfehlung. Übereinstimmung besteht darin, dass Patienten mit zervikalen Lymphknotenmetastasen grundsätlich aggressiv multimodal behandelt werden sollten - analog zu Patienten mit lokal fortgeschrittenem Kopf-Hals-Tumoren (Shehadeh et al. 2006; 
Cerezo et al. 2011; Zhuang et al. 2014). Soweit möglich, sollte das Therapiekonzept dabei auch ein operatives Vorgehen beinhalten. Im Vergleich mit Patienten mit fortgeschrittenen Tumoren der Kopf-Hals-Region bekannter Primärtumorlokalisationen werden mittlerweile bei Patienten mit zervikalem CUP-Syndrom über ähnliche oder sogar noch günstigere Behandlungsergebnisse berichtet (Christiansen et al 2006; Beldi et al. 2007; Pavlidis et al. 2009; Perkins et al. 2012). Trotz fehlendem Primärtumornachweis kann das zervikale CUP-Syndrom aufgrund der bestehenden therapeutischen Möglichkeiten daher als eine potenziell kurable Erkrankung angesehen werden.

\subsection{Primärtumordemaskierung nach Abschluss der Primärbehandlung (späte Primärtumordemaskierung)}

Die Frage, inwieweit die Primärtumordemaskierung im Rahmen der Tumornachsorge mit einer verbesserten Prognose einhergeht, ist von besonderem Interesse, zumal die gezielte Primärtumorsuche im Rahmen der Tumornachsorge z.T. mit aufwändigen und z.T. invasiven Maßnahmen verbunden sein kann.

\subsubsection{Aufdeckungsrate und Lokalisation des Primärtumors}

Die Angaben über die Aufdeckungsrate von okkulten Primärtumoren bei zervikalen Lymphknotenmetastasen nach Abschluss der Primärbehandlung variieren in der Literatur zwischen 0 und 46\% (Christiansen et al. 2005; Waltonen et al. 2009; Beldi et al. 2007; Pavlidis et al. 2009; Fakhrian et al. 2012). Diese große Spannweite beruht möglicherweise $u$. a. auch auf unterschiedlichem Umfang der jeweils angewandten Untersuchungsmethoden im Rahmen der Nachsorge. Auch wird der Zeitpunkt, ab welchem Zeitpunkt von einer „späten“ Primärtumordemaskierung ausgegangen wird uneinheitlich definiert.

So berichten z. B. Waltonen et al. (2009) über eine Primärtumoridentifikation in 45,9\% der von innen untersuchten Patienten. Das untersuchte Kollektiv umfasste jedoch auch solche Fälle, bei denen sich nur aufgrund der klinischen Untersuchung kein Hinweis auf einen Primärtumor ergab. Die Detektion der Primärtumoren erfolgte dann allerdings noch im weiteren Verlauf der Primärdiagnostik mittels CT, PET und Panendoskopie und somit noch vor Beginn der Primärtherapie (Waltonen et al. 2009). Ähnlich schlossen Weber et al. (2001) und Issing et al. (2003) in ihrer Analyse auch solche 
Patienten mit ein, bei denen die jeweiligen Primarien bereits im Rahmen der Panendoskopie, also ebenfalls zum Zeitpunkt der Primärdiagnostik, identifiziert wurden, was zumindest teilweise die angegebenen hohen Primärtumoraufdeckungsraten von $44 \%$ bzw. $21,6 \%$ erklären könnte.

Andere Untersucher definieren im Einklang mit unserer Studie die späte Primärtumordemaskierung ausschließlich nach Abschluss der Primärtherapie mit entsprechend niedrigeren Aufdeckungsraten zwischen 0 und 10,3\% (Subramanian und Chilla 1988; Strojan und Anicin 1998; Christiansen et al. 2005; Guntinas-Lichius et al. 2006; Perkins et al. 2012). In der vorliegenden Studie wurde bei 4 Patienten (6,9\%) im Follow-up ein Primärtumor diagnostiziert (Tab. 13, S. 72).

Auch die Unterscheidung zwischen Primärtumor und neu aufgetretener Tumormanifestation im Sinne eines Zweittumors im Follow-up wird kontrovers definiert. In der Literatur wird diesbezüglich überwiegend die Auffassung vertreten, dass bei identischem histopathologischen Befund Tumoren, die 5 und mehr Jahre nach Auftreten der Lymphknotenmetastasen detektiert werden, als Zweittumoren einzustufen sind (Marcial-Vega et al. 1990; Wang et al. 1990; Cerezo et al. 2011). In der vorliegenden Studie beruhte die Unterscheidung auf dem histopathologischen Befund bzw. den aus den Krankenakten zu entnehmenden individuellen Einschätzungen der Untersucher, ohne Bindung an ein festes Zeitintervall nach Abschluss der Primärbehandlung.

Einige Autoren berichten über niedrigere Aufdeckungsraten des okkulten Primärtumors im Follow-up bei Patienten, die einer erweiterten Strahlentherapie (extended field radiation) zugeführt wurden im Vergleich zu Fällen mit limitiertem Bestrahlungsfeld. Ein statistisch signifikanter Unterschied im Gesamtüberleben bzw. in der regionären Kontrolle konnte diesbezüglich jedoch nicht nachgewiesen werden (Weir et al. 1995; Reddy und Marks 1997; Iganej et al. 2002; Perkins et al. 2012), so dass nach bisheriger Datenlage ein erweitertes Strahlenfeld offenbar keinen eindeutigen Vorteil in Bezug auf die lokale Kontrolle bietet (Kirschner et al. 1997; Sinnathamby et al. 1997; Koscielny et al. 2000; Beldi et al. 2007). Dies konnte auch in der vorliegenden Studie bestätigt werden, bei der zwei von den drei im Rahmen der Nachsorge im HNO-Gebiet demaskierten Primärtumoren in zuvor bestrahlter Mukosaregion lokalisiert waren.

Die im Follow-up demaskierten Primärtumoren werden nach Literaturangaben überwiegend im Bereich der Tonsilla palatina, im Zungengrund und Nasopharynx 
beobachtet (Beldi et al. 2007; Pavlidis et al. 2009; Fakhrian et al. 2012). Außerhalb der Kopf-Halsregion dominieren die Lunge und der Ösophagus (Sinnathamby et al. 1997; Grau et al. 2000).

\subsubsection{Prognostischer Einfluss der Primärtumordemaskierung im Follow- up}

Der prognostische Einfluss der Primärtumordemaskierung im Follow-up wird kontrovers diskutiert. Einige Autoren berichten über eine Abnahme des Gesamtüberlebens bei Aufdeckung eines Primärtumors (Koscielny et al. 2000; Issing et al. 2003), wohingegen andere Autoren die späte Demaskierung als prognostisch eher günstig einstufen - sofern der Primärtumor operabel erscheint (Jones et al. 1993; Haas et al. 2002). In unserer Studie konnte in nur vier Fällen (6,7\%) ein Primärtumor im Follow-up im Mittel 29,5 Monate nach Erstbehandlung identifiziert werden.

Dieses Ergebnis steht in Einklang mit anderen Studien, bei denen Primärtumoren nach Zeitspannen von 20 bis 24 Monaten gefunden werden konnten (Issing et al. 2003; Beldi et al. 2007; Fakhrian et al. 2012) (Tab. 13). Alle 4 Patienten unserer Analyse verstarben tumorabhängig, so dass daher in unserem Patientengut nicht von einer Prognoseverbesserung ausgegangen werden kann. Aufgrund der kleinen Fallzahl erschien eine weiterführende statistische Analyse jedoch nicht sinnvoll.

\begin{tabular}{|l|c|c|c|c|}
\hline \multicolumn{1}{|c|}{$\begin{array}{c}\text { Autoren (Quelle) } \\
\text { [Jahreszahl] }\end{array}$} & $\begin{array}{c}\text { Anzahl } \\
\text { untersuchte } \\
\text { Patienten }\end{array}$ & $\begin{array}{c}\text { PT } \\
\text { gefunden }\end{array}$ & $\begin{array}{c}\text { PT im HNO- } \\
\text { Bereich }\end{array}$ & $\begin{array}{c}\text { Zeitdauer bis PT } \\
\text { gefunden }\end{array}$ \\
\hline $\begin{array}{l}\text { Subramanian und Chilla } \\
\text { [1990] }\end{array}$ & $59(100 \%)$ & $10,3 \%$ & $60,0 \%$ & k.A. \\
Strojan und Anicin [1998] & $56(100 \%)$ & $5(8,9 \%)$ & $5(100 \%)$ & 21 Monate (median) \\
Grau et al. [2000] & $352(100 \%)$ & $19 \%$ & $50,0 \%$ & k.A. \\
$\begin{array}{l}\text { Guntinas-Lichius et al. } \\
\text { [2006] }\end{array}$ & $46(100 \%)$ & $3(6,5 \%)$ & $3(100 \%)$ & 23,57 Monate (mittel) \\
Fahkrian et al. [2012] & $65(100 \%)$ & $11(17 \%)$ & $6(55 \%)$ & 20 Monate (median) \\
Perkins et al. [2012] & $46(100 \%)$ & $3(6,5 \%)$ & $3(100 \%)$ & k.A. \\
Eigene Studie & $58(100 \%)$ & $4(6,9 \%)$ & $3(75,0 \%)$ & 32,5 Monate (mittel) \\
\hline
\end{tabular}

Tab. 13: Literaturangaben zur Primärtumordemaskierung beim zervikalen CUP-Syndrom nach Abschluss der Primärtherapie 


\subsection{Tumornachsorge}

Nach Abschluss der Primärtherapie erfolgen in regelmäßigen Abständen ambulante Nachsorgeuntersuchungen. Die allgemeinen Ziele der Tumornachsorge für Patienten mit Kopf- und Halsmalignomen sind „(1) die Erhebung der therapeutischen Effizienz, (2) das Management von Beeinträchtigungen, (3) die frühzeitige Erfassung von neuen Tumormanifestationen und (4) die psychosoziale Rehabilitation und Integration des Patienten“ (Haas et al. 2001, S.177). Jede Tumornachsorgeuntersuchung beinhaltet eine sorgfältige Zwischenanamnese, die Erhebung des loko-regionären Befundes durch Endoskopie, Palpation und Sonographie des Halses. Einmal jährlich werden die Durchführung einer Röntgen- bzw. CT-Thorax-Untersuchung und die Abdomensonographie empfohlen (Lefebvre et al. 1990; Dellian et al. 2003). Wichtig ist in diesem Zusammenhang die Erfassung neuer Ereignisse (loko-regionäre Rezidive, Fernmetastasen und Zweittumoren), die bei Patienten mit zervikalem CUP-Syndrom in der Mehrzahl in den ersten beiden Jahren nach Abschluss der Primärbehandlung beobachtet werden können (Abbruzzese et al. 1994; León et al. 1999; León et al. 2000; Haas et al. 2001; Dellian et al. 2003).

\subsubsection{Regionäre Kontrolle}

Das Auftreten von Halslymphknotenrezidiven (regionären Rezidiven) wird in der Literatur mit Häufigkeiten zwischen 9\% und ca. $30 \%$ angegeben (Colletier et al. 1998; Issing et al. 2003; Ligey et al. 2009; Fakhrian et al. 2012) und wird somit im Mittel häufiger als eine späte Primärtumordemaskierung beobachtet (Nieder et al. 2001; Cerezo et al. 2011). In der vorliegenden Studie entwickelten 25,0\% des Gesamtkollektivs durchschnittlich 14,2 Monate nach Primärtherapie regionäre Rezidive (Tab. 15, S.76). In der Subgruppenanalyse fiel auf, dass diese häufiger nach alleiniger operativer Behandlung (62,5\%, Gruppe A) auftraten als nach multimodaler Primärbehandlung (ca. 20\%, Gruppe C/D). Die mehrheitlich favorisierte Therapiekombination aus Neck Dissection und adjuvanter Radio- bzw. Radiochemotherapie wies in unserer Studie bezüglich der Rezidivhäufigkeit, ähnlich den Ergebnissen anderer Studien, die besten Ergebnisse auf (Tab. 14). 


\begin{tabular}{|c|c|c|c|}
\hline \multirow[b]{2}{*}{$\begin{array}{l}\text { Autoren (Beispiele)/ } \\
\text { [Jahreszahl] }\end{array}$} & \multirow{2}{*}{$\begin{array}{c}\text { Anzahl } \\
\text { untersuchte } \\
\text { Patienten } \\
\end{array}$} & \multicolumn{2}{|c|}{ Rezidivrate nach } \\
\hline & & $\begin{array}{l}\text { alleiniger } \\
\text { Operation }\end{array}$ & $\begin{array}{c}\text { multimodaler } \\
\text { Therapie }\end{array}$ \\
\hline Jesse et al. [1973] & $210(100 \%)$ & $24,0 \%$ & $14,0 \%$ \\
\hline Bataini et al. [1987] & $138(100 \%)$ & k.A. & $17,0 \%$ \\
\hline Wang et al. [1990] & $158(100 \%)$ & $11,0 \%$ & $20,0 \%$ \\
\hline Koscielny et al. [2000] & $83(100 \%)$ & $18,2 \%$ & $14,7 \%$ \\
\hline Eigene Studie & $58(100 \%)$ & $62,5 \%$ & $20,9 \%$ \\
\hline
\end{tabular}

Tab. 14: Auftreten regionärer Rezidive beim zervikalen CUP-Syndrom in Abhängigkeit von der Primärtherapie

Im Hinblick auf die Ausdehnung des Strahlenfeldes wird sowohl bei limited field radiation also auch bei extended field radiation über regionäre Rezidive berichtet (Fakhrian et al. 2012), wobei für letztere jedoch eine tendenziell geringere Rezidivrate angegeben wird (Ligey et al. 2009). Grau et al. (2000) konnten sogar eine statistisch signifikante Reduktion von regionären Rezidiven durch ein ausgedehntes Bestrahlungsfeld nachweisen, jedoch ohne signifikanten Einfluss auf das Gesamtüberleben. In unserer Studie blieb die Ausdehnung des Strahlenfeldes ohne statistisch signifikanten Einfluss $(p=0.57)$ auf die regionäre Kontrolle.

Einzig Wang et al. (1990) berichten über eine tendenziell höhere, jedoch statistisch nicht signifikante regionäre Rezidivrate nach multimodaler Therapie. In dieser Studie wurden jedoch sowohl operierte Patienten mit anschließender adjuvanter Radio- und Radiochemotherapie als auch Patienten nach primärer Radiochemotherapie zusammengefasst.

Für alle behandelten CUP-Patienten lag die 3- bzw. 5-Jahresrate für die regionäre Kontrolle in unserer Studie bei $73,7 \%$ bzw. 67,3\%. Einen detaillierten Überblick über die jeweilige Behandlung (Gruppe A-D) liefert Tab. 9 (S. 47). Das Auftreten eines regionären Rezidivs wirkte sich auf das krankheitsspezifische Überleben nur bei der univariaten Analyse $(p=0.02)$ negativ aus. Da bei der Mehrzahl der betroffenen Patienten meist mit kurativem Ansatz eine multimodale Primärbehandlung bestehend aus Operation und Bestrahlung erfolgt war, erschienen weitere therapeutische 
Optionen im Rezidivfall mangels Strahlenreserve bzw. aufgrund Inoperabilität oft limitiert.

\subsubsection{Auftreten von Fernmetastasen im Follow-up}

Das Auftreten von Fernmetastasen wirkt sich naturgemäß negativ auf Prognose bzw. Gesamtüberleben aus. Die Literaturangaben über das Auftreten von Fernmetastasen beim zervikalen CUP-Syndrom variieren zwischen 11 und 30\% (Strojan und Anicin 1998; Ligey et al. 2009; Perkins et al. 2012).

Möglicherweise liegt die Ursache dieser großen Spannbreite im unterschiedlichen Umfang der diagnostischen Maßnahmen, die im Rahmen der Nachsorgeuntersuchung durchgeführt wurden. Diese variierten offenbar zwischen den verschiedenen Studien in nicht unerheblichem Umfang (Dietl et al. 2007). Ebenfalls zu berücksichtigen sind die unterschiedlichen Zusammensetzungen der jeweiligen Patientenkollektive und das jeweilige Studiendesign. León et al. (2000) erklären die höhere Zahl an systemischen Metastasen in Autopsiestudien durch eine bessere Sensitivität und einen Selektionseffekt, da nur in solchen Fällen eine Autopsie vorgenommen wurde, bei denen die Tumorerkrankung einen letalen Verlauf genommen hat.

Eine bevorzugte Lokalisation für Fernmetastasen von Plattenepithelkarzinomen im HNO- Bereich stellt die Lunge dar, gefolgt von Knochen, Leber, Gehirn und Haut (AlOthman et al 2003; Dietl et al. 2007; Spector et al. 2012). Dies entspricht auch den bevorzugten Lokalisationen bei zervikalem CUP-Syndrom, wobei zum Teil Abweichungen in der genannten Reihenfolge zu finden sind (Kirschner et al. 1997; Madani et al. 2007; Chen et al. 2011).

Nach Literaturangaben variiert die durchschnittliche Zeitspanne zwischen Erstdiagnose und dem Auftreten von Fernmetastasen zwischen 7 und 23 Monaten (Fernandez et al. 1998; Strojan und Anicin 1998; Fakhrian et al. 2012). In Übereinstimmung mit anderen Studien wurden in der vorliegenden Studie bei 21 Patienten (36.2\%) Fernmetastasen nach einem Zeitintervall von durchschnittlich 17 Monaten diagnostiziert (Tab. 15). 


\begin{tabular}{|l|c|c|c|}
\hline \multicolumn{1}{|c|}{$\begin{array}{c}\text { Autoren (Beispiele)/ } \\
\text { [Jahreszahl] }\end{array}$} & $\begin{array}{c}\text { Anzahl } \\
\text { untersuchte } \\
\text { Patienten }\end{array}$ & $\begin{array}{c}\text { Anteil der } \\
\text { regionären } \\
\text { Rezidive }\end{array}$ metastasen \\
\hline \hline Bataini et al. [1987] & $138(100 \%)$ & k.A. & $25,0 \%$ \\
Wang et al. [1990] & $71(100 \%)$ & k.A. & $13,0 \%$ \\
\hline Fernandez et al. [1998] & $67(100 \%)$ & $34,0 \%$ & $22,0 \%$ \\
\hline Strojan und Anicin [1998] & $56(100 \%)$ & $18,0 \%$ & $11,0 \%$ \\
\hline Christiansen et al. [2005] & $28(100 \%)$ & $21,0 \%$ & $25,0 \%$ \\
\hline Beldi et al. [2007] & $113(100 \%)$ & $7,2 \%$ & $10,1 \%$ \\
Ligey et al. [2009] & $95(100 \%)$ & $21,0 \%$ & $30,0 \%$ \\
\hline Eigene Studie & $58(100 \%)$ & $25,9 \%$ & $36,2 \%$ \\
\hline
\end{tabular}

Tab. 15: Häufigkeit von regionären Rezidiven bzw. Fernmetasta sen bei Patienten mit zervikalem CUP-Syndrom

In der vorliegenden Auswertung starben fast ein Drittel der behandelten Patienten an den Folgen der Fernmetastasierung, obwohl bei der Hälfte aller Patienten durch die Primärbehandlung eine loko-regionäre Kontrolle erreicht werden konnte. Dies stellt ein wesentliches Ergebnis der vorliegenden Studie dar.

Die multivariaten Analysen zeigten darüber hinaus, dass im untersuchten Kollektiv das Auftreten von Fernmetastasen einen negativen Einfluss auf das Gesamtüberleben und krankheitsspezifische Überleben darstellte, unabhängig von den anderen im Rahmen dieser Arbeit analysierten möglichen prognostischen Faktoren (Geschlecht, Therapiemodalität, Lymphknotenstatus, Histologie, extrakapsuläres Wachstum und Bestrahlungsfeld usw.).

Fernmetastasen traten insbesondere in Fällen mit fortgeschrittenen Lymphknotenstadien $(48,8 \%)$ auf. Zudem ist hervorzuheben, dass in unserer Studie bei $76,2 \%$ der Patienten, bei denen Fernmetastasen diagnostiziert wurden, die histologische Aufarbeitung der initialen zervikalen Lymphknotenmetastase( $n$ ) einen Kapseldurchbruch ergeben hatte. Dies könnte darauf hinweisen, dass fortgeschrittene Halsmetastasierung bzw. Kapselruptur die Entwicklung von Fernmetasten begünstigen. In der durchgeführten Untersuchung konnte jedoch lediglich in der univariaten Analyse ein negativer Einfluss $(p=0.04)$ des extrakapsulären Wachstums auf Gesamtüberleben und krankheitsspezifisches Überleben nachgewiesen werden. 
In der Literatur werden extrakapsuläres Wachstum und fortgeschrittenes Lymphknotenstadium ebenfalls als prognostisch ungünstige Faktoren gewertet (Jereczek-Fossa et al. 2004; Beldi et al. 2007; Ligey et al. 2009; Wallace et al. 2011; Fakhrian et al. 2012). In einer multivariaten Analyse fanden Erkal et al. (2001a) demgegenüber zwar eine signifikant höhere Assoziation von Fernmetastasen mit extrakapsulärem Wachstum $(p=0.001)$, jedoch nicht mit dem Lymphknotenstatus $(p=0.24)$ (Erkal et al. 2001a). Daher wird bei fortgeschrittenen Lymphnotenstadien und insbesondere bei nachgewiesenem extrakapsulärem Wachstum über den Vorteil einer begleitender Chemotherapie diskutiert (Ligey et al. 2009; Wallace et al. 2011).

In unserer Studie konnte ein erhöhtes Auftreten von Fernmetastasen (59\%) in der Gruppe C (ND + RT) gegenüber der Gruppe D (ND + RCT; 36\%) verzeichnet werden. Dies lässt vermuten, dass eine im Rahmen der Primärbehandlung durchgeführte Chemotherapie das Risiko einer systemischen Disseminierung mit nachfolgender Entwicklung von Fernmetastasen minimieren könnte. Weiterführende statistische Analysen erschienen allerdings aufgrund der jeweils kleinen Subpopulationen nicht sinnvoll. Eingehende Studien zur Entwicklung von Fernmetastasen in Anhängigkeit von der Primärtherapiemodalität finden sich in der Literatur nicht (Strojan et al. 2013b). Bei Auftreten von Fernmetastasen ist, wie auch in unserer Studie, zumeist eine palliative Situation gegeben, welche in erster Linie chemotherapeutisch behandelt wird (Spector et al. 2011; Fakhrian et al. 2012). In diesem Zusammenhang beobachteten Spector et al. (2011) bei Patienten mit Plattenepithelkarzinomen der Kopf-Hals Region bekannter Primärtumorlokalisation und systemischer Disseminierung eine signifikante Verbesserung der Lebenserwartung $(p=0.0001)$ durch eine palliative Chemotherapie (median 285 Tage versus 70 Tage). Allerdings ist hervorzuheben, dass nur Patienten mit einer ausreichenden gesundheitlichen Konstitution eine Chemotherapie erhalten hatten (Spector et al. 2011).

Einen neuen Stellenwert in der Diagnostik von malignen Ereignissen nimmt die FDGPET ein, die in unserer Studie nicht berücksichtigt wurde. Rusthoven et al. (2004) konnten durch FDG-PET in $16 \%$ der Fälle neue regionale Metastasen und $11 \%$ Fernmetastasen gegenüber der konventionellen Diagnostik nachweisen. Keller et al. (2011) weisen auf die Möglichkeit eines Ganzkörperscreening mittels PET oder $\mathrm{PET} / \mathrm{CT}$ zur Aufdeckung eine malignen Ereignissen insbesondere auch außerhalb des Kopf-Hals-Bereiches hin. In diesem Zusammenhang berichten die Autoren über einen Zweittumornachweis in 18,4\% der Fälle außerhalb des Kopf-Hals-Bereiches. 


\subsubsection{Zweittumoren}

Im Gegensatz zu Fernmetastasen werden Zweittumoren bei Patienten mit zervikalem CUP-Syndrom nur mit Häufigkeiten zwischen $4 \%$ und $12 \%$ beschrieben (GuntinasLichius et al. 2006; Beldi et al. 2007; Ligey et al. 2009; Chen et al. 2011; Perkins et al. 2012). Dies entspricht annähernd auch der Zweittumorinzidenz bei Kopf-HalsKarzinomen mit bekannten Primärtumor (Erkal et al. 2001b).

In der vorliegenden Studie wurde bei 9 Patienten (15,0\%) im Beobachtungszeitraum ein Zweittumor diagnostiziert, der sich histopathologisch von den zervikalen Metastasen unterschied und daher nicht als Primärtumor eingestuft wurde. In Übereinstimmung mit unserer Studie werden Zweittumoren, häufig in der Lunge beobachtet (Kirschner et al. 1997; Chen et al. 2011). Allerdings kommt dieses Organsystem auch als Lokalisation des okkulten Primärtumors in Betracht insbesondere bei Patienten mit supraklavikulären Lymphknotenmetastasen (Mozet et al. 2013). In der vorliegenden Studie wurde im Follow-up bei einem Patienten in der Lunge der Primärtumor diagnostiziert. Insgesamt lässt sich im Einzelfall oft nur schwer abgrenzen, inwieweit es sich bei neu diagnostizierten malignen pulmonalen Manifestationen um den Primärtumor, einen neu aufgetretenen Zweittumor oder um eine Fernmetastasierung handelt - insbesondere bei identischen histopathologischen Befunden. Dies erfolgt in der Regel durch patientenbezogene Einschätzung im Rahmen einschlägiger interdisziplinärer Tumorkonferenzen. Mögliche Ursache für den Zusammenhang von Bronchialkarzinomen und Plattenepithelkarzinome im HNOBereich ist das vergleichbare Noxenprofil von Nikotin- und Alkoholkonsum (Oen et al. 1995). Da in der vorliegenden Studie die Lunge nicht nur bevorzugter Ort von Zweittumoren, sondern auch von Fernmetastasen war, unterstreicht dies die Bedeutung regelmäßiger bildgebender Untersuchungen von Lunge bzw. Thorax im Rahmen der Nachsorge.

\subsection{Grenzen der Studie und Ausblick}

Insgesamt muss unsere Analyse unter dem Aspekt einer retrospektiven Studie gesehen werden, die im Vergleich zu Fällen mit bekanntem Primärtumor ein eher seltenes Krankheitsbild thematisiert. Dementsprechend beschränken sich entsprechende Analysen einer einzelnen Institution in der Regel auf kleine Fallzahlen, was naturgemäß weitergehende statistische Analysen limitiert bzw. für bestimmte Fragestellungen nicht sinnvoll erscheinen lässt und Vergleiche mit anderen Studien 
einschränkt. Insbesondere für die multivariaten Analysen sind die Fallzahlen der Studie trotz des langen Beobachtungszeitraumes sehr klein.

Erschwerend kommt hinzu, dass in dem meist über Jahrzehnte dauernden Beobachtungszeitraum im Detail unterschiedliche Therapiekonzepte bezüglich Operation, Strahlen- und Chemotherapie verfolgt wurden. Innerhalb der analysierten Population und Subpopulationen zeigten sich ferner nicht selten Inhomogenitäten, die eine Subgruppenanalyse erschwerten. So wies z.B. die kleine Gruppe der primär bestrahlten Patienten in unserem Kollektiv (Gruppe B) einen erhöhten Anteil an fortgeschrittenem Halslymphknoten-Metastasierungsstadien auf, da eine primäre Radio(chemo)therapie in der Regel bei fortgeschrittenen und inoperablen Fällen erfolgte.

Weiterhin erfolgte die Analyse zur Ausdehnung der Strahlenfelder (extended vs. limited field radiation) unabhängig von einer eventuell begleitenden Chemotherapie, dem Lymphknotenstatus oder dem Risikoprofil, was neben den jeweils relativ kleinen Fallzahlen der einzelnen Therapiegruppen die Interpretation der Ergebnisse limitiert. Darüber hinaus erfolgte in unserem Kollektiv keine Bestimmung des HPV-Status, welcher als ein unabhängiger und starker prognostischer Faktor bei Plattenepithelkarzinomen insbesondere des Oropharynx in den letzten Jahren zunehmend an Bedeutung gewonnen hat (Ang et al. 2010).

Aufgrund dieser genannten Limitationen, welche zum Teil dem Studiendesign einer retrospektiven Analyse geschuldet sind, erwächst zunehmend der Wunsch nach prospektiven, multizentrischen Studien (Christiansen et al. 2005; Beldi et al. 2007; Chen et al. 2011; Balaker et al. 2012). Die erste angestrebte randomisierte Studie beim zervikalen CUP-Syndrom, insbesondere zur Evaluation des Zielvolumens und zur Ausdehnung der Bestrahlungsfeldes der postoperativen Strahlentherapie, wurde durch die European Organization for Research on Treatment of Cancer, die Radiation Therapy Oncology Group und weitere Gruppen aus Deutschland, Dänemark, Kanada und Australien 2002 initiiert (EORTC-24001-22005, Randomized phase III study on the selection of the target volume in postoperative radiotherapy for cervical lymph node metastases of squamous cell carcinoma from an unknown primary (CUP)). Von den Ergebnissen dieser Studie erhoffte man sich eine Therapiestrategie, welche die Herausforderung zwischen Therapiemaximierung und Reduktion von Nebenwirkungen bewältigen könnte (Jereczek-Fossa et al. 2004; Christiansen et al. 2005). 
Schwierigkeiten im Zusammenhang mit der Patientenrekrutierung führten jedoch zur vorzeitigen (2004) Beendigung der Studie (Perkins et al. 2012; Mozet et al. 2013).

Die im Vergleich zu Kopf-Hals-Malignomen mit bekanntem Primärtumor niedrige Inzidenz des zervikalen CUP-Syndroms erschwert nicht unerheblich die Durchführung einer prospektiven Studie (Fakhrian et al. 2012). Inwieweit in absehbarer Zeit erneut der Versuch einer prospektiven Studie unternommen werden kann, ist derzeit noch nicht eindeutig absehbar (Strojan et al. 2013b). Daher erscheinen retrospektive Analysen zur interessanten Problematik zervikaler Halsmetastasen bei unbekanntem Primärtumor nach wie vor von Bedeutung. 


\section{Zusammenfassung}

In der vorliegenden, retrospektiv durchgeführten Studie wurden Daten von insgesamt 98 Patienten ausgewertet, die mit dem klinischen Bild zervikaler Lymphknotenmetastasen bei unbekanntem Primärtumor in der Hals-Nasen-Ohren Klinik der Universität Göttingen im Zeitraum von 1986 bis 2006 vorstellig bzw. behandelt wurden.

Bei 22 Patienten konnte im Rahmen der in Vollnarkose durchgeführten erweiterten Panendoskopie einschließlich diagnostischer Tonsillektomie, Zungengrund- und Nasopharynxbiopsie der Primärtumor identifiziert werden. Die Tatsache, dass sich 5 dieser identifizierten Primarien erst im Rahmen der histopathologischen Aufarbeitung (4x Tonsille, 1x Nasopharynx) zeigten, unterstreicht die Notwendigkeit insbesondere der diagnostischen Tonsillektomie im Rahmen der Panendoskopie. 16 Patienten erhielten keine Panendoskopie und $\mathbf{2}$ weitere Patienten wurden nicht therapiert. Diese 18 Patienten wurden nicht in die weitere Datenanalyse einbezogen.

Die 58 therapierten Patienten mit zervikaler Metastasierung ohne nachweisbaren Primärtumor waren überwiegend männlichen Geschlechts mit positiver Alkohol- bzw. Nikotinanamnese. Die Halslymphknotenschwellung war zu 88,3\% initial unilateral aufgetreten und stellte sich zumeist in einem fortgeschrittenen Lymphknotenstadium (N2b/c/N3) dar. Hinsichtlich der histopathologischen Halslymphknotenanalyse handelte es sich in $80 \%$ der Fälle um Metastasen von Plattenepithelkarzinomen. Von den 58 behandelten Patienten ohne Primärtumornachweis wurden 8 Patienten ausschließlich operativ behandelt (Neck Dissection), 5 Patienten unterzogen sich einer primären Radio- und Radiochemotherapie, während bei 45 Patienten nach einer operativen Therapie eine adjuvante Radio- bzw. Radiochemotherapie durchgeführt wurde. Die 3bzw. 5-Jahresgesamtüberlebensrate lag für alle 58 therapierten Patienten bei $52,9 \%$ bzw. 40,9\%, die 3- bzw. 5-Jahres-krankheitsspezifische Überlebensrate bei 50,9\% bzw. 39,7\% und die regionäre Kontrolle bei $73,7 \%$ bzw. 67,3\%.

Im Vergleich zum Gesamtkollektiv wiesen Patienten mit alleiniger Neck Dissection $(n=8)$ ein besseres Gesamtüberleben nach 3 (88\%) bzw. 5 Jahren (75\%) auf. Für diese überwiegend aus Patienten mit solitären Lymphknotenstadien ( $\mathrm{pN} 1 / 2 \mathrm{a})$ bestehende Subgruppe ergab sich jedoch der höchste Anteil (62,5\%) an regionären Rezidiven. Patienten, die primär radio(chemo)therapiert wurden $(n=5)$, wiesen im Vergleich der Therapiemodalitäten nach 3 und 5 Jahren das niedrigste Gesamtüberleben (jeweils $20 \%$ ) und krankheitsspezifische Überleben (jeweils 67\%) auf. Allerdings überwogen in 
dieser Patientengruppe die fortgeschrittenen und z.T. inoperablen Halsmetastasierungsstadien (N3).

Derzeit wird zur Behandlung des zervikalen CUP-Syndroms ein multimodales Therapiekonzept favorisiert, bestehend aus Operation (Neck Dissection) und adjuvanter Radiochemotherapie. Für dieses Behandlungsschema ermittelten wir eine 3- bzw. 5-Jahresrate von 64 bzw. 54\% für das Gesamtüberleben, 67 bzw. 53\% für das krankheitsspezifische Überleben und 88 bzw. 76\% für die regionäre Kontrolle.

Es konnten somit bei Patienten mit zervikalem CUP-Syndrom durch operative Therapie mit adjuvanter Radiochemotherapie ähnliche oder z.T. sogar bessere onkologische Resultate erreicht werden als bei Patienten mit bekanntem Primärtumor und Halsmetastasierung.

In Hinblick auf prognostische Faktoren konnte für den Lymphknotenstatus bei Patienten mit zervikalem CUP-Syndrom ein tendenzieller Einfluss ( $p=0.07$ univariat) auf Gesamtüberleben und krankheitsspezifisches Überleben nachgewiesen werden. Das Vorliegen einer Kapselruptur beeinflusste sowohl Gesamtüberleben $(p=0.04$ univariat) als auch krankheitsspezifisches Überleben ungünstig ( $p=0.04$ univariat). Für die regionäre Kontrolle konnte für beide Parameter kein Zusammenhang nachgewiesen werden. Die Ausdehnung des Strahlenfeldes (limited field radiation vs. extended field radiation), die histopathologische Tumorentität der Lymphknotenmetastasen und eine Primärtumordemaskierung im Follow-up blieben ohne Einfluss auf Gesamtüberleben, krankheitsspezifisches Überleben und regionäre Kontrolle. Frauen wiesen ein tendenziell besseres Gesamtüberleben ( $p=0.14$ univariat) als Männer auf. Das Geschlecht hatte indes keinen Einfluss auf das krankheitsspezifische Überleben und die regionäre Kontrolle.

Ein Primärtumor wurde nach Abschluss der Primärtherapie bei 4 Patienten (Hypopharynx $n=2$; Larynx $n=1$; Lunge $n=1$ ) im Follow-up identifiziert, wobei dieser in 2 Fällen in der zuvor bestrahlten Region (extended field radiation) lag.

Trotz des zum Teil hohen diagnostischen und therapeutischen Aufwandes wird die Prognose des zervikalen CUP-Syndroms in vielen Fällen trotz vergleichsweise guter loko-regionärer Kontrolle insbesondere aufgrund von Fernmetastasen limitiert, welche bei 35\% unseres Kollektivs diagnostiziert wurden. Die multivariaten Analysen ergaben, dass sich im untersuchten Kollektiv das Auftreten von Fernmetastasen - unabhängig von den anderen im Rahmen dieser Arbeit analysierten möglichen prognostischen Faktoren (Geschlecht, Therapiemodalität, Lymphknotenstatus, Histologie, extra- 
kapsuläres Wachstum und Bestrahlungsfeld) - negativ auf Gesamtüberleben und krankheitsspezifisches Überleben auswirkten. Nahezu ein Drittel der behandelten Patienten starb an den Folgen der Fernmetastasierung, obwohl bei der Hälfte der Patienten nach primärer Behandlung eine loko-regionäre Tumorkontrolle erreicht werden konnte. Das Auftreten von Fernmetastasen im Follow-up war bei Patienten, die eine postoperative Radiochemotherapie erhalten hatten, seltener (36\%) als nach alleiniger adjuvanter Radiotherapie (56\%). Dies lässt vermuten, dass eine im Rahmen der Primärbehandlung durchgeführte systemische Chemotherapie das möglicherweise spätere Auftreten von Fernmetastasen minimieren kann.

Zur weiteren Analyse prognostischer Faktoren sowie zur näheren Beurteilung unterschiedlicher Therapiemodalitäten erscheinen prospektive multizentrische Untersuchungen größerer Patientenkollektive erforderlich. 


\section{$7 \quad$ Literaturverzeichnis}

Abbruzzese JL, Abbruzzese MC, Hess KR, Raber MN, Lenzi R, Frost P (1994):

Unknown primary carcinoma: natural history and prognostic factors in 657 consecutive patients. J Clin Oncol $\underline{12}, 1272-1280$

Abbruzzese JL, Abbruzzese MC, Lenzi R, Hess KR, Raber MN (1995): Analysis of a diagnostic strategy for patients with suspected tumors of unknown origin.

J Clin Oncol $\underline{13}$, 2094-2103

Al-Othman MO, Morris CG, Hinerman RW, Amdur RJ, Mendenhall WM (2003):

Distant metastases after definitive radiotherapy for squamous cell carcinoma of the head and neck. Head Neck $\underline{25}$, 629-633

Ambrosch P (1996): Screeninguntersuchungen zur Früherkennung von Karzinomen der oberen Luft- und Speisewege. HNO $\underline{44}, 609-611$

Ang KK, Harris J, Wheeler R, Weber R, Rosenthal DI, Nguyen-Tân PF, Westra WH, Chung $\mathrm{CH}$, Jordan RC, Lu C, Kim H, Axelrod R, Silverman CC, Redmond KP, Gillison ML (2010): Human Papillomavirus and Survival of Patients with Oropharyngeal Cancer. N Engl J Med $\underline{363}$, 24-35

Arnold W, Ganzer U: Checkliste Hals-Nasen-Ohrenheilkunde. 4. Auflage; Georg Thieme Verlag Stuttgart 2005

Aslani M, Sultanem K, Voung T, Hier M, Niazi T, Shenouda G (2007): Metastatic carcinoma to the cervical nodes from an unknown head and neck primary site: Is there a need for neck dissection? Head Neck $\underline{29}, 585-90$

Balaker AE, Abemayor E, Elashoff D, St John MA (2012): Cancer of unknown primary: Does treatment modality make a difference? Laryngoscope $\underline{122}, 1279-1282$

Barrie JR, Knapper WH, Strong EW (1970): Cervical nodal metastases of unknown origin. Am J Surg 120, 466-470 
Bataini JP, Rodriguez J, Jaulerry C, Brugere J, Ghossein NA (1987): Treatment of metastatic neck nodes secondary to an occult epidermoid carcinoma of the head and neck. Laryngoscope $\underline{97}, 1080-1084$

Beldi D, Jereczek-Fossa BA, D'Onofrio A, Gambaro G, Fiore MR, Pia F, Krengli M (2007): Role of radiotherapy in the treatment of cervical lymph node metastases from an unknown primary site: retrospective analysis of 113 patients. Int $\mathrm{J}$ Rad Oncol Biol Phys $\underline{69}, 1051-1058$

Bernier J, Domenge C, Ozsahin M, Matuszewska,K, Lefèbvre JL, Greiner RH, Giralt J, Maingon P, Rolland F, Bolla M (2004): Postoperative Irradiation with or without Concomitant Chemotherapy for Locally Advanced Head and Neck Cancer. N Engl J Med 350, 1945-1952

Böcker W, Höfler HK, Lax S, Poremba C, Moll R, Tannapfel A, Probst-Hensch N: Tumorerkrankungen. In: Böcker W, Denk H, Heitz PhU, Moch H (Hrsg.): Pathologie. 4. Auflage, Urban \& Fischer, München/Jena 2008, 167-215.

Boenninghaus HG, Lenarz TH: Hals-Nasen-Ohren-Heilkunde. 13. Auflage; Springer Verlag Berlin 2007

Cerezo L, Raboso E, Ballesteros Al (2011): Unknown primary cancer of the head and neck: a multidisciplinary approach. Clin TransI Oncol $\underline{13}, 88-97$

Chen AM, Farwell DG, Lau DH, Li BQ, Luu Q, Donald PJ (2011): Radiation therapy in the management of head-and-neck cancer of unknown primary origin: how does the addition of concurrent chemotherapy affect the therapeutic ratio? Int $\mathrm{J}$ of Radiat Oncol Biol Phys $\underline{\text { 11, 346-352 }}$

Christiansen H, Hermann RM, Martin A, Nitsche M, Schmidberger H, Pradier O (2005): Neck lymph node metastases from an unknown primary tumor retrospectivestudy and review of literature. Strahlenther Onkol $\underline{181}$, 355-362

Christiansen H, Hermann RM, Martin A, Florez R, Kahler E, Nitsche M, Hille A, Steiner W, Hess CF, Pradier O (2006): Long-term Follow-up after transoral laser micro- 
surgery and adjuvant radiotherapy for advanced recurrent squamos cell carcinoma of the head and neck. Int J Radiat Oncol Biol Phys $\underline{65}$, 1067-1074

Colletier PJ, Garden AS, Morrison WH, Goepfert H, Geara F, Ang KK (1998):

Postoperative radiation for squamous cell carcinoma metastatic to cervica lymph nodes from an unknown primary site: outcomes and patterns of failure. Head Neck 20, 674-681

Coster JR, Foote RL, Olsen KD, Jack SM, Schaid DJ, DeSanto LW (1992): Cervical nodal metastasis of squamous cell carcinoma of unknown origin: indications for withholding radiation therapy. Int J Radiat Oncol Biol Phys $\underline{23}$, 743-749

Dammer R, Bonkowski V, Kutz R, Friesenecker J, Schüsselbauer T (1999): Die Früherkennung von Mehrfachtumoren bei der Primärdiagnostik oraler Karzinome mit Hilfe der Panendoskopie. Mund Kiefer Gesichtschir $\underline{3}$, 61-66

de Braud F, Heilbrun LK, Ahmed K, Sakr M, Ensley JF, Kish JA, Tapazoglou I, AlSaffraf M (1989): Metastatic squamous cell carcinoma of an unknown primary localized to the neck. Advantages of an aggressive treatment. Cancer $\underline{64}, 510-$ 515

Dellian M, Mast G, Zimmermann F (2003): Nachsorgeem pfehlungen bei malignen Tumoren im Kopf-Hals-Bereich. In: Wollenberg B, Zimmermann F (Hrsg.): Manual Kopf-Hals-Malignome 3. Auflage; Tumorzentrum München und W. Zuckerschwerdt Verlag, München 2003, 123-127

Dietl B, Marienhagen J, Schaefer C, Pohl F, Kölbl O (2007): Häufigkeit und Topographie von Fernmetastasen bei Patienten mit HNO-Tumoren und ihre Konsequenzen für das prätherapeutische Staging. Strahlenther Onkol $\underline{183}, 138-$ 143

Dillon WP, Harnsberger HR (1991): The impact of radiologic imaging on staging of cancer of the head and neck. Sem Oncol $\underline{18}, 64-79$ 
Dunst J, Sauer R, Weidenbecher M (1988): Halslymphknotenmetastasen bei unbekanntem Primärtumor. Strahlenther Onkol $\underline{164}$, 129-135

Durmus K, Rangarajan SV, Old MO, Agrawal A, Teknos TN, Ozer E (2014): Transoral robotic approach to carcinoma of unknown primary. Head Neck $\underline{36}, 848-852$

Erkal HŞ, Mendenhall WM, Amdur RJ, Villaret DB, Stringer SP (2001a): Squamous cell carcinomas metastatic to cervical lymph nodes from an unknown head-andneck mucosal site treated with radiation therapy alone or in combination with neck dissection. Int J Radiat Oncol Biol Phys $\underline{50}$, 55-63

Erkal HS, Mendenhall WM, Amdur RJ, Villaret DB, Stringer SP (2001b): Synchronous and metachronous squamous cell carcinomas of the head and neck mucosal sites. J Clin Oncol 19, 1358-1362

Fakhrian K, Thamm R, Knapp S, Molls M, Pigorsch S, Haller B, Geinitz H. (2012): Radio (chemo) therapy in the management of squamous cell carcinoma of cervical lymph nodes from an unknown primary site. Strahlenther Onkol $\underline{188}$, $56-61$

Fakhry C, Westra WH, Li S, Cmelak A, Ridge JA, Pinto H, Forastiere A, Gillison ML (2008): Improved survival of patients with human HPVillomavirus-positive head and neck squamous cell carcinoma in a prospective clinical trial. J Natl Cancer Inst $\underline{100}, 261-269$

Feinmesser R, Freeman JL, Noyek AM, Birt D (1987): Metastatic neck disease. A clinical/ radiographic/ pathologic correlation study. Arch Otolaryngol Head Neck Surg $\underline{113}, 1307-1310$

Fernandez JA, Suarez C, Martinez JA, Llorente JL, Rodrigo JP, Alvarez JC (1998): Metastatic squamous cell carcinoma in cervical lymph nodes from an unknown primary tumour: prognostic factors. Clin Otolaryngol Allied Sci $\underline{23}, 158-163$ 
Glynne-Jones RG, Anand AK, Young TE, Berry RJ (1990): Metastatic carcinoma in the cervical lymph nodes from an occult primary: a conservative approach to the role of radiotherapy. Int J Radiat Oncol Biol Phys $\underline{18}$, 289-294

Grau C, Johansen LV, Jakobsen J, Geertsen P, Andersen E, Jensen BB (2000): Cervical lymph node metastases from unknown primary tumours. Results from a national survey by the Danish Society for Head and Neck Oncology. Radiother Oncol 55, 121-129

Guntinas-Lichius O, Klussmann PJ, Dinh S, Dinh M, Schmidt M, Semrau R, Mueller RP (2006): Diagnostic work-up and outcome of cervical metastases from an unknown primary. Acta oto-laryngol $\underline{126}, 536-544$

Haas I, Hauser U, Ganzer U (2001): The dilemma of Follow-up in head and neck cancer patients. Eur Arch Otorhinolaryngol 258, 177-183

Haas I, Hoffmann TK, Engers R, Ganzer U (2002): Diagnostic strategies in cervical carcinoma of an unknown primary (CUP). Eur Arch Otorhinolaryngol $\underline{259}, 325-333$

Habermalz H, Gerstenberg E, Kuckuck A, Ernst H (1972): Halslymphknotenmetastasen bei unbekanntem Primärtumor: Ausgangsort, Therapie, Prognose. Strahlentherapie $\underline{144}, \mathbf{2 6 7 - 2 7 5}$

Hauswald H, Lindel K, Rochet N, Debus J, Harms W (2008): Surgery with complete resection improves survival in radiooncologically treated patients with cervical lymph node metastases from cancer of unknown primary. Strahlenther Onkol 184,150-156

Hegewisch-Becker S, Hossfeld H (1997): Metastasen bei unbekanntem Primärtumor. Onkologe $\underline{3}, 338-341$

Hemminki K, Bevier M, Hemminki A, Sundquist J (2011): Survival in cancer of unknown primary site: population-based analysis by site and histology. Ann Oncol $\underline{23}$, 1854-1863 
Hildmann H, Kosberg RD, Tiedjen KU (1987): Lymphszintigraphische Untersuchungen der regionalen Lymphwege bei Patienten mit Kopf-Hals-Tumoren. HNO $\underline{35}$, 3133

Hoffmann J, Scheiderbauer H, Krimmel M, Grund KE, Reinert S (2002): Aussagekraft panendoskopischer Untersuchungen im Rahmen der Ausbreitungsdiagnostik bei Mundhöhlenkarzinomen. Mund Kiefer Gesichtschir $\underline{6}, 111-116$

Hossfeld DK, Wittekind C (2005): Metastasen bei unbekanntem Primärtumor: Das CUP-Syndrom. Dtsch Arztebl 102, 904-907

Huang CC, Tseng FY, Yeh TH, Wen YH, Hsu CJ, Ko JY, Lou PJ, Chen YS (2008): Prognostic factors of unknown primary head and neck squamous cell carcinoma. Otolaryngol Head Neck Surg $\underline{139}$, 429-435

Hübner G, Bokemeyer C: CUP-Syndrom - Tumorerkrankung mit unbekanntem Primärtumor. Deutsche Gesellschaft für Hämatologie und Onkologie, o.O. 2005 (https://www.onkopedia.com/de/onkopedia/archive/guidelines/cup-syndrom/cupsyndrom-stand-september-2005/@@view/pdf-summary/index.pdf; Zugriff am 21.05.2016)

Iganej S, Kagan R, Anderson P, Rao A, Tome M, Wang R, Dowlatshahi M, Cosmatos $H$, Morgan $T$ (2002): Metastatic squamous cell carcinoma of the neck from an unknown primary: management options and patterns of relapse. Head Neck $\underline{24}$, 236-246

Issing WJ, Taleban B, Tauber S (2003): Diagnose und Management von Plattenepithelkarzinomen mit unbekanntem Primärtumor im Kopf-HalsBereich. Carcinoma of unknown primary, a survey of 167 patients. Laryngorhinootologie $\underline{82}, 659-665$

Jereczek-Fossa B, Jassem J, Orecchia R (2004): Cervical lymph node metastases of squamos cell carcinoma from an unknown primary. Cancer Treat Rev $\underline{30}, 153-$ 164 
Jesse RH, Perez CA, Fletcher GH (1973): Cervical lymph node metastasis: unknown primary cancer. Cancer $\underline{31}, 854-859$

Jones AS, Cook JA, Phillips DE, Roland NR (1993): Squamous carcinoma presenting an enlarged cervical lymph node. Cancer $\underline{72}, 1756-1761$

Jungehülsing M, Eckel HE, Staar S, Ebeling O (1997): Diagnostik und Therapie des okkulten Primärtumors mit Lymphknotenmetastasen im Kopf-, Halsbereich. HNO $\underline{45}, 573-583$

Kaplan EL, Meier P (1958): Nonparametric estimation from incomplete observations. J Am Stat Assoc $\underline{58}, 301-396$

Karni RJ, Rich JT, Sinha P, Haughey BH (2011): Transoral laser microsurgery: a new approach for unknown primaries of the head and neck. Laryngoscope 121 , 1194-1201

Kazak I, Haisch A, Jovanovic S (2003): Bilateral synchronous tonsillar carcinoma in cervical cancer of unknown primary site (CUPS). Eur Arch Otorhinolaryngol $\underline{260}, 490-493$

Keller F, Psychogios G, Linke R, Lell M, Kuwert T, Iro H, Zenk J (2011): Carcinoma of unknown primary in the head and neck: comparison between positron emission tomography (PET) and PET/CT. Head Neck $\underline{33}, 1569-1575$

Kirschner MJ, Fietkau R, Waldfahrer F, Iro H, Sauer R (1997): Zur Therapie von zervikalen Lymphknotenmetastasen ohne bekannten Primärtumor. Strahlenther Onkol $\underline{173}, 362-368$

Koch WM, Bhatti N, Williams MF, Eisele DW (2001): Oncologic rationale for bilateral tonsillectomy in head and neck squamous cell carcinoma of unknown primary source. Otolaryngol Head Neck Surg $\underline{124}$, 331-333

Koscielny S, Gudziol H, Kretzschmar J (2000): Halslymphknotenmetastasen bei unbekanntem Primärtumor. Laryngorhinootologie $\underline{79}$, 483-489 
Kothari P, Randhawa PS, Farrell R (2008): Role of tonsillectomy in the search for a squamous cell carcinoma from an unknown primary in the head and neck. $\mathrm{Br} \mathrm{J}$ Oral Maxillofac Surg 뜨, 283-287

Lapeyre M, Malissard L, Peiffert D, Hoffstetter S, Toussant B, Renier S, Dolivet G, Geoffrois L, Fichet V, Simon C, Bey P (1997): Cervical lymph node metastasis from an unknown primary: is a tonsillectomy necessary? Int J Radiat Oncol Biol Phys $\underline{39}$, 291-296

Lefebvre JL, Coche-Dequeant B, Van JT, Buisset E, Adenis A (1990): Cervical lymph nodes from an unknown primary tumor in 190 patients. Am J Surg 160, 443-446

León X, Quer M, Diez S, Orús C, López-Pousa A, Burgués J (1999): Second neoplasm in patients with head and neck cancer. Head Neck 21, 204-210

León X, Quer M, Orús C, del Prado Venegas M, Lopez M (2000): Distant metastases in head and neck cancer patients who achieved loco-regional control. Head Neck $\underline{22}, 680-686$

Ligey A, Gentil J, Créhange G, Montbarbon X, Pommier P, Peignaux K, Truc G, Maingon $P$ (2009): Impact of target volumes and radiation technique on locoregional control and survival for patients with unilateral cervical lymph node metastases from an unknown primary. Radiother Oncol $\underline{93}$, 483-487

Lindberg R (1972): Distribution of cervical lymph node metastases from squamous cell carcinoma of the upper respiratory and digestive tracts. Cancer $\underline{29}, 1446-1449$

Lörincz BB, Laban S, Knecht R (2013): Die Entwicklung von TORS in Europa. HNO $\underline{61}$, 294-299

Madani I, Vakaet L, Bonte K, Boterberg T, De Neve W (2008): Intensity-modulated radiotherapy for cervical lymph node metastases from unknown primary cancer. Int J Radiat Oncol Biol Phys 1ㅜ, 1158-1166 
Maier H, Tisch M (1999): Beruf und Krebs im Kopf-Hals-Bereich. HNO 47, 10251037

Marcial-Vega VA, Cardenes H, Perez CA, Devineni VR, Simpson JR, Fredrickson JM, Sessions DG, Spector GG, Thawley SE (1990): Cervical metastases from unknown primaries: radiotherapeutic management and appearance of subsequent primaries. Int J Radiat Oncol Biol Phys $\underline{19}$, 919-928

McQuone SJ, Eisele DW, Lee DJ, Westra WH, Koch WM (1998): Occult tonsillar carcinoma in the unknown primary. Laryngoscope $108,1605-1610$

Mehta V, Johnson P, Tassler A, Kim S, Ferris RL, Nance M, Johnson JT, Duvvuri U (2013): A new paradigm for the diagnosis and management of unknown primary tumors of the head and neck: A role for transoral robotic surgery. Laryngoscope $\underline{123}, 146-151$

Mende U, Zoller J, Dietz A, Wannenmacher M, Born IA, Maier H (1996): Die Sonographie im Primärstaging von Kopf-Hals-Tumoren. Radiologe $\underline{36}$, 207-216

Mendenhall WM, Mancuso AA, Parsons JT, Stringer SP, Cassisi NJ (1998): Diagnostic evaluation of squamous cell carcinoma metastatic to cervical lymph nodes from an unknown head and neck primary site. Head Neck $\underline{20}$, 739-744

Mistry RC, Qureshi SS, Talole SD, Deshmukh S (2008): Cervical Lymph node metastases of squamos cell carcinoma from an unknown primary: Outcomes and patterns of failure. Indian J Cancer $\underline{45}, 54-58$

Mozet C, Wuttke P, Bertolini J, Horn LC, Dietz A (2008): Zervikale und axillare Metastasen unbekannten Ursprungs als CUP-Syndrom. Onkologe 14, 898-907

Mozet C, Wichmann G, Stumpp P, Dietzsch S, Dietz A (2013): Zervikales CUPSyndrom. Onkologe 19, 44-51

Nagel TH, Hinni ML, Hayden RE, Lott DG (2014): Transoral laser microsurgery for the unknown primary: Role for lingual tonsillectomy. Head Neck $\underline{36}$, 942-946 
Neben K, Hübner G, Folprecht G, Jäger K, Krämer A (2008): Metastasen ohne Primärtumor. Fortschritte in Diagnostik und Therapie des CUP-Syndroms. Dtsch Arztebl 105, 733-740

Nguyen C, Shenouda G, Black MJ, Vuong T, Donath D, Yassa M (1994): Metastatic squamous cell carcinoma to cervical lymph nodes from unknown primary mucosal sites. Head Neck $\underline{16}, 58-63$

Nieder C, Gregoire V, Ang KK (2001): Cervical lymph node metastases from occult squamous cell carcinoma: cut down a tree to get an apple? Int J Radiat Oncol Biol Phys $\underline{50}, 727-733$

Oen AL, de Boer MF, Hop WC, Knegt P (1995): Cervical metastasis from the unknown primary tumor. Eur Arch Otorhinolaryngol 252, 222-228

Olsen KD, Caruso M, Foote RL, Stanley RJ, Lewis JE, Buskirk SJ, Frassica DA, DeSanto LW, O`Fallon WM, Hoverman VR (1994): Primary head and neck cancer. Histopathologic predictors of recurrence after Neck dissection patients with lymph node involvement. Arch Otolaryngol Head Neck Surg 120, 1370-1374

Patel RS, Clark J, Wyten R, Gao K, O'Brien CJ (2007): Squamous cell carcinoma from an unknown head and neck primary site: a "selective treatment"approach. Arch Otolaryngol Head Neck Surg $\underline{133}$, 1282-1287

Paulsen F, Belka C, Alber M, Budach W, Bamberg M (2003): Intensitätsmodulierte Strahlentherapie. Onkologe $\underline{9}, 315-327$

Pavlidis N, Pentheroudakis G, Plataniotis G (2009): Cervical lymph node metastases of squamous cell carcinoma from an unknown primary site: a favourable prognosis subset of patients with CUP. Clin TransI Oncol 11, 340-348

Perkins SM, Spencer CR, Chernock RD, Haughey BH, Nussenbaum B, Adkins DR, Kupermann DI, Thorstad WL (2012): Radiotherapeutic Management of Cervical Lymph Node Metastases From an Unknown Primary Site. Arch Otolaryngol Head Neck Sur 138, 656-661 
Pfreundner L, Pahnke J, Schwager K, Flentje M (1997): Zervikale Lymphknotenmetastasen bei unbekanntem Primärtumor. Onkologe 4 , 354-363

Psyrri A, Gouveris P, Vermorken JB (2009): Human papillomavirus-related head and neck tumors: clinical and research implication. Curr opin oncol 21, 201-205

Rades D (2008): Bildgebende Diagnostik beim CUP-Syndrom. Unter Berücksichtigung der Positronenemissionstomographie. Onkologe $\underline{14}$, 879-881

Randall DA, Johnstone PA, Foss RD, Martin PJ (2000): Tonsillectomy in diagnosis of the unknown primary tumor of the head and neck. Otolaryngol Head Neck Surg $\underline{122}, 52-55$

Reddy SP, Marks JE (1997): Metastatic carcinoma in the cervical lymph nodes from an unknown primary site: results of bilateral neck plus mucosal irradiation vs. ipsilateral neck irradiation. Int J Radiat Oncol Biol Phys $\underline{37}$, 797-802

Regelink G, Brouwer J, de Bree R, Pruim J, van der Laan BF, Vaalburg W, Hoekstra OS, Comans EF, Vissink A, Leemans CR (2002): Detection of unknown primary tumours and distant metastases in patients with cervical metastases: value of FDG-PET versus conventional modalities. Eur J Nucl Med Mol Imaging $\underline{29}$, 1024-1030

Robbins KT (1998): CLASSIFICATION OF NECK DISSECTION: current concepts and future considerations. Otolaryngol Clin North Am 31, 639-655

Rusthoven KE, Koshy M, Paulino AC (2004): The role of fluorodeoxyglucose positron emission tomography in cervical lymph node metastases from an unknown primary tumor. Cancer 101, 2641-2649

Sandherr M, Rastetter J, Hanauske AR (1997): Klinik und Grundzüge der Chemotherapie bei Metastasen eines unbekannten Primärtumors. Onkologe $\underline{3}$, 350-353 
Schmalbach CE, Miller FR (2007): Occult primary head and neck carcinoma. Curr Oncol Rep $\underline{9}, 139-146$

Schwenzer NF, Pfannenberg C, Reischl G, Werner MK, Schmidt H (2012): Einsatz von MR/PET in der onkologischen Bildgebung. Fortschr Röntgenstr 184, 780787

Seeber S, Strumberg D (2006): Metastasen bei unbekanntem Primärtumor. Urologe $\underline{45}, 614-619$

Sharma SJ, Linke JJ, Kroll T, Klußmann JP, Guntinas-Lichius O, Wittekindt C (2013): Praxis der Tumorendoskopie an deutschen HNO-Kliniken. Laryngo-RhinoOtologie $\underline{92}, 166-169$

Shehadeh NJ, Ensley JF, Kucuk O, Black C, Yoo GH, Jacobs J, Lin HS, Heilbrun LK, Smith D, Kim H (2006): Benefit of postoperative chemoradiotherapy for patients with unknown primary squamous cell carcinoma of the head and neck. Head Neck. 28, 1090-1098

Simon C, Plinkert PK (2008): Multimodale Therapiestrategien bei der Behandlung von Kopf- und Halskarzinomen. HNO $\underline{56}, 575-584$

Sinnathamby K, Peters LJ, Laidlaw C, Hughes PG (1997): The occult head and neck primary: to treat or not to treat? Clin Oncol $\underline{9}, 322-329$

Snow GB: Klinik und Pathologie der zervikalen Lymphknotenmetastasen. In: Naumann $\mathrm{HH}$, Herbst J, Herberhold C, Kastenbauer E (Hrsg.) : Oto-Rhino-Laryngologie in Klinik und Praxis, Band 3 Hals. 1. Auflage; Thieme, Stuttgart 1995, 228-241

Spector ME, Chinn SB, Rosko AJ, Worden FP, Ward PD, Divi V, Bradford CR (2012): Diagnostic modalities for distant metastasis in head and neck squamous cell carcinoma: Are we changing life expectancy? Laryngoscope 122, 1507-1511

Spiro RH, DeRose G, Strong EW (1983): Cervical node metastasis of occult origin. Am J Surg $\underline{146}$, 441-446 
Spitz MR (1994): Epidemiology and risk factors for head and neck cancer. Semin Oncology $\underline{21}, 281-288$

Steiner W (1993): Krebsfrüherkennung im Bereich der oberen Luft- und Speisewege. Teil I. HNO $\underline{41}, 360-367$

Steiner W (2003): Irrwege in der Onkologie. Irrungen, Irrwege und Wege in der Diagnostik und Therapie von Tumoren der oberen Luft- und Speisewege n Klinik und Praxis. Laryngorhinootologie $\underline{82}$, 764-765

Stoeckli SJ, Mosna-Firlejczyk K, Goerres GW (2003): Lymph node metastasis of squamos cell carcinoma from an unknown primary: impact of positron emission tomography. Eur J Nucl Med Mol Imaging $\underline{30}$, 411-416

Strojan P, Anicin A (1998): Combined surgery and postoperative radiotherapy for cervical lymph node metastases from an unknown primary tumour. Radiother Oncol $\underline{49}, 33-40$

Strojan P, Ferlito A, Medina JE, Woolgar JA, Rinaldo A, Robbins KT, Fagan JJ, Mendenhall WM, Paleri V, Silver CE (2013a): Contemporary management of lymph node metastases from an unknown primary to the neck: I. A review of diagnostic approaches. Head Neck $\underline{35}, 123-132$

Strojan P, Ferlito A, Langendijk JA, Corry J, Woolgar JA, Rinaldo A, Silver CE, Paleri V, Fagan JJ, Pellitteri PK (2013b): Contemporary management of lymph node metastases from an unknown primary to the neck: II. A review of therapeutic options. Head Neck $\underline{35}$, 286-293

Subramanian R, Chilla R (1995): Halslymphknotenmetastasen bei unbekanntem Primärtumor. HNO $\underline{43}$, 299-303

Thierauf J, Lindemann J, Bommer M, Veit JA, Hoffmann TK (2015): Stellenwert der Feinnadelaspirationszytologie und Stanzbiospie im Kopf-Hals-Bereich. LaryngoRhino-Otol 94, 311-316 
Thönessen D, Hof H, Krempien R, Münter MW, Bischof M, Herfarth KK, Schulz-Ertner D, Fleckenstein K: Kopf-Hals-Tumore. In: Wannenmacher M, Wenz F, Debus J (Hrsg.): Strahlentherapie. 2. überarbeitete Auflage; Springer Verlag Berlin 2013, 431-515

Tribius S, Petersen C, Knecht R, Ihloff AS (2010): Strahlentherapie bei Kopf-HalsTumoren. HNO $\underline{58}, 1168-1173$

Ultmann JE (1991): Cancer of unknown primary site. J Cancer Res Clin Oncol 117, 505-509

van den Brekel MW, Castelijns JA, Stel HV, Golding RP, Meyer CJ, Snow GB (1993): Modern imaging techniques and ultrasound-guided cytology for the assessment of neck node metastases: a prospective comparative study. Eur Arch Otorhinolaryngol 250, 11-17

Wallace A, Richards GM, Harari PM, Kirwan JM, Morris CG, Katakam H, Mendenhall WM (2011): Head and neck squamous cell carcinoma from an unknown primary site. Am J Otolaryngol 32, 286-290

Waltonen JD, Ozer E, Hall NC, Schuller DE, Agrawal A (2009): Metastatic carcinoma of the neck of unknown primary origin: evolution and efficacy of the modern workup. Arch Otolaryngol Head Neck Surg $\underline{135}, 1024-1029$

Wang RC, Goepfert H, Barber AE, Wolf P (1990). Unknown primary squamous cell carcinoma metastatic to the neck. Arch Otolaryngol Head Neck Surg $\underline{116}, 1388-$ 1393

Wannenmacher M, Wenz F, Debus J, Bahnsen: Allgemeine Grundlagen. In: Wannenmacher M, Wenz F, Debus J (Hrsg.): Strahlentherapie. 2. überarbeitete Auflage; Springer Verlag Berlin 2013, 3-10

Weber A, Tannapfel A (2002): Prognosefaktoren bei Kopf-Hals-Karzinomen. HNO $\underline{50}$, 35-42 
Weber A, Schmoz S, Bootz F (2001): CUP (carcinoma of unknown primary) syndrome in head and neck: clinic, diagnostic, and therapy. Onkologie $\underline{24}, 38-43$

Weir L, Keane T, Cummings B, Goodman P, O'Sullivan B, Payne D, Warde P (1995): Radiation treatment of cervical lymph node metastases from an unknownprimary: an analysis of outcome by treatment volume and other prognostic factors. Radiother Oncol $\underline{35}$, 206-211

Wendt TG, Grabenbauer GG, Rödel CM, Thiel HJ, Aydin H, Rohloff R, Wustrow TP, Iro H, Popella C, Schalhorn A (1998): Simultaneous radiochemotherapy versus radiotherapy alone in advanced head and neck cancer: a randomized multicenter study. J Clin Oncol. 16, 1318-1324

Werner JA, Dünne AA (2001): Value of Neck Dissection in patients with squamous cell carcinoma of unknown primary. Onkologie $\underline{24}, 16-20$

Werner JA, Dünne AA, Lippert BM (2001): Die Neck-Dissection im Wandel der Zeit. Onkologe $\underline{7}, 522-532$

Wittekind C, Weber A, Weidenbach H (2001): Pathologie und Prognosefaktoren von Plattenepithelkarzinomen des Kopf-Hals-Bereiches. Onkologe $\underline{7}$, 498-504

Zbären P, Speiser M (1993): Halslymphknotenmetastasen. Schw. Rundschau Med Prax 82, 1452- 1456

Zengel P, Assmann G, Mollenhauer M, Jung A, SotlarK, Kirchner T, Ihrler S (2012): Cancer of unknown primary originating from oropharyngeal carcinomas are strongly correlated to HPV positivity. Virchows Arch 461, 283-290

Zhuang SM, Wu XF, Li JJ, Zhang GH (2014): Management of lymph node metastases from an unknown primary site to the head and neck (Review). Mol Clin Oncol $\underline{2}$, 917-922 


\section{DANKSAGUNG}

Meinem Doktorvater Herrn Prof. Dr. med. R. Rödel möchte ich für die Überlassung des Themas, sein stetes Engagement, seine Geduld und die Unterstützung herzlich danken.

Ich danke den Mitarbeitern des Instituts für Medizinische Statistik der Universität Göttingen für die freundliche Unterstützung bei den statistischen Auswertungen sowie Herrn Prof. Dr. med. H. Christiansen für die wissenschaftliche Unterstützung. 


\section{LEBENSLAUF}

Am 01.09.1981 wurde ich als drittes Kind von Dr. Arwed Blomeyer und Emma Blomeyer, geb. Restle, in Soest geboren. Von 1988 bis 1992 besuchte ich die Gemeinschaftsgrundschule in Brakel, wechselte anschließend auf das Gymnasium Brede in Brakel und legte dort 2001 meine allgemeine Hochschulreife ab.

Zum Sommersemester 2002 nahm ich an der Georg-August-Universität zu Göttingen mein Studium der Humanmedizin auf, legte dort 2004 die Ärztliche Vorprüfung und 2008 die Ärztliche Prüfung erfolgreich ab, so dass ich im Januar 2009 meine Approbation erhielt.

Von September 2009 bis Oktober 2012 arbeitete ich als Assistenzärztin in der Inneren Medizin I am Klinikum Oldenburg. Zum Wintersemester 2012 schrieb ich mich für den weiterbildenden Studiengang Public Health an der Charité - Universitätsmedizin Berlin, Berlin School of Public Health ein, den ich am 04.03.2014 mit dem Master of Public Health (MPH) erfolgreich abschloss.

Von April bis November 2014 war ich am Alexianer St. Joseph-Krankenhaus BerlinWeißensee (Zentrum für Neurologie, Psychiatrie, Psychosomatik und Suchtmedizin) als Assistenzärztin tätig.

Seit dem 01.01.2015 arbeite ich als Ärztin in Weiterbildung zum Facharzt für öffentliches Gesundheitswesen beim Gesundheitsdienst des Kreises Höxter. 